\title{
Effects of health literacy interventions on health-related outcomes in socioeconomically disadvantaged adults living in the community: a systematic review
}

\author{
Coraline Stormacq ${ }^{1,2,3} \cdot$ Jacqueline Wosinski ${ }^{2,3,4} \cdot$ Evelyne Boillat $^{2} \cdot$ Stephan Van den Broucke ${ }^{5}$ \\ ${ }^{1}$ Université Catholique de Louvain, Faculté de Santé Publique, Woluwé-Saint-Lambert, Belgium, ${ }^{2}$ La Source, School of Nursing Sciences, HES-SO \\ University of Applied Sciences and Arts of Western Switzerland, Lausanne, Switzerland, ${ }^{3}$ Bureau d'Echanges des Savoirs pour des praTiques \\ exemplaires de soins (BEST): A JBI Centre of Excellence, ${ }^{4}$ Ngoma School of Nursing, Adventist University of Central Africa, Kigali, Rwanda, and \\ ${ }^{5}$ Université Catholique de Louvain, Faculté de Psychologie et des Sciences de l'Éducation, Louvain-la-Neuve, Belgium
}

\section{A B S T R A C T}

Objectives: The objectives of this review were: i) to identify and synthesize the best available evidence on the effectiveness on health-related outcomes of health literacy interventions for enabling socioeconomically disadvantaged people living in the community to access, understand, appraise and apply health information; and ii) to identify components of health literacy interventions associated with improved health-related outcomes.

Introduction: Health literacy is defined as a person's competence in accessing, understanding, appraising and applying health information in order to make sound health decisions. A high level of health literacy is positively related to better health outcomes. However, nearly half of the American and European populations have low health literacy levels. Socioeconomically disadvantaged groups in particular present with the weakest health literacy levels, suggesting that differences in health literacy levels contribute to health disparities. Therefore, there is a need to understand the conditions under which health literacy interventions aiming at improving health-related outcomes among socioeconomically disadvantaged people can be implemented.

Inclusion criteria: This review considered studies on socioeconomically disadvantaged adults living in the community identified using the socially stratifying PROGRESS factors (Place of residence, Race/ethnicity, Occupation, Gender, Religion, Education, Socioeconomic status, Social capital). This review considered studies evaluating the following interventions: i) targeting health literacy based on either a clinical and/or a public health approach, ii) delivered at the individual, interpersonal, community or societal level, iii) delivered by any healthcare/social work professional, and iv) using a single or multicomponent strategy. The comparator was no treatment, standard care or a variation of the intervention. All randomized and non-randomized controlled trials as well as quasi-experimental designs were included. Outcomes considered were: i) health-related quality of life and health-related outcomes, ii) health behavior outcomes, and iii) outcomes related to the access and use of healthcare services.

Methods: A three-step strategy was conducted for primary research published up to May 2018 across seven databases without any language restriction. A search for gray literature was also conducted. Titles and abstracts were screened for assessment against the inclusion criteria. Studies that met the inclusion criteria were retrieved in full and then assessed in detail against the inclusion criteria. Critical appraisal was undertaken using the standardized critical appraisal instruments from JBI. Data were extracted from included studies using standardized data extraction tools from JBI. A meta-analysis was not possible; findings have been presented in a narrative form.

Results: Twenty-one studies were included in the review. Three studies addressed the health literacy competency of understanding health information, and 18 addressed the competency of applying health information. Thirteen studies were found as effective based on a variety of health-related outcomes (mainly clinical outcomes), preventive health practices and behaviors, and health-promoting behaviors. Results enabled identification of some effective intervention operational components, including cultural appropriateness, tailoring, skills building, goal setting and active discussions. Multi-faceted interventions, combining both an information transfer medium and contact with an interventionist, appear to be more effective than single modality interventions. The use of an appropriate theoretical foundation is also an important factor for successful interventions.

Conclusion: To improve health-related outcomes among socioeconomically disadvantaged people, health literacy interventions are more likely to be successful if they are theory-based, are multi-faceted and use person-centered operational components such as cultural appropriateness, tailoring, skills building, goal setting and active discussions.

Correspondence: Coraline Stormacq, c.stormacq@ecolelasource.ch

The authors declare no conflict of interest.

This is an open access article distributed under the terms of the Creative Commons Attribution-Non Commercial-No Derivatives License 4.0 (CCBY-NC-ND), where it is permissible to download and share the work provided it is properly cited. The work cannot be changed in any way or used commercially without permission from the journal.

DOI: 10.11124/JBISRIR-D-18-00023 
Keywords community; effectiveness; health literacy; health-related outcomes; socioeconomic status

JBI Evid Synth 2020; 18(7):1389-1469.

\section{Summary of Findings}

\section{Effects of health literacy interventions on health-related outcomes in socioeconomically disadvantaged adults living in the community: a systematic review}

Bibliography: Stormacq C, Wosinski J, Boillat E, Van den Broucke S. Effects of health literacy interventions on health-related outcomes in socioeconomically disadvantaged adults living in the community: a systematic review. JBI Evid Synth 2020;18(7):1389-1469.

\section{\begin{tabular}{l|l|l|l|l}
\hline Outcomes & № of participants & Certainty of the evidence & Comments
\end{tabular} (studies) (GRADE)}

Health literacy interventions compared to standard care, no intervention or delayed intervention (passive comparison)

\begin{tabular}{|l|l|l|l|}
\hline Health-related quality of life & $83(1 \mathrm{RCT})$ & $\begin{array}{l}\oplus \oplus \bigcirc \bigcirc \\
\text { LOW }\end{array}$ & $\begin{array}{l}1 \text { study showed moderate improvements } \\
\text { to health-related quality of life } \\
\text { Certainty of the evidence is low due to } \\
\text { indirectness and imprecision. }\end{array}$ \\
\hline $\begin{array}{l}\text { Health-related outcomes, } \\
\text { including clinical outcomes } \\
\text { andpatient-reported outcomes }\end{array}$ & $\begin{array}{l}1275 \text { (4 RCTs and one quasi- } \\
\text { experimental study) }\end{array}$ & $\begin{array}{l}\oplus \bigcirc \bigcirc \bigcirc \\
\text { VERY LOW }\end{array}$ & $\begin{array}{l}1 \text { study showed small to moderate } \\
\text { improvements in health-related } \\
\text { outcomes } \\
\text { Certainty of the evidence is very low due } \\
\text { to indirectness and inconsistency across } \\
\text { all studies, and imprecision (4 studies) }\end{array}$ \\
\hline Health behaviors & $\begin{array}{l}3003 \text { (6 RCTs and one quasi- } \\
\text { experimental study) }\end{array}$ & $\begin{array}{l}\text { VERY LOW } \\
\text { VEO }\end{array}$ & $\begin{array}{l}5 \text { studies showed small to moderate } \\
\text { improvements in health behaviors } \\
\text { Certainty of the evidence is very low due } \\
\text { to indirectness and inconsistency across } \\
\text { all studies, and imprecision (5 studies) }\end{array}$ \\
\hline
\end{tabular}

Health literacy interventions compared to minimal/alternative intervention

\begin{tabular}{|l|l|l|l|}
\hline $\begin{array}{l}\text { Health-related outcomes, } \\
\text { including clinical outcomes } \\
\text { and patient-reported } \\
\text { outcomes }\end{array}$ & 1917 (9 RCTs) & $\begin{array}{l}\text { †OOO } \\
\text { VERY LOW }\end{array}$ & $\begin{array}{l}4 \text { studies showed small to moderate } \\
\text { improvements in health-related outcomes } \\
\text { Certainty of the evidence is very low due } \\
\text { to indirectness and inconsistency across } \\
\text { all studies, and imprecision (9 studies) }\end{array}$ \\
\hline Health behaviors & $\begin{array}{l}4728 \text { (10 RCTs and one quasi- } \\
\text { experimental study) }\end{array}$ & $\begin{array}{l}\text { †ERY LOW } \\
\text { VER }\end{array}$ & $\begin{array}{l}6 \text { studies showed small to moderate } \\
\text { improvements in health behaviors } \\
\text { Certainty of the evidence is very low due } \\
\text { to indirectness and inconsistency across } \\
\text { all studies, and imprecision (9 studies) }\end{array}$ \\
\hline
\end{tabular}

The outcomes of interest are health-related quality of life, health-related outcomes and health behaviors for which a single pooled effect estimate was not available and only a narrative synthesis of the evidence was provided.

$\mathrm{RCT}$ : randomized controlled trial

GRADE Working Group grades of evidence

High certainty: We are very confident that the true effect lies close to that of the estimate of the effect

Moderate certainty: We are moderately confident in the effect estimate: The true effect is likely to be close to the estimate of

the effect, but there is a possibility that it is substantially different

Low certainty: Our confidence in the effect estimate is limited: The true effect may be substantially different from the estimate of the effect

Very low certainty: We have very little confidence in the effect estimate: The true effect is likely to be substantially different from the estimate of effect 


\section{Introduction}

iteracy is "the capacity to read, write and have basic numeric skills,"1(p.291) allowing people to effectively function and participate in society. ${ }^{1}$ Approximately $25 \%$ of the adult population in the world is illiterate or has poor literacy skills. ${ }^{1}$ Low literacy levels are associated with a variety of adverse health outcomes. ${ }^{2}$ In addition to literacy skills required to adequately function in everyday life, the notion of literacy has expanded to include health literacy (HL) in order to effectively function in the healthcare system. "Health literacy is linked to literacy and entails people's knowledge, motivation and competencies to access, understand, appraise and apply health information in order to make judgments and take decisions in everyday life concerning healthcare, disease prevention and health promotion to maintain or improve quality of life during the life course." ${ }^{\text {(p.3) }}$ Health literacy is a relatively new concept, introduced for the first time in the 1970s, and has been discussed in studies over the last two decades. The HL concept has many implications for health care, health education and health promotion, ${ }^{4}$ and is strongly correlated with the social determinants of health, health behaviors and health outcomes. ${ }^{3}$ Therefore, HL is considered one of the most important issues in health care and public health ${ }^{3-5}$ and is increasingly being addressed in current health and social policies.

\section{Health literacy: a public health concern}

Today, each individual is confronted, at some point, with multiple health issues and decisions. ${ }^{6}$ Society and healthcare systems are becoming more complex, ${ }^{5,7}$ and consequently, requirements for literacy and optimal use of health information have become more and more important ${ }^{5}$ for maintaining a good health status. Increasingly, people are asked to take an active part in health decisions ${ }^{7}$ and become "informed patients." 6 To navigate this new healthcare environment, ${ }^{7}$ many abilities and skills are needed, such as informationseeking, communication, critical thinking and problem-solving. ${ }^{3}$ A good level of HL appears to positively influence health and the ability to effectively navigate the healthcare system, as shown by cross-sectional studies, via better choices and health decisions, more active involvement in discussions with health professionals, ${ }^{8-10}$ greater self-efficacy, ${ }^{11-15}$ better abilities in self-care, ${ }^{11}$ adoption of positive health behaviors, ${ }^{16-19}$ increased prevention, ${ }^{20-22}$ better health outcomes, ${ }^{17}$ social capital development ${ }^{6}$ and lower healthcare costs. $^{23}$ Good levels of HL contribute to improved global health in the general population. ${ }^{24}$ According to a national study, ${ }^{25}$ nearly half of the adult American population shows a low or marginal level of functional HL, particularly socially and socioeconomically disadvantaged groups. Similarly, in Europe, almost half of the population has limited HL. ${ }^{26}$ Due to poor understanding of health messages ${ }^{27}$ low HL skills are associated with a range of adverse health effects: ${ }^{17}$ increased mortality, ${ }^{17,21}$ poorer self-reported health status, ${ }^{28-31}$ greater use of emergency services but less use of preventive services, higher rates of chronic diseases and adoption of adverse health behaviors (smoking, consumption of alcohol and illicit products, sedentary lifestyles), ${ }^{28}$ which lead to higher healthcare costs. ${ }^{5,7,21,28,29}$ Given the significant consequences of low HL, the importance of HL is increasingly being discussed in health policies in Europe, and HL has been recognized as a priority within the Strategy of the European Commission 2008-2013. ${ }^{3,32}$ A public health imperative, ${ }^{6,31}$ $\mathrm{HL}$ is also considered an important predictor of health status and health behaviors in the general population, ${ }^{31}$ and is recognized as a major determinant of health by the World Health Organization. ${ }^{33}$ Therefore, HL is a key public health issue ${ }^{1}$ and must take a central place in future research, actions and health policy debates. ${ }^{6}$

\section{Health literacy dimensions and health literacy skills}

To promote and maintain good health, to function effectively in the healthcare context and to enable people to act on their health condition, a set of skills or competencies is required. From this perspective, HL can be considered a "constellation of skills" or a multidimensional concept. ${ }^{3,34}$

To describe the skills that are essential to function effectively in the health system, Sorensen et al. ${ }^{3}$ proposed an integrative conceptual model of HL. This model focuses on the three domains of the health continuum (health care, disease prevention and health promotion), and both clinical and community settings are considered. Besides basic reading and writing skills needed in everyday situations to function and participate effectively in society, ${ }^{3}$ defined as functional literacy, ${ }^{35}$ four types of competencies, each representing an essential dimension of HL, are required in order to navigate the health 
continuum: "1) Access: refers to the ability to seek, find and obtain health information; 2) Understand: refers to the ability to comprehend the health information that is accessed; 3) Appraise: describes the ability to interpret, filter, judge and evaluate the health information that has been accessed; and 4) Apply: refers to the ability to communicate and use the information to make a decision to maintain and improve health."3(p.9) Progressing on these four levels allows people to acquire a multitude of social, personal and cognitive skills that are essential for a greater control on one's own health, ${ }^{6}$ and "to exert greater control over life events and situations." not simply a set of functional capabilities" such as reading, writing and numeracy skills, ${ }^{35(\mathrm{p} .2075)}$ but a wide range of complementary skills and competencies that can be built upon. However, HL does not impact health directly. ${ }^{14,15,36-38}$ Health literacy levels influence some health promotion or health education constructs, such as specific healthrelated knowledge, self-care, self-management, selfefficacy, problem-solving, decision-making and empowerment. ${ }^{14,15,36,37}$ These can be considered proxy outcomes of a HL process and suggest that there are different ways to operationalize the HL concept in interventions. These interventions can take many forms, such as education and disease management interventions, interventions aiming at improving patient-provider communication, interventions aimed at improving access to health information, and interventions for improving usability of healthcare systems and services. Therefore, proxy measures of the impact of HL on healthrelated outcomes need to be assessed.

\section{Clinical approach and public health approach to health literacy}

There are two complementary HL approaches to HL: the "clinical" approach and the "public health" approach. ${ }^{39,40}$ In the clinical approach, HL represents the necessary skills needed to navigate in a clinical setting and often includes aspects such as selecting care providers ${ }^{41}$ understanding and completing consent forms, ${ }^{1,41}$ and understanding medicine labels, how to take medication, ${ }^{1,41}$ verbal information given by health professionals, ${ }^{1}$ and how to manage the disease. ${ }^{41}$ In this context, HL is considered a construction at the individual or patient level, ${ }^{39}$ and the focus is on the "therapeutic dyad" patient-healthcare provider. ${ }^{39}$ From this clinical perspective, HL strategies should focus primarily on the effectiveness of clinical care. Health literacy interventions mainly focus on the improvement of HL skills and the adaptation of health communications at the patient level ${ }^{39}$ in people with low HL levels and are related to patient education.

To extend the HL concept to the community setting, the public health approach, introduced by Freedman in 2009 , was developed ${ }^{39}$ to incorporate social and environmental factors, and other determinants of health that cause low levels of HL among populations. Public health literacy is defined as "the degree to which individuals and groups can obtain, process, understand, evaluate and act upon information needed to make public health decisions that benefit the community."39(p.448) From this public health perspective, HL can be considered a tool, an asset or a means for individuals to exert greater control and to act on all personal, social and environmental factors that determine health, thus reflecting a health promotion orientation. ${ }^{35}$ In this respect, this perspective can be operationalized across the continuum of strategies in health care, health prevention, health education and health promotion. ${ }^{39}$ Therefore, public health literacy is a comprehensive HL conceptualization, and public health literacy interventions need to be assessed for their effectiveness.

\section{The role of socioeconomic status in health} literacy, health outcomes and health disparities Demographic and social factors, such as socioeconomic status (educational attainment, occupation, income), ${ }^{4,14,26}$ social support, ${ }^{3,14}$ culture and language ${ }^{3}$ and personal characteristics (e.g. age, ${ }^{3,29,40}$ gender, ${ }^{3,28}$ race and ethnicity), ${ }^{3,28}$ influence HL skills and are thus considered antecedents of HL. ${ }^{3,17}$ These can have a positive impact on HL and promote good levels of HL. Conversely, antecedents can negatively impact HL (e.g. low level of education, disadvantaged socioeconomic status, belonging to a minority group, immigration), thereby indicating risk factors for low HL levels. Considering the relationship between socioeconomic status and HL, it is not surprising to note that the weakest health-related skills are found among the most disadvantaged socioeconomic groups. Advantaged social and socioeconomic groups are those placed on the higher levels of the 
social hierarchy, and thus tend to have greater $\mathrm{HL}$ skills. Conversely, disadvantaged social and socioeconomic groups are those at the bottom of the social ladder, with a lack of material resources, ${ }^{42}$ lower educational attainment, and less desirable or underpaid professions. In a HL context, the socially and socioeconomically disadvantaged are those at risk of low HL levels. Thus, different HL levels contribute to health disparities. ${ }^{20}$ Health disparity is defined as differences in health status and health outcomes ${ }^{43,44}$ between social groups "that is not only unnecessary and avoidable, but in addition, are considered unfair and unjust." ${ }^{44(p .219)}$ A health disparity includes differences that occur through age, sex, race/ethnicity, education, income, disability, geographic location, sexual orientation or religion, ${ }^{45}$ and which systemically and adversely impact socially and economically disadvantaged groups. ${ }^{42,43}$ Health literacy levels then become a modifiable risk factor for health disparities on which it is possible to act to reach greater health equity. Ways to improve health status and reduce disparities among disadvantaged people through HL strategies need to be further explored. ${ }^{40,46}$

\section{Existing systematic reviews}

A search undertaken in sources such as the Cochrane Database of Systematic Reviews, Best BETS, Campbell Collaboration, the JBI Database of Systematic Reviews and Implementation Reports and PubMed identified no quantitative systematic reviews that examined $\mathrm{HL}$ interventions to improve health-related outcomes among socioeconomically disadvantaged groups. One systematic review focused on the relationship between HL, numeracy and health outcomes in the diabetes population. ${ }^{47}$ This review shed light on certain HL proxy measures, such as knowledge, self-efficacy, self-care and self-monitoring, but there was not enough consistent evidence showing that HL levels were associated with diabetes-related outcomes. Two systematic reviews ${ }^{48,49}$ on the effectiveness of interventions for improving health-related outcomes of people with limited or low literacy only considered HL as the ability to read, write and use numbers effectively, and did not address HL as a broader concept. One systematic review ${ }^{50}$ measuring interventions to mitigate the effects of low HL and to improve health outcomes and use of healthcare services may be relevant to the topic of this proposed review, but it did not address the public health approach of HL and hence was not within the scope of this review. One systematic review ${ }^{51}$ on the effectiveness of interventions in primary health care and in the community for improving HL in adults and promoting positive change in lifestyle behavior did not refer to disadvantaged groups. The author had called for the inclusion of these groups in future HL studies.

This proposed systematic review aimed to identify and synthesize the best available evidence with regard to HL interventions in the community, allowing for a better understanding of the conditions under which effective HL interventions to improve health-related outcomes (including quality of life outcomes, clinical outcomes, health behaviors, and access and use of healthcare services) among socioeconomically disadvantaged people can be implemented. This will enable the development of interventions to reduce health disparities by implementing a comprehensive HL strategy. This review addressed all dimensions and components of HL in order to shed light on interventions that can positively influence health outcomes and reduce health disparities.

\section{Review objectives}

The overall objective of this systematic review was to identify and synthesize the best available evidence on the effectiveness of health literacy interventions in socioeconomically disadvantaged people living in the community for improving health-related outcomes.

More specifically, the objectives of this systematic review were: i) to identify and synthesize evidence on the effectiveness of single or complex health literacy interventions in enabling socioeconomically disadvantaged people living in the community to access, understand, appraise and apply health information; and ii) to identify components and characteristics of $\mathrm{HL}$ interventions that are associated with improved health-related outcomes in socioeconomically disadvantaged people. This second objective, important for the development of future HL interventions, is a deviation from the a priori protocol. ${ }^{52}$

\section{Inclusion criteria \\ Participants}

This review considered studies that included adults aged 18 years or over of any ethnicity and cultural group, who are socially or socioeconomically disadvantaged in the community. 
PROGRESS factors, including Place of residence, Race/ethnicity/culture/language, Occupation, Gender, Religion, Education, Socioeconomic status, Social capital or age, ${ }^{53}$ served to identify "disadvantaged" people and social groups. These are "socially stratifying factors that drive variations in health outcomes" $53(\mathrm{p} .58)$ and contribute to disparities in health. For example, people living in rural areas, from a minority group, with low education or low income ${ }^{26}$ are considered as disadvantaged and at risk of health disparities. In this review, studies considering any or several of these factors were considered for inclusion. In this review, studies conducted in any community setting were considered, such as community centers, community preventive services, community-based health promotion settings, community healthcare facilities, primary healthcare centers, homes or worksite settings.

Exclusion criteria: studies involving/targeting children aged under 18 years, people living in nursing or other institutional living facilities, people with cognitive impairments or dementia for whom HL or one of its components - is difficult to measure or evaluate, healthcare professionals (e.g. physician, nurse), or non-health professionals (e.g. community workers, social workers), and studies that do not give an indication of the socioeconomic status were excluded.

\section{Interventions}

This review considered studies focused on the following interventions:

i) Those that targeted HL using a clinical approach (in a clinical setting, at the patient or individual level, e.g. patient-provider communication interventions or education and disease management interventions) and/or a public health approach (in a community setting, or at the population level, e.g. awareness campaigns and mass public education related to a health issue affecting the whole community), any of its dimensions, and operationalized by any healthcare, prevention, education or health promotion strategy.

ii) Those delivered at the individual/intrapersonal level, encompassing the characteristics and personal factors of an individual, such as knowledge, skills, lifestyles, behavior and attitudes $^{54,55}$ (e.g. education interventions and disease management interventions); the interpersonal level, including social interactions, social influences and social support ${ }^{54,56}$ (e.g. interventions aimed at improving patientprovider interaction/communication); the community level, with a focus on populations, groups and organizations, and including social and physical environments considered to have an impact on health outcomes ${ }^{54,57}$ (e.g. interventions aimed to improve access to accurate and appropriate health information); or at the societal level, including economic, social, educational and health policies ${ }^{54}$ (e.g. interventions for improving usability of a healthcare system and health services).

iii) Those delivered by any healthcare or social work professional from within or outside the healthcare system, such as physician, nurse, community worker or social educator with a professional degree recognized in the country where the intervention takes place.

iv) Those that were either single strategy or complex interventions.

Exclusion criteria: studies concerning general literacy (e.g. reading, writing and calculating) were excluded.

\section{Comparators}

This review considered studies that offered no comparison, a passive comparison (such as no treatment or standard care), or an active comparison (such as variation of the intervention).

\section{Outcomes}

This review considered studies that included the following outcome measures, based on the Outcome Model for Health Promotion ${ }^{4}$ and informed by the Outcomes of Interest to the Cochrane Consumers and Communication Review Group ${ }^{58}$ but were not limited to:

Primary outcomes: those considered as final outcomes of a HL process, that is, outcomes related to the capacity to apply health information in order to promote and maintain good health, such as: i) health-related quality of life and health-related outcomes (general health status, perceived health status, well-being, life expectancy, morbidity, mortality, disability); ii) health behaviors (self-efficacy, healthy lifestyles and preventive health practices, compliance/adherence and behavior change); and iii) access 
and use of healthcare services (preventive service use, office visits, hospitalizations).

Examples of measurement tools for the primary outcomes included: health status: - Short-Form-36 Health Survey; ${ }^{59}$ quality of life - EuroQol; ${ }^{60}$ wellbeing - Satisfaction with Life Scale; ${ }^{61}$ self-efficacy Self-Efficacy Scale; ${ }^{62}$ disability - OECD LongTerm Disability Questionnaire; ${ }^{63}$ health-related behaviors - Health-Promoting Lifestyle Profile; ${ }^{64}$ and access to healthcare services - Unmet Health Care Needs indicators. ${ }^{65}$

Secondary outcomes: those leading to the application of health information, comprising the basic level of HL and other components of a HL process, such as: i) functional HL (reading, writing and numeracy skills) as a prerequisite for more advanced HL skills (accessing, understanding, appraising and applying health information); ii) knowledge and understanding (information access and use, health-related knowledge acquisition, participant satisfaction with the information provided or received); iii) communication (communication enhancement, communication skills); iv) participant decision-making ([shared] decision-making process, decision made, satisfaction with the decisions made); v) support (social interactions, social support, help-seeking behavior); vi) skills acquisition (selfcare and self-management skills, self-monitoring, self-advocacy, self-learning skills, social skills, coping skills, empowerment skills, critical thinking, problem-solving ability and navigation skills); vii) predisposing factors of health behavior change (attitudes, beliefs, intent to change health behavior); and viii) other relevant outcomes.

Exclusion criteria: studies that used cognitive impairment or dementia as an outcome of interest, studies considering HL levels as an outcome, and studies on cost-effectiveness outcomes of HL interventions were excluded.

To ensure the quality of analyzed evidence, a decision was made to only consider reliable and validated patient-reported or clinical outcomes. This selection criteria deviates from the a priori protocol. $^{52}$

\section{Types of studies}

This review considered any experimental study design, including randomized controlled trials and non-randomized controlled trials, as well as quasiexperimental designs for inclusion.

\section{Methods}

This systematic review was conducted in accordance with the JBI methodology for systematic reviews of effectiveness. ${ }^{66}$ This review was conducted in accordance with an a priori protocol. ${ }^{52}$

\section{Search strategy}

The search strategy aimed to locate both published and unpublished studies. A three-step search strategy was utilized in this review. An initial limited search of MEDLINE and CINAHL was undertaken, followed by an analysis of the text words contained in the title and abstract, and of the index terms used to describe the article. A second search using all identified keywords and index terms was then undertaken across all included databases. Thirdly, the reference lists of all reports and articles that met inclusion criteria were searched for additional studies. Studies published in any language were considered for inclusion in this review. Assessment for inclusion of papers in languages other than Romance languages (e.g. Spanish, French, Portuguese, Italian) and Germanic languages (e.g. English, German, Dutch) were based on the English-language abstracts, where available. Relevant studies were translated into English. No date limits were imposed on database searching. Individual search strategies were developed for each database to take into account the differences in Thesaurus terminology and indexing. Titles and abstracts of studies retrieved in the search were assessed for relevance against the inclusion and exclusion criteria. Bibliographic details of the studies were downloaded or manually entered into the references management database, EndNote X7.7 (Clarivate Analytics, PA, USA).

The databases searched included: PubMed, CINAHL, the Cochrane Central Register of Controlled Trials (CENTRAL), Embase, PsycINFO, TRoPHI and Web of Science.

The search for gray literature and unpublished studies included clinical trial registers, technical and official reports from government or academic institutions, conference papers and proceedings, theses and dissertations, and an internet search of Doaj, Google, Google Scholar, MedNar, Worldcat and Scopus. The databases searched for clinical trial registers included: ClinicalTrials.gov, EU Clinical Trial Register, Current Controlled Trials (CCT), and UK Clinical Trials Gateway. The databases searched for theses and dissertations included: 
ProQuest Dissertations and Theses Global (PQDT Global) and DART-Europe E-theses portal. The search for gray literature and unpublished studies included a simplified version of the database search strategy.

The search strategy as detailed in the a priori protocol $^{52}$ was altered. The ERIC database, essentially educational and aimed at a teaching audience, was not searched because it was not considered relevant to the target population of our systematic review. Moreover, due to the large number of references generated by the search strategy, a hand search of relevant journals not included in electronic databases was not conducted.

A PRISMA flow diagram was used to summarize the study selection process. It includes the total numbers of studies identified and screened from all databases used for the review and from hand searches, studies assessed for eligibility, studies included in the review, and studies excluded from the review with reasons for exclusions. ${ }^{67}$ The search strategies used for the databases searched are detailed in Appendix I.

\section{Study selection}

Following the search, all identified citations were collated and uploaded into EndNote X7.7 and duplicates removed. In the first stage, titles and abstracts were screened by two independent reviewers for relevance. Studies that seemed relevant were retrieved in full. In the second stage, the full text of selected citations were assessed in detail against the inclusion criteria and study details imported into the JBI System for the Unified Management, Assessment and Review of information (JBI SUMARI; JBI, Adelaide, Australia). Full-text studies that did not meet the inclusion criteria were excluded, and reasons for exclusion recorded. Included studies underwent a process of critical appraisal. The results of the search are presented in a PRISMA flow diagram. ${ }^{68}$ Any disagreements that arose between the reviewers were resolved through discussion, or with a third reviewer.

\section{Assessment of methodological quality}

Quantitative papers selected for retrieval were assessed independently by two reviewers for methodological validity prior to inclusion in the review using the standardized critical appraisal instruments from JBI for experimental and quasi-experimental studies. ${ }^{69}$ Studies that did not meet the $70 \%$ threshold for the relevant appraisal instrument were excluded. Any disagreements that arose between the reviewers were resolved through discussion, or with a third reviewer.

\section{Data extraction}

Quantitative data were extracted from papers included in the review using the standardized data extraction tool from JBI SUMARI. The data extracted included specific details about the interventions, populations, study methods and outcomes of significance to the review question and objectives. Authors of quantitative primary studies were contacted for missing information or to clarify unclear data.

\section{Data synthesis}

Statistical pooling of quantitative data in a metaanalysis was not possible. Therefore, the findings have been presented in narrative form, including tables and figures to aid in data presentation, where appropriate.

\section{Assessing certainty in the findings}

A Summary of Findings was created using GRADEpro software (McMaster University, ON, Canada). The Grading of Recommendations Assessment, Development and Evaluation (GRADE) approach for grading the quality of evidence was followed. ${ }^{70}$

\section{Results}

\section{Study inclusion}

The comprehensive three-step strategy outlined above was conducted up to May 2018, using the databases and gray literature sources cited above, leading to the identification of 27,516 studies: PubMed (9915), CINAHL (3895), CENTRAL (1205), Embase (2710), PsycINFO (710), TROPHI (73), Web of Science (4094), ProQuest (52), Scopus (4385), ClinicalTrials.gov (104), EU Clinical Trial Register (1), CCT (89), UK Clinical Trial Gateway (72), and DART (211). Sixty-five additional references were identified using Doaj, Google, Google Scholar, MedNar and Worldcat. Seventy-one records were also identified through reference lists, resulting in a total of 27,652 studies. A total of 6504 duplicates identified through EndNote X7.7 and hand searching were removed, resulting in 21,148 studies. These were screened for relevance based on title and abstract by two independent reviewers. 
From the 21,148 studies, 19,429 were excluded based on title, and 1719 were selected for full-text analysis. Among these, 1552 studies did not meet the inclusion criteria and were excluded (reasons for exclusion are listed in Appendix II), and 35 studies could not be retrieved in full text, resulting in 132 studies. These were then assessed for methodological quality. During the critical appraisal process, five authors of primary studies were contacted for additional information. All responded but two were unable to provide the requested information, leading to the exclusion of these two studies. Among the remaining 130 studies, 109 were then excluded. As a result, 21 studies were retained for content analysis. The PRISMA flowchart of the selection process for papers is outlined in Figure $1 .{ }^{68}$

\section{Methodological quality}

Among the 132 papers critically assessed for methodological validity, 111 studies were excluded on

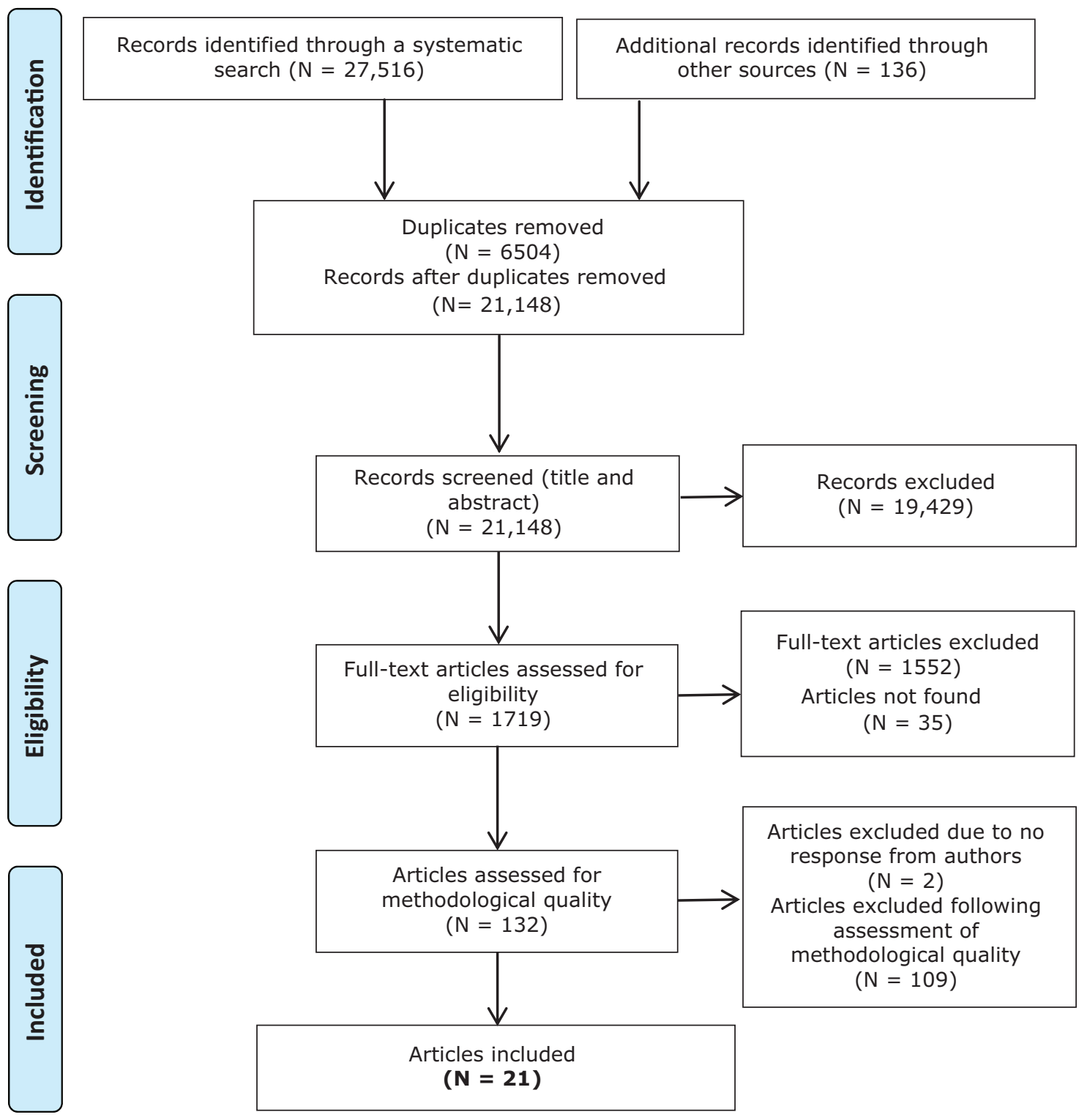

Figure 1: Search results and study selection and inclusion ${ }^{68}$ 
the basis of methodological quality because they did not meet the $70 \%$ cut-off checklist score. ${ }^{69}$ The reasons for exclusion for each of the excluded studies are in Appendix II. Twenty-one studies met the reviewers' appraisal criteria. These 21 studies were assessed as being of high or very high quality. Tables 1 and 2 present the quality assessment scores for the 21 studies that were retained, according to study design. As these tables indicate, there was variation in the quality of the included studies. Two studies met all the critical appraisal criteria $^{71,72}$; three studies achieved a score of $90 \%$ or more $\mathrm{e}^{73-75}$; seven studies achieved a score of $80 \%$ or more ${ }^{76-82}$; and nine studies achieved a score of a minimum of $70 \% .{ }^{83-91}$

Among the randomized controlled trials (RCTs), three were cluster RCTs. ${ }^{71,73,74}$ Sixteen studies were considered truly random, ${ }^{71,73,75-81,83,85-89,91}$ with a clear description of the specific randomization procedure used. Three studies used stratified randomization, ${ }^{74,84,90}$ which may have induced a risk of selection bias. Randomization was computer-based in 13 studies. ${ }^{71,73,75,77-79,81,84-86,89-91}$ The methods of randomization included block randomization $^{73,78-80,83,87-89,91}$ and simple randomization. ${ }^{71,75,76,79,81,84,85,89}$

Group allocation was concealed from the allocator in 14 studies, ${ }^{22,71,73-77,79,80,84-86,89,90}$ while the concealment of the allocation from the allocator was unclear or not mentioned in five studies, ${ }^{78,83,87,88,91}$ inducing potential performance bias.

Only 13 studies demonstrated equivalency

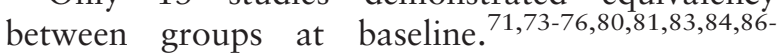
88,91 Slight differences between participants in the experimental group (EG) and control group (CG) were identified in five studies, $77-79,85,89$ and comparability of groups was unclear in one study, ${ }^{90}$ which may have induced selection bias.

Blinding of participants to the treatment allocation was applied in nine studies, ${ }^{71,74,76-78,83,84,88,91}$ but unclear in three studies, ${ }^{73,80,81}$ inducing performance bias. An unavoidable performance bias

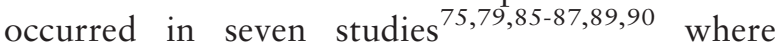
blinding of participants was not possible due to the behavioral, psychosocial or computer-based nature of the intervention. For the same reasons, blinding of those delivering the treatment was not possible in all the included studies. Assessors were blinded to treatment allocation in 10 studies. $^{71,73-}$ $75,77-79,81,85,90$ Assessors were aware of the assignment status of participants in three studies, ${ }^{76,80,89}$ while blinding of assessors was not mentioned in six studies, ${ }^{83,84,86-88,91}$ which generates performance and detection bias.

In all studies, EGs and CGs were treated identically other than for the named intervention.

Intention-to-treat analysis was performed in 11 studies. ${ }^{71,74,75,77-80,83,87,89,90}$ In two studies where intention-to-treat was not conducted, attrition analysis was performed and missing data taken into account. $^{73,76}$

In six studies, ${ }^{81,84-86,88,91}$ withdrawal of study participants was not addressed, thus inducing attrition bias.

In all of the included studies, participants were analyzed in the groups to which they were randomized, and outcomes measured in the same way between groups.

Outcomes were measured consistently and in a reliable way in 14 studies. ${ }^{71,73-75,78-81,84,86,87,89-91}$ In contrast, the reliability of the measures used was unclear or insufficiently described in five studies, ${ }^{76,77,83,85,88}$ inducing possible detection bias.

All studies reported appropriate statistical analysis, appropriate use of statistical tests and appropriate trial design.

With regard to the two quasi-experimental studies, one met all the methodological criteria. ${ }^{72}$ In the other one, ${ }^{82}$ follow-up was incomplete and participants who withdrew were not included in the analysis, thus inducing attrition bias.

Further details of the critical appraisals for the included studies can be found in Tables 1 and 2 .

\section{Characteristics of included studies}

The 21 studies retained for this review included 19 RCTs and two quasi-experimental studies. ${ }^{72,82}$ All studies were published between $2004^{84}$ and $2017^{73,87}$ and were available in English. A table of the description of the included studies is provided in Appendix III.

\section{Participants}

All studies focused on socioeconomically disadvantaged people, as defined by the PROGRESS factors. ${ }^{53}$ Seven studies included participants from ethnic minorities, ${ }^{71,74,76,79,80,86,89}$ four studies included low-income participants, ${ }^{73,77,84,91}$ and one study included participants based on their low socioeconomic status. ${ }^{90}$ Nine studies used 
Table 1: Critical appraisal results for randomized controlled trials

\begin{tabular}{|c|c|c|c|c|c|c|c|c|c|c|c|c|c|}
\hline Study & Q1 & Q2 & Q3 & Q4 & Q5 & Q6 & Q7 & Q8 & Q9 & Q10 & Q11 & Q12 & Q13 \\
\hline Baig et al., $2015^{83}$ & $Y$ & U & $Y$ & Y & NA & U & $Y$ & Y & $\mathrm{Y}$ & $Y$ & U & Y & $Y$ \\
\hline Block et al., $2004^{84}$ & $N$ & $Y$ & $Y$ & Y & NA & U & $Y$ & $\mathrm{U}$ & $Y$ & $Y$ & $Y$ & Y & Y \\
\hline Gopalan et al., $2013^{76}$ & $Y$ & Y & Y & $Y$ & NA & $\mathrm{N}$ & Y & $Y$ & Y & Y & U & Y & Y \\
\hline Heisler et al., $2014^{85}$ & $Y$ & Y & $N$ & $\mathrm{~N}$ & NA & $Y$ & $Y$ & $Y$ & $\mathrm{Y}$ & Y & U & $Y$ & $Y$ \\
\hline Jackson et al., $2011^{77}$ & $Y$ & Y & $N$ & $Y$ & NA & $Y$ & $Y$ & $Y$ & $Y$ & Y & U & $Y$ & $Y$ \\
\hline Kim et al., $2009^{86}$ & Y & Y & Y & $\mathrm{N}$ & NA & U & $Y$ & $\mathrm{~N}$ & Y & Y & $Y$ & $Y$ & $Y$ \\
\hline Koniak-Griffin et al., $2015^{78}$ & $Y$ & U & $N$ & $Y$ & NA & $Y$ & $Y$ & $Y$ & $\mathrm{Y}$ & $\mathrm{Y}$ & Y & $Y$ & Y \\
\hline Kripalani et al., $2007^{79}$ & Y & $Y$ & $N$ & $N$ & NA & Y & Y & Y & Y & $Y$ & $Y$ & Y & $Y$ \\
\hline Kripalani et al., $2012^{75}$ & Y & $Y$ & Y & $N$ & NA & $Y$ & Y & Y & $Y$ & $Y$ & $Y$ & Y & Y \\
\hline Lutes et al., $2011^{87}$ & Y & U & $Y$ & $N$ & NA & U & Y & Y & $Y$ & $Y$ & $Y$ & Y & $Y$ \\
\hline Martin et al., $2011^{88}$ & $Y$ & U & $Y$ & $Y$ & NA & U & $Y$ & $Y$ & $Y$ & $\mathrm{Y}$ & $\mathrm{U}$ & $Y$ & $Y$ \\
\hline Mohan et al., $2014^{89}$ & $Y$ & $Y$ & $\mathrm{~N}$ & $\mathrm{~N}$ & NA & $\mathrm{N}$ & $Y$ & $Y$ & $Y$ & $\mathrm{Y}$ & $\mathrm{Y}$ & $Y$ & $Y$ \\
\hline Muchiri et al., $2015^{90}$ & $N$ & $Y$ & $\mathrm{U}$ & $\mathrm{N}$ & NA & $Y$ & $Y$ & Y & $Y$ & $\mathrm{Y}$ & $\mathrm{Y}$ & $Y$ & $Y$ \\
\hline Peragallo et al., $2012^{80}$ & $Y$ & Y & $Y$ & U & NA & $\mathrm{N}$ & $Y$ & $Y$ & $Y$ & Y & Y & $Y$ & $Y$ \\
\hline Phelan et al., $2017^{73}$ & $Y$ & $Y$ & Y & U & NA & $Y$ & Y & $Y$ & $\mathrm{Y}$ & Y & Y & $Y$ & $Y$ \\
\hline Sadler et al., $2011^{71}$ & $Y$ & $Y$ & Y & Y & NA & $Y$ & $Y$ & $Y$ & $Y$ & $Y$ & $Y$ & $Y$ & $Y$ \\
\hline Samuel-Hodge et al., $2009^{74}$ & $N$ & $Y$ & $Y$ & $Y$ & NA & $Y$ & $Y$ & Y & $Y$ & $Y$ & $Y$ & $Y$ & $Y$ \\
\hline Stockwell et al., $2014^{91}$ & $\mathrm{Y}$ & U & $Y$ & $Y$ & NA & U & Y & $N$ & $Y$ & $Y$ & $Y$ & Y & Y \\
\hline Tu et al., $2016^{81}$ & $Y$ & $Y$ & $Y$ & U & NA & $Y$ & $Y$ & U & $Y$ & $Y$ & $Y$ & $Y$ & $Y$ \\
\hline Total \% & 84 & 73 & 69 & 48 & - & 52 & 100 & 79 & 100 & 100 & 73 & 100 & 100 \\
\hline
\end{tabular}

$\mathrm{Y}=$ yes; $\mathrm{N}=$ no; $\mathrm{U}=$ unclear; $\mathrm{NA}=$ not applicable

$\mathrm{JBI}$ critical appraisal checklist for randomized controlled trials: Q1 = Was true randomization used for assignment of participants to treatment groups? Q2 $=$ Was allocation to treatment groups concealed? Q3 = Were treatment groups similar at baseline? Q4 = Were participants blind to treatment assignment? Q5 = Were those delivering treatment blind to treatment assignment? Q6 = Were outcome assessors blind to treatment assignment? Q7 = Were treatment groups treated identically other than the intervention of interest? Q8 = Was follow-up complete, and if not, were strategies to address incomplete follow-up utilized? Q9 = Were participants analyzed in the groups to which they were randomized? Q10 = Were outcomes measured in the same way for treatment groups? Q11 = Were outcomes measured in a reliable way? Q12 = Was appropriate statistical analysis used? $\mathrm{Q} 13=$ Was the trial design appropriate, and any deviations from the standard RCT design (individual randomization, parallel groups) accounted for in the conduct and analysis of the trial?

Table 2: Critical appraisal results for quasi-experimental studies

\begin{tabular}{|c|c|c|c|c|c|c|c|c|c|}
\hline Study & Q1 & Q2 & Q3 & Q4 & Q5 & Q6 & Q7 & Q8 & Q9 \\
\hline Park, $2011^{72}$ & $Y$ & $Y$ & $Y$ & $Y$ & $Y$ & $Y$ & $Y$ & $Y$ & $Y$ \\
\hline Yang et al., $2016^{82}$ & $Y$ & $Y$ & $Y$ & $Y$ & $Y$ & $\mathrm{~N}$ & $Y$ & $\mathrm{Y}$ & $Y$ \\
\hline Total \% & 100 & 100 & 100 & 100 & 100 & 50 & 100 & 100 & 100 \\
\hline
\end{tabular}

$\mathrm{Y}=\mathrm{Yes}, \mathrm{N}=\mathrm{No}$

$\mathrm{JBI}$ critical appraisal checklist for quasi-experimental studies (non-randomized experimental studies): Q1 = Is it clear in the study what is the 'cause' and what is the 'effect' (i.e. there is no confusion about which variable comes first)? Q2 = Were the participants included in any comparisons similar? Q3 = Were the participants included in any comparisons receiving similar treatment/care, other than the exposure or intervention of interest? Q4 = Was there a control group? Q5 $=$ Were there multiple measurements of the outcome both pre and post the intervention/exposure? $\mathrm{Q} 6=$ Was follow-up complete, and if not, was follow-up adequately reported and strategies to deal with loss to follow-up employed? Q7 = Were the outcomes of participants included in any comparisons measured in the same way? Q8 = Were outcomes measured in a reliable way? Q9 = Was appropriate statistical analysis used? 
more than one PROGRESS factor to include participants. Inclusion criteria were both based on ethnic minority and low income status of participants in four studies, ${ }^{78,81,83,85}$ on ethnic minority and low socioeconomic status in one study, ${ }^{75}$ on rural place of residence and ethnic minority in one study, ${ }^{87}$ on low educational attainment combined with old age in one study, ${ }^{72}$ on low income combined with old age in one study, ${ }^{82}$ and on rural place of residence associated with low income and ethnic minority in one study. ${ }^{88}$ In addition to the socioeconomically disadvantaged status, all studies included participants with health disparities: disparities in morbidity, mortality rates, burden of illness, risk factors and other health-related outcomes in 19 studies, ${ }^{71-78,80-90}$ disparities in access and use of healthcare services in three studies, ${ }^{79,81,90}$ disparities in health behaviors in two studies, ${ }^{82,89}$ and disparities in access to health information in one study. ${ }^{79}$

Among the included studies, sample sizes ranged from $82^{90}$ to 1153 participants. ${ }^{91}$ The number of participants included in the EGs ranged from $41^{86,90}$ to $576,{ }^{91}$ and from $41^{90}$ to $577^{91}$ in the CGs. The mean age of the participants ranged from $26.1^{77}$ to $72.64^{82}$ years in the EGs, and from $26.9^{77}$ to $72.11^{82}$ years in the CGs. Three studies expressed age of participants in categories. ${ }^{72,81,91}$

Among the 12 studies that included both men and women, ${ }^{72,74-76,81-83,85,86,88-90} 10$ studies included more women than men. ${ }^{72,74,75,81-83,85,88-90}$ Conversely, two studies included more men than women. ${ }^{76,86}$ Eight studies included only female participants, ${ }^{71,73,77,78,80,84,87,91}$ and one study only males. ${ }^{79}$

Six studies ${ }^{75-77,79,81,89}$ recruited participants from various clinical settings such as pre-natal practices, ${ }^{77}$ internal medicine practices, ${ }^{76}$ primary care clinics $^{75,79,81}$ and safety net clinics. ${ }^{89}$ Fifteen studies ${ }^{71-}$ $74,78,80,82-88,90,91$ recruited participants from community settings, including community health centers, ${ }^{73,82,85,87,88,90,91}$

organizations, ${ }^{72,78,80,82,84}$ churches, ${ }^{74,78,80,83,86,87}$ grocery stores, ${ }^{82,86}$ laundromats, ${ }^{78,82}$ supermarkets, ${ }^{80}$ beauty salons, ${ }^{71}$ ethnic media, ${ }^{86}$ and programs providing services to low-income populations. ${ }^{84}$

Eighteen studies were conducted in the United States of America (USA), ${ }^{71,73-81,83-89,91}$ two in South Korea, ${ }^{72,82}$ and one in South Africa. ${ }^{90}$

\section{Interventions}

The included interventions addressed health issues in the three domains of the health continuum. For the healthcare domain, health topics addressed included diabetes control and/or self-management, ${ }^{74,76,83,85}$, ${ }^{86,90}$ medication adherence ${ }^{75,88,89}$ and safe medication use. ${ }^{72}$ For the disease prevention domain, health issues included cardiovascular risks reduction, ${ }^{82}$ human immunodeficiency viruses (HIV) risk reduction, ${ }^{80}$ breast cancer screening, ${ }^{71}$ colorectal cancer (CRC) and fecal occult blood testing (FOBT) screening, ${ }^{81}$ prostate cancer screening, ${ }^{79}$ and promotion of influenza vaccination during pregnancy. ${ }^{91}$ For the health promotion domain, health topics included healthy lifestyle behaviors ${ }^{78,84,87}$ such as healthy eating and physical activity, nutrition and physical activity during pregnancy, ${ }^{77}$ and weight loss in the postpartum period. ${ }^{73}$

The length of intervention ranged from less than one hour ${ }^{77,79}$ (intervention in which participants received a handout or a unique session with a computer program just before the appointment with the doctor) to 12 months. ${ }^{73,74,87}$ The duration of the intervention was unclear or unspecified in five studies. $^{71,75,81,88,89}$ The length of follow-up varied from a post-intervention assessment taking place immediately after treatment $\mathrm{t}^{72-74,79,82,84,86,87}$ to 12 months post intervention. ${ }^{75}$

The intervention was conducted individually in 12 studies, ${ }^{75-77,79,81,82,84,85,87-89,91}$ in a group format in four studies ${ }^{72,80,83,90}$ and in combination in five studies. ${ }^{71,73,74,78,86}$

Eleven studies were delivered at the individual level, ${ }^{72,73,75,76,81,82,84,85,88-90}$ four were delivered both at the individual and interpersonal level, ${ }^{77,79,80,91}$ five at both the individual and community level, ${ }^{71,74,78,83,87}$ and one at the individual, interpersonal and community level. ${ }^{86}$ No study was delivered at the societal level. Five interventions used a single strategy, ${ }^{75,76,79,89,91}$ and 16 studies were complex interventions with multiple components. ${ }^{71-74,77,78,80-88,90}$

One intervention ${ }^{86}$ was exclusively delivered by health professionals. Five interventions were delivered by trained members of the community. ${ }^{71,78,80,83,87}$ One intervention ${ }^{90}$ combined both health professionals and a lay interventionist (horticulture officer). Two interventions ${ }^{77,84}$ were computer-based, and one ${ }^{91}$ used text messages to deliver health information to participants. Four 
interventions used printed information. ${ }^{75,76,79,89}$ The remaining seven studies ${ }^{72-74,81,82,85,88}$ used a combination of both interventionists (professional or lay) and educational materials to deliver the intervention.

\section{Comparison}

Among the 21 studies included in this review, 16 had two arms, ${ }^{71,73,74,77,78,80-83,85,86,88-91}$ four studies had three arms, ${ }^{72,76,79,84}$ and one study had four arms. ${ }^{75}$ Eleven of the included studies had an active $\mathrm{CG},{ }^{71,73,74,78,79,83-85,87,88,90}$ and 10 had a passive CG. ${ }^{72,75-77,80-82,86,89,91}$ Active CG conditions included a minimal intervention in four studies, ${ }^{73,74,83,90}$ and an alternative intervention in seven studies. ${ }^{71,78,79,84,85,87,88}$ Passive CG conditions included standard or usual care in seven studies, ${ }^{75-}$ $77,81,82,89,91$ no intervention in one study, ${ }^{72}$ and a delayed intervention in two studies. ${ }^{80,86}$

\section{Outcomes}

For primary outcomes, measures and measurement tools used to assess outcomes varied across studies. Primary outcomes were classified into three categories: health-related quality of life, health-related outcomes and health behaviors. Among the included studies, none addressed access and use of healthcare services outcomes.

Health-related quality of life: Only one study ${ }^{86}$ assessed health-related quality of life using the Diabetes Quality of Life Measure. ${ }^{92}$

Health-related outcomes: Health-related outcomes as assessed in the studies included a variety of clinical outcomes, and only a few patient-reported outcomes. Clinical outcomes included HbA1cin seven studies, ${ }^{74,76,83,85-87,90}$ fasting blood glucose in three studies, ${ }^{78,82,86}$ total cholesterol in three studies, ${ }^{78,82,90}$ low-density lipoprotein (LDL) cholesterol in four studies, ${ }^{78,83,86,90}$ high-density lipoprotein (HDL) cholesterol in three studies, ${ }^{78,86,90}$ triglycerides in three studies, ${ }^{78,86,90}$ systolic and diastolic blood pressure in seven studies, $^{74,78,82,83,86,87,90}$ waist circumference in three studies, ${ }^{73,78,83}$ weight assessed in different ways according to the context of the study in five studies, ${ }^{73,74,77,78,87}$ body mass index (BMI) in four studies, ${ }^{78,82,86,90}$ and chlamydia infection in one study. ${ }^{80}$ Patient-reported outcomes included the diabetesrelated health status ${ }^{93}$ in one study, ${ }^{74}$ the general health status assessed via the MOS 36-Item Short-
Form Health Survey (SF-36) ${ }^{94}$ in one study, ${ }^{74}$ and depression assessed via the 10-item Center for Epidemiologic Studies Depression Scale ${ }^{95}$ in one study ${ }^{80}$ and the Kim Depression Scale for Korean Americans $^{96}$ in another study. ${ }^{86}$

Health behaviors: Outcomes related to health behaviors included:

i) Healthy lifestyles, including healthy eating behaviors and physical activity outcomes. Healthy eating behaviors were assessed in two studies ${ }^{73,84}$ using the National Cancer Institute Automated Self-Administered 24Hour dietary assessment tool, ${ }^{97}$ or a 24 -hour recall of number of fruits, vegetables and juices consumed. Physical activity levels were assessed in three studies ${ }^{73,74,78}$ using accelerometers.

ii) Medication adherence, assessed in five studies $^{75,85,87-89}$ using various measurement tools, including pill count in one study, ${ }^{88}$ the Morisky Medication Adherence Scale ${ }^{98}$ in two studies, ${ }^{85,87}$ the Cumulative Medication Gap $^{99}$ in one study, ${ }^{75}$ and the Adherence to Refills and Medications Scale ${ }^{100}$ in one study. ${ }^{89}$

iii) Diabetes-related self-efficacy, assessed using the Diabetes Care Self-Efficacy Scale ${ }^{101}$ in three studies. $^{85,87}$ and the Chronic Disease SelfEfficacy scale ${ }^{101}$ in one study. ${ }^{86}$

iv) Self-efficacy related to medication assessed in one study ${ }^{72}$ using the Self-Efficacy for Appropriate Medication Use Scale. ${ }^{102}$

v) Preventive health practices, including condom use assessed in one study, ${ }^{80}$ adherence to mammography screening guidelines in one study, ${ }^{71}$ receipt of influenza vaccination in one study, ${ }^{91}$ FOBT screening in one study, ${ }^{81}$ and prostatespecific antigen (PSA) test ordered and digital rectal examination in one study. ${ }^{75}$

Secondary outcomes were classified into five categories:

Knowledge and understanding: Diabetes knowledge was assessed in three studies ${ }^{74,83,86}$ using the Diabetes Knowledge Questionnaire, ${ }^{103}$ the Diabetes Knowledge Test, ${ }^{104}$ and the Diabetes Knowledge Scale. ${ }^{105}$

Skills acquisition: Empowerment was assessed in two studies ${ }^{74,87}$ using the Diabetes Empowerment Scale Short Form; ${ }^{106}$ and diabetes self-care was assessed in two studies ${ }^{86,87}$ using the Summary of Diabetes Self-Care Activities measure. ${ }^{107}$ 
Decision-making: Decision-making was assessed in one study ${ }^{85}$ using the Anti-hyperglycemic Medication Decisional Conflict Scale. ${ }^{108}$

Communication: Communication of health information with a healthcare provider was assessed in one study ${ }^{79}$ in terms of frequency of discussion about prostate cancer with the doctor during the medical visit, and communication of health information and negotiation of safe sexual practices with the partner was assessed in one study ${ }^{80}$ using the Communication with Partner scale. ${ }^{109}$

Attitudes and beliefs: Perceived barriers to condom use were assessed in one study. ${ }^{80}$

\section{Review findings}

The possibility of a meta-analysis based on two studies $^{75,89}$ and pooling 640 participants was considered, but due to heterogeneity of the interventions, different follow-up times and differences in the ways the outcomes were measured in the two studies, a metaanalysis was not feasible. A narrative review of the findings of 21 studies was more appropriate.

In a first stage, studies included in the review were classified according to the HL competency addressed. None of the studies addressed the competency to access health information, i.e. interventions that assist socioeconomically disadvantaged people to develop their ability to seek, find and obtain reliable health information, ${ }^{3}$ or to make reliable health information available to socioeconomically disadvantaged people by creating HL-friendly settings using multiple channels and dissemination strategies. ${ }^{110}$ Likewise, none of the studies addressed the competency to appraise health information, i.e. interventions that assist socioeconomically disadvantaged people to evaluate the quality and credibility of health information and to develop their critical-thinking skills. ${ }^{3,111}$ Three studies addressed the competency to understand health information. ${ }^{75,76,89}$ They included interventions that assist socioeconomically disadvantaged people to develop their ability to comprehend health information ${ }^{3}$ by simplifying and improving health information materials (e.g. use of plain language, simple text, illustrations, pictographs, icons, meaningful formats and targeted information; development of easy-toread and easy-to-use materials). Eighteen studies addressed the competency to apply health information. ${ }^{71-74,77-88,90,91}$ These interventions were designed to: i) assist socioeconomically disadvantaged people to develop their ability to communicate, share, negotiate and use health information to make informed and appropriate decisions around specific health behaviors $^{3}$ (e.g. improve or enhance the communication of health information as well as the decisionmaking, goal setting and problem-solving skills of socioeconomically disadvantaged people); and/or ii) assist socioeconomically disadvantaged people to develop their ability to act upon health information, to engage in appropriate health actions (positive health behaviors) and implement informed health decision-making by helping them to build, develop or improve specific skills such as self-monitoring, self-management, self-care, copings and selfefficacy. Within these HL competencies, interventions were then, in a second stage, grouped according to the three domains of the health continuum (health care, disease prevention and health promotion) and the health topic addressed. Finally, in the third stage, interventions were classified according to their theoretical foundations. Six studies did not specify a theoretical foundation. ${ }^{75,77,79,81,89,91}$ Theoretical underpinnings of the interventions were described in 15 stud-

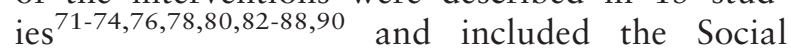
Cognitive Theory, ${ }^{112-115}$ Transtheoretical Model of Behavior Change, ${ }^{116-118}$ Health Belief Model, ${ }^{119,120}$ Community-based Participatory Research principles, ${ }^{121,122}$ Self-determination Theory, ${ }^{123}$ Knowledge Attitude Behavior Model, ${ }^{124}$ Freirian pedagogy, ${ }^{125}$ Adult Learning Theory ${ }^{126}$ and Small Changes model of behavior change. ${ }^{127,128}$

A combination of various theoretical backgrounds was used in eight studies. ${ }^{71,74,76,80,82,83,88,90}$

Within the included studies, a wide variety of operational components, that is, tools and techniques used to develop HL skills, were found. They included adaptation to the cultural setting and/or level of literacy, ${ }^{71-76,78,80,81,83,85-90}$ assessment of preferences and subsequent tailoring, $73,74,77,78,80,82,84-88,90$ skills training, 72,74 , $77,78,80,82-88,90$ goal setting, ${ }^{74,78,82-85,87,88,90}$ individual or group discussions, ${ }^{72-74,78,80-82,85-87,90}$ and group activities (such as role play). ${ }^{78,80}$ In the same manner, a wide range of HL materials (specific tools or medium used to disseminate health information), were used within the interventions. They included print-based materials (such as handouts, booklets and brochures), ${ }^{71,72,74-}$ $76,78,79,81,82,84,85,87-90$ interactive multimedia 
computer programs, ${ }^{73,77,84,85,88}$ videos, ${ }^{73,78,80,}$ 81,88 text messages, ${ }^{91}$ and increasing awareness of community resources. ${ }^{74,83,87}$

The HL competency and domain of the health continuum addressed, theoretical foundations used, as well as mode of delivery, intervention's operational components and HL materials delivered for each included intervention are provided in Table 3. A full description of the studies, a summary of the significant findings for primary and secondary outcomes, as well as the tools used to assess them are shown in Appendix III. Only parametric results of the comparison of outcomes at post-test were reported.

Table 3: Health literacy competency addressed, health continuum domain, theoretical foundations and components of included interventions

\begin{tabular}{|c|c|c|c|c|}
\hline $\begin{array}{l}\text { HL compe- } \\
\text { tency }\end{array}$ & $\begin{array}{l}\text { Health continuum domain } \\
\text { and health topic }\end{array}$ & $\begin{array}{l}\text { Theoretical } \\
\text { foundations }\end{array}$ & Study & $\begin{array}{l}\text { Mode of delivery, intervention's operational components } \\
\text { and HL materials used }\end{array}$ \\
\hline \multirow[t]{3}{*}{$\begin{array}{l}\text { Under- } \\
\text { stand }\end{array}$} & \multirow[t]{2}{*}{$\begin{array}{l}\text { Health care: Medication } \\
\text { adherence }\end{array}$} & \multirow[t]{2}{*}{ Atheoretical } & Kripalani et al., $2012^{75}$ & $\begin{array}{l}\text { Mode of delivery: } \\
\text { Single strategy: Individual print-based intervention: illus- } \\
\text { trated medication schedule in a grid format } \\
\text { Intervention's operational components: } \\
\text { No detail provided } \\
\text { HL materials: } \\
\text { Plain language, color illustrations, icons }\end{array}$ \\
\hline & & & Mohan et al., $2014^{89}$ & $\begin{array}{l}\text { Mode of delivery: } \\
\text { Single strategy: Individual print-based intervention: illus- } \\
\text { trated medication schedule in a grid format } \\
\text { Intervention's operational components: } \\
\text { No detail provided } \\
\text { HL materials: } \\
\text { Plain language, color illustrations, icons, pictures }\end{array}$ \\
\hline & $\begin{array}{l}\text { Health care: Diabetes con- } \\
\text { trol and self-management }\end{array}$ & $\begin{array}{l}\text { SCT (self- } \\
\text { efficacy) })^{112-115}+ \\
\text { HBM }^{119,120}\end{array}$ & Gopalan et al., $2013^{76}$ & $\begin{array}{l}\text { Mode of delivery: } \\
\text { Single strategy: Individual print-based information about } \\
\text { diabetes control (diabetes report cards) } \\
\text { Intervention's operational components: } \\
\text { No detail provided } \\
\text { HL materials: } \\
\text { Meaningful communication formats }\end{array}$ \\
\hline \multirow[t]{2}{*}{ Apply } & $\begin{array}{l}\text { Health care: Medication } \\
\text { adherence }\end{array}$ & $\begin{array}{l}\mathrm{SCT}^{112-115}+ \\
\operatorname{TTM}^{116-118}\end{array}$ & Martin et al., $2011^{88}$ & $\begin{array}{l}\text { Mode of delivery: } \\
\text { Complex strategy: } 4 \text { individual face-to-face sessions with a } \\
\text { CHA using a multimedia computer-based program about } \\
\text { hypertension medication adherence (CHA = liaison } \\
\text { between the computer and the participant) } \\
+4 \text { follow-up phone contacts } \\
\text { Intervention's operational components: } \\
\text { Culturally appropriate intervention, tailoring, goal setting, } \\
\text { skills training (self-monitoring) } \\
\text { HL materials: } \\
\text { Interactive multimedia computer program, low literacy } \\
\text { videos and handouts, use of narratives }\end{array}$ \\
\hline & $\begin{array}{l}\text { Health care: Safe medica- } \\
\text { tion use }\end{array}$ & $\begin{array}{l}\text { SCT (Self- } \\
\text { efficacy) })^{112-115}\end{array}$ & Park, $2011^{72}$ & $\begin{array}{l}\text { Mode of delivery: } \\
\text { Complex strategy: } 3 \text { weekly } 40-\text { min group educational } \\
\text { sessions (face-to-face) about safe medication, led by a } \\
\text { nurse } \\
\text { Intervention's operational components: } \\
\text { Skills training (reading labels, calculating dosage, keeping } \\
\text { a medication log), group discussions } \\
\text { HL materials: } \\
\text { Pictorial guide map, use of symbolic images, } \\
\text { information booklet }\end{array}$ \\
\hline
\end{tabular}


Table 3: (Continued)

\begin{tabular}{|c|c|c|c|c|}
\hline $\begin{array}{l}\text { HL compe- } \\
\text { tency }\end{array}$ & $\begin{array}{l}\text { Health continuum domain } \\
\text { and health topic }\end{array}$ & $\begin{array}{l}\text { Theoretical } \\
\text { foundations }\end{array}$ & Study & $\begin{array}{l}\text { Mode of delivery, intervention's operational components } \\
\text { and HL materials used }\end{array}$ \\
\hline & \multirow[t]{5}{*}{$\begin{array}{l}\text { Health care: Diabetes con- } \\
\text { trol and self-management }\end{array}$} & $\begin{array}{l}\mathrm{SCT}^{112-115}+\mathrm{TTM} \\
\text { (Stages of Change } \\
\text { Model) })^{116-118}+ \\
\text { adult learning the- } \\
\text { ory }^{126}\end{array}$ & Samuel-Hodge et al., $2009^{74}$ & $\begin{array}{l}\text { Mode of delivery: } \\
\text { Complex strategy: One } 60 \text {-min individual face-to-face } \\
\text { counseling visit with a dietitian } \\
+12 \text { bi-weekly face-to-face group sessions about diabetes } \\
\text { led by a dietitian and a church diabetes advisor or a } \\
\text { health professional from the local community } \\
+ \text { one monthly phone contact with the church diabetes } \\
\text { advisor } \\
\text { Intervention's operational components: } \\
\text { Culturally appropriate intervention, tailoring, goal setting, } \\
\text { skills training (self-monitoring, planning meals, problem- } \\
\text { solving), group discussions, small-group activities, game } \\
\text { format } \\
\text { HL materials: } \\
\text { Visual and hands-on activities, awareness of community } \\
\text { resources, printed postcard messages }\end{array}$ \\
\hline & & $\begin{array}{l}\mathrm{SCT}^{112-115}+ \\
\mathrm{HBM}^{119,120}+\text { The } \\
\text { Knowledge Atti- } \\
\text { tude Behaviour } \\
\text { model }^{124}\end{array}$ & Muchiri et al., $2015^{90}$ & $\begin{array}{l}\text { Mode of delivery: } \\
\text { Complex strategy: } 8 \text { 2-hr weekly face-to-face education } \\
\text { group sessions about diabetes and nutrition, led by a } \\
\text { dietitian and a nutrition and food science university } \\
\text { student } \\
\text { + follow-up sessions } \\
\text { + vegetable gardening with a horticulture officer } \\
\text { Intervention's operational components: } \\
\text { Culturally appropriate intervention, tailoring, group goal } \\
\text { setting, skills training, group discussions } \\
\text { HL materials: } \\
\text { Educational materials (pamphlets and posters) }\end{array}$ \\
\hline & & $\begin{array}{l}\text { SCT (self-efficacy } \\
\text { theory) }\end{array}$ & Kim et al., $2009^{86}$ & $\begin{array}{l}\text { Mode of delivery: } \\
\text { Complex strategy: } 6 \text { weekly face-to-face psycho- } \\
\text { behavioral education sessions in groups led by a nurse } \\
\text { and a nutritionist } \\
\text { + monthly phone counseling } \\
\text { Intervention's operational components: } \\
\text { Culturally appropriate intervention, tailoring, skills training } \\
\text { (self-monitoring, self-care, food labels reading, communi- } \\
\text { cation skills, problem-solving), individual discussions } \\
\text { HL materials: } \\
\text { No detail provided }\end{array}$ \\
\hline & & $\begin{array}{l}\text { CBPR princi- } \\
\text { ples }^{121,122}\end{array}$ & Heisler et al., $2014^{85}$ & $\begin{array}{l}\text { Mode of delivery: } \\
\text { Complex strategy: One individual face-to-face 2-hr session } \\
\text { with a CHW + web-based diabetes medication decision } \\
\text { aid on tablet computer } \\
+2 \text { phone calls } \\
\text { Intervention's operational components: } \\
\text { Tailoring, motivational interviewing, goal setting, } \\
\text { individual discussions } \\
\text { HL materials: } \\
\text { Interactive web-based decision aid program, use of } \\
\text { graphical styles, pictographs and animations adapted to } \\
\text { people with low literacy; printed educational booklets }\end{array}$ \\
\hline & & $\begin{array}{l}\text { CBPR princi- } \\
\text { ples }^{121,122}+\text { the } \\
\text { self-determination } \\
\text { theory }^{123}\end{array}$ & Baig et al., $2015^{83}$ & $\begin{array}{l}\text { Mode of delivery: } \\
\text { Complex strategy: } 8 \text { weekly 90-min group sessions (face- } \\
\text { to-face) led by trained peer lay leaders with diabetes, or } \\
\text { with a family member with diabetes } \\
\text { Intervention's operational components: } \\
\text { Motivational interviewing, goal setting, skills training } \\
\text { (problem-solving) } \\
\text { HL materials: } \\
\text { Photovoice exercises (use of photographs and storytell- } \\
\text { ing), awareness of community resources }\end{array}$ \\
\hline
\end{tabular}


Table 3: (Continued)

\begin{tabular}{|c|c|c|c|c|}
\hline $\begin{array}{l}\text { HL compe- } \\
\text { tency }\end{array}$ & $\begin{array}{l}\text { Health continuum domain } \\
\text { and health topic }\end{array}$ & $\begin{array}{l}\text { Theoretical } \\
\text { foundations }\end{array}$ & Study & $\begin{array}{l}\text { Mode of delivery, intervention's operational components } \\
\text { and HL materials used }\end{array}$ \\
\hline & \multirow[t]{2}{*}{$\begin{array}{l}\text { Disease prevention: Risk } \\
\text { reduction }\end{array}$} & $\begin{array}{l}\text { SCT (self- } \\
\text { efficacy) }^{112-115}\end{array}$ & Yang et al., $2016^{82}$ & $\begin{array}{l}\text { Mode of delivery: } \\
\text { Complex strategy: } 8 \text { 40-min individual face-to-face ses- } \\
\text { sions (home visits) by a nurse to promote healthy } \\
\text { lifestyles } \\
+4 \text { 10-min phone calls } \\
\text { Intervention's operational components: } \\
\text { Tailoring, goal setting, skills training (self-monitoring), } \\
\text { individual discussions } \\
\text { HL materials: } \\
\text { Educational brochures }\end{array}$ \\
\hline & & $\begin{array}{l}\mathrm{SCT}^{112-115}+ \\
\text { Freire's } \\
\text { pedagogy }^{125}\end{array}$ & Peragallo et al., $2012^{80}$ & $\begin{array}{l}\text { Mode of delivery: } \\
\text { Complex strategy: } 5 \text { 2-hr face-to-face educational sessions } \\
\text { in groups about HIV risk reduction, led by Hispanic female } \\
\text { facilitators } \\
+ \text { one booster sessions at 6-month follow-up } \\
\text { Intervention's operational components: } \\
\text { Culturally adapted intervention, tailoring, skills training } \\
\text { (activities promoting self-efficacy, condom use), group } \\
\text { discussions } \\
\text { HL materials: } \\
\text { Videos }\end{array}$ \\
\hline & $\begin{array}{l}\text { Disease prevention: Risk } \\
\text { message - promotion of } \\
\text { influenza vaccination } \\
\text { during pregnancy }\end{array}$ & Atheoretical & Stockwell et al., $2014^{91}$ & $\begin{array}{l}\text { Mode of delivery: } \\
\text { Single strategy: Individual text-based intervention: } 5 \text { weekly } \\
\text { educational text messages about influenza vaccination } \\
\text { Intervention's operational components: } \\
\text { Group-specific appropriate intervention } \\
\text { HL materials: } \\
\text { Text messages written at a } 4^{\text {th }} \text { grade level }\end{array}$ \\
\hline & \multirow[t]{3}{*}{$\begin{array}{l}\text { Disease prevention: Risk } \\
\text { message - screening }\end{array}$} & Atheoretical & Tu et al., $2006^{81}$ & $\begin{array}{l}\text { Mode of delivery: } \\
\text { Complex strategy: One individual face-to-face educational } \\
\text { session about CRC screening, led by a health educator } \\
\text { + FOBT instruction sheet and FOBT kit } \\
\text { Intervention's operational components: } \\
\text { Culturally appropriate intervention, individual } \\
\text { discussions } \\
\text { HL materials: } \\
\text { Motivational video on CRC screening, motivational and } \\
\text { informational pamphlet }\end{array}$ \\
\hline & & & Kripalani et al., $2007^{79}$ & $\begin{array}{l}\text { Mode of delivery: } \\
\text { Single strategy: Individual print-based intervention: hand- } \\
\text { outs about prostate cancer } \\
\text { Intervention's operational components: } \\
\text { No detail provided } \\
\text { HL materials: } \\
\text { Handouts with simple text, written at a } 6^{\text {th }} \text { grade reading } \\
\text { level, large characters, color illustrations, focus on the } \\
\text { most important information }\end{array}$ \\
\hline & & $\begin{array}{l}\text { CBPR princi- } \\
\text { ples }^{121,122}+ \\
\mathrm{HBM}^{119,120}\end{array}$ & Sadler et al., $2011^{71}$ & $\begin{array}{l}\text { Mode of delivery: } \\
\text { Complex strategy: Individual face-to-face discussions and } \\
\text { group discussions about breast cancer screening with } \\
\text { cosmetologists and other clients in a beauty salon (HL- } \\
\text { friendly environment) } \\
\text { Intervention's operational components: } \\
\text { Culturally appropriate intervention, individual and group } \\
\text { discussions } \\
\text { HL materials: } \\
\text { Enlarged articles from lay newspapers and magazines, } \\
\text { binders of information, posters, brochures, hands-on, } \\
\text { storytelling }\end{array}$ \\
\hline
\end{tabular}


Table 3: (Continued)

\begin{tabular}{|c|c|c|c|c|}
\hline $\begin{array}{l}\text { HL compe- } \\
\text { tency }\end{array}$ & $\begin{array}{l}\text { Health continuum domain } \\
\text { and health topic }\end{array}$ & $\begin{array}{l}\text { Theoretical } \\
\text { foundations }\end{array}$ & Study & $\begin{array}{l}\text { Mode of delivery, intervention's operational components } \\
\text { and HL materials used }\end{array}$ \\
\hline & \multirow[t]{3}{*}{$\begin{array}{l}\text { Health promotion: Healthy } \\
\text { lifestyle behaviors }\end{array}$} & $\begin{array}{l}\mathrm{TTM}^{116-118} \text { (stages } \\
\text { of readiness for } \\
\text { change) }\end{array}$ & Block et al., $2004^{84}$ & $\begin{array}{l}\text { Mode of delivery: } \\
\text { Complex strategy: Individual computer-based intervention: } \\
\text { one-time experience with a CD-ROM during } 15 \text { to } 20 \\
\text { minutes } \\
\text { + phone calls } \\
\text { Intervention's operational components: } \\
\text { Tailoring, goal setting } \\
\text { HL materials: } \\
\text { Interactive CD-ROM, handouts and educational } \\
\text { materials }\end{array}$ \\
\hline & & $\begin{array}{l}\text { The Small Changes } \\
\text { model of behavior } \\
\text { change }^{127-131}\end{array}$ & Lutes et al., $2017^{87}$ & $\begin{array}{l}\text { Mode of delivery: } \\
\text { Complex strategy: Individual phone sessions: } 16 \text { 20- } \\
30 \text { min lifestyle coaching sessions with a CHW } \\
\text { Intervention's operational components: } \\
\text { Culturally appropriate intervention, tailoring, motivational } \\
\text { interviewing, goal setting, skills training (coping, self- } \\
\text { monitoring, problem-solving), individual discussions } \\
\text { HL materials: } \\
\text { Educational manual, awareness of community resources }\end{array}$ \\
\hline & & $\begin{array}{l}\text { CBPR princi- } \\
\text { ples }^{121,122}\end{array}$ & Koniak-Griffin et al., $2015^{78}$ & $\begin{array}{l}\text { Mode of delivery: } \\
\text { Complex strategy: } 8 \text { face-to-face group education sessions } \\
\text { led by promotoras (CHWs) } \\
+8 \text { individual teaching and coaching sessions } \\
\text { ( } 4 \text { face-to-face sessions and } 4 \text { phone calls sessions) } \\
\text { + physical activity DVD } \\
\text { + culturally appropriate recipes } \\
\text { Intervention's operational components: } \\
\text { Culturally appropriate intervention, tailoring, goal setting, } \\
\text { skills training (self-monitoring, problem-solving), individual } \\
\text { and group discussions, role plays } \\
\text { HL materials: } \\
\text { Physical activity DVD, videos, low literacy culturally } \\
\text { adapted brochures }\end{array}$ \\
\hline & \multirow[t]{2}{*}{$\begin{array}{l}\text { Health promotion: Healthy } \\
\text { lifestyle behaviors during } \\
\text { pregnancy }\end{array}$} & Atheoretical & Jackson et al., $2011^{77}$ & $\begin{array}{l}\text { Mode of delivery: } \\
\text { Complex strategy: Individual computer-based intervention: } \\
\text { one } 10-15 \text { min session with the multimedia interactive } \\
\text { Video Doctor tool } \\
\text { + educational worksheet } \\
\text { Intervention's operational components: } \\
\text { Motivational interviewing, tailored counseling } \\
\text { HL materials: } \\
\text { Multimedia interactive program, tailored educational } \\
\text { messages }\end{array}$ \\
\hline & & $\mathrm{SCT}^{112-115}$ & Phelan et al., $2017^{73}$ & $\begin{array}{l}\text { Mode of delivery: } \\
\text { Complex strategy: Individual internet-based weight loss } \\
\text { program } \\
\text { + face-to-face education sessions } \\
\text { Intervention's operational components: } \\
\text { Cultural adaptation, tailoring, individual and group } \\
\text { discussions } \\
\text { HL materials: } \\
\text { Interactive multimedia program, videos, message board }\end{array}$ \\
\hline
\end{tabular}

$\mathrm{CBPR}=$ community-based participatory research; $\mathrm{CHA}=$ community health advisor; $\mathrm{CHW}=$ community health worker; $\mathrm{CRC}=$ colorectal cancer; FOBT $=$ fecal occult blood testing; HBM = health belief model; HIV = human immunodeficiency virus; HL = health literacy; hrs = hours; min = minute(s); SCT = social cognitive theory; TTM $=$ Transtheoretical Model of Behavior Change. 


\section{Interventions addressing the competency to understand health information in the Health care domain of the health continuum}

Effectiveness of an illustrated medication schedule for improving medication adherence $e^{75}$

This RCT included 435 patients aged 18 years or over with coronary heart disease, mainly African Americans and with a low socioeconomic status (121 participants in $\mathrm{EG}_{1}, 102$ in $\mathrm{EG}_{2}, 116$ in $\mathrm{EG}_{3}$, and 96 in the CG). Participants in $\mathrm{EG}_{1}$ received: i) illustrated medication instructions (called the Universal Medication Schedule) ${ }^{132}$ consisting of a grid including textual, visual and illustrated information to make instructions more understandable to take medicine correctly; and ii) a brief five-minute introduction to the tool from a pharmacist. Participants in $\mathrm{EG}_{2}$ received mailed refill reminder postcards. Participants in $\mathrm{EG}_{3}$ received both illustrated medication instructions and reminder postcards. Participants in the CG received usual care. Although participants in $\mathrm{EG}_{3}$ and $\mathrm{EG}_{2}$ had greater medication adherence (36.9\% and $34.2 \%$, respectively) than participants in the CG $(28.3 \%)$, differences were not statistically significant at 12 months follow-up. This intervention offered a tool to facilitate the understanding of the medication treatment.

\section{Effectiveness of an illustrated medication schedule for} improving medication adherence ${ }^{89}$

This RCT included 200 Latino patients with diabetes, 99 participants in the EG and 101 in the CG. Participants in the EG received: i) an illustrated medication schedule (Universal Medication Schedule $)^{132}$ in both Spanish and English, containing simplified and understandable medication instructions (using plain language, illustrations, pictures and icons); and ii) a brief two-minute introduction to the tool (using a video and a one-page sheet explaining how to use the tool). Participants in the CG received traditional prescription instructions. The results showed no significant differences between the groups in medication adherence at one-week follow-up. However, while the differences between the groups with regard to the overall understanding of medication and medication indications, medication strength, medication units and medication frequency were significant, these outcomes were assessed using a non-validated questionnaire in Spanish and were therefore not considered for this systematic review. When evaluating the effectiveness of this type of education tool, medication understanding should be evaluated using validated questionnaires.

\section{Effectiveness of two different formats for} communicating diabetes control ${ }^{76}$

This RCT included 177 adult patients with poorly controlled diabetes, mainly African American women with low numeracy $\left(58\right.$ in $\mathrm{EG}_{1}, 61$ in $\mathrm{EG}_{2}$ and 58 in the CG). The intervention provided participants with various meaningful formats to help them understand health information. Participants in $\mathrm{EG}_{1}$ received feedback about their current glycemic control (HbA1c value) using diabetes report cards containing a letter grade system of evaluation, ranging from $A$ to $F$. Participants in $\mathrm{EG}_{2}$ received the same feedback but using faces expressing emotions (happiness, crying, etc.) to reflect the current $\mathrm{HbA} 1 \mathrm{c}$ level. Participants in the CG received standard feedback about glycemic control (HbA1c level). Results showed no significant differences between groups in HbA1c levels at six months follow-up.

\section{Combined findings}

The competency of understanding health information in the Healthcare domain of the health continuum was addressed in three studies. ${ }^{75,76,89}$ In relation to the outcomes considered in this systematic review, none of these three interventions showed any effectiveness. Based on our findings, interventions that aim to improve the understanding of health information should: i) assess understanding skills directly (to be consistent with the purpose of the study), rather than hypothesize that a good understanding or comprehension of health information will lead to better health outcomes (in the three above mentioned studies that addressed the competency of understanding health information, there was too big a gap between understanding skills and the health outcomes measured); and ii) use validated measurement tools to assess understanding skills.

\section{Interventions addressing the competency of applying health information in the Healthcare domain of the health continuum}

Effectiveness of a multimedia medication adherence intervention ${ }^{88}$

This RCT included 434 rural low-income hypertensive adults, mainly African Americans (221 in the EG and 213 in the CG). In the EG, the intervention included: i) four sessions of an adherence promotion 
program delivered by a community health advisor using a computer-based program. This computer program delivered tailored health information about hypertension, medication adherence and self-monitoring (using a cyber-nurse, a video doctor, tailored feedback, discussion points with the community health advisor, videos, narratives and goal setting); and ii) follow-up phone calls two weeks after each session to review and reinforce the goals set. Participants in the CG received a computerbased program delivering general information about cancer. At six months, the differences between both groups were not statistically significant, despite the greater proportion of adherent participants in the EG compared to the CG.

\section{Effectiveness of a culturally relevant interactive pictorial education for safe medication use ${ }^{72}$}

This RCT included 136 Korean community-dwelling older adults with a low educational level (45 in $\mathrm{EG}_{1}$, 45 in $E_{2}$, and 46 in the CG). Participants in $E_{1}$ received three sessions of interactive pictorial education for safe medication delivered by a nurse, using a pictorial guide map with symbolic images and an information booklet. The intervention was informed by the self-efficacy theory ${ }^{113}$ and enabled participants to make healthy choices, initiate discussions about medication, read labels, calculate the dosage, and keep a medication log. Participants in $\mathrm{EG}_{2}$ received conventional education about safe medication during three education sessions and received an information booklet. Participants in the CG received no intervention. At post-test, there was a significant improvement in self-efficacy in $\mathrm{EG}_{1}$ and $\mathrm{EG}_{2}$ compared to the $\mathrm{CG}$ $(P<0.001)$, with higher improvements in $\mathrm{EG}_{1}$ than in $\mathrm{EG}_{2}(P<0.05)$. These results suggest that an educational intervention using written health information in combination with visual materials, visual cues and an active discussion with a healthcare provider to communicate health messages is more effective than text-based information alone. The combination of these different elements promoted the understanding and retention of information. Since post-test outcomes were assessed immediately after the intervention and only three weeks after baseline measurements, it is unclear if these results would have lasted over a longer period of time. Although self-efficacy is a proxy measure of the actual behavior, it is unclear if the participants effectively increased their capacity to use medication safely.
Effectiveness of a culturally appropriate, churchbased diabetes self-management program ${ }^{74}$

This RCT included 201 African Americans with type 2 diabetes (117 in the EG and 84 in the CG). Participants in the EG received a diabetes selfmanagement intervention including an eight-month intensive phase followed by a four-month reinforcement phase. The intensive phase, led by a dietician and a church health advisor, included four components: i) one individual counseling session to assess dietary habits, psychological issues and barriers; ii) 12 group education sessions focusing on diabetes, nutrition, dietary behaviors and physical activity; iii) eight monthly phone contacts from a diabetes advisor; and iv) three postcard messages from the diabetes care provider. After this intensive phase, participants underwent a four-month reinforcement phase during which they received one monthly phone contact. Participants in the CG received minimal intervention, including, by mail, two pamphlets on diabetes self-care, and three bimonthly newsletters with general health information and study updates. At eight months and just after the intensive phase, there was significant reduction in $\mathrm{HbA1c}$ levels in the EG compared to the $\mathrm{CG}(P=0.009)$, as well as significant higher diabetes knowledge $(P=0.003)$ and significant improvement in diabetes-related mental well-being $(P=0.004)$. However, no significant differences were found between the groups at eight months follow-up for physical activity, systolic blood pressure, weight, SF-36 scores (physical and mental health components scores), and diabetes-related social well-being. At 12 months follow-up, just after the reinforcement phase, the significant differences that had been observed at eight months were no longer significant, except for diabetes-related mental well-being $(P=0.02)$. A culturally appropriate multicomponent educational and behavioral intervention for ethnic minorities with type 2 diabetes thus seemed effective for glycemic control, knowledge and diabetes-related mental well-being. However, due to the multiple educational and behavioral components of the intervention, it is unclear which of the elements contributed (the most) to the effectiveness of the intervention.

\section{Effects of a nutrition education program on $\mathrm{Hb} 1 \mathrm{Ac}$ and other diabetes-related outcomes ${ }^{90}$}

This RCT included 82 African adults with a low socioeconomic status and with type 2 diabetes (41 in the EG and 41 in the CG). Participants in the EG 
received a nutrition education program that consisted of: i) eight group education sessions about diabetes and nutrition; ii) six follow-up sessions; iii) a demonstration of vegetable gardening; and iv) educational materials (pamphlets and posters). During sessions, participants were asked to set group goals. Participants in the CG received the educational materials only, in addition to their usual care. No differences in HbA1c, BMI, total cholesterol, LDL-cholesterol, HDL-cholesterol, triglycerides and blood pressure were found between groups at posttest (six months) or at 12 months follow-up.

\section{Effects of a community-based self-help intervention program on type 2 diabetes ${ }^{86}$}

This RCT included 83 Korean American immigrants with type 2 diabetes and an uncontrolled glucose level (41 in the EG and 42 in the CG). Participants in the EG received a culturally tailored behavioral intervention program including: i) six weekly educational sessions offered by bilingual nurses, focusing on type 2 diabetes and diabetes management guidelines, glucose and blood pressure self-monitoring, problem solving and communication skills; and ii) monthly telephone counseling by a nurse for five months including reinforcement of knowledge, discussion of barriers to self-management, and problem-solving. Participants in the CG received a delayed intervention. At post-test, compared to the $\mathrm{CG}$, the EG demonstrated a significant reduction in HbA1c levels $(P=0.01)$, significantly lower levels of triglycerides $(P=0.00)$ and significant improvements in diabetes knowledge $(P=0.00)$, self-care activities $(P=0.00)$, self-efficacy $(P=0.01)$ and quality of life $(P=0.03)$. No significant differences between the groups were found for fasting blood glucose (FBG), BMI, blood pressure, HDL, LDL and depression scores. These findings indicate that a culturally tailored intervention focusing on selfefficacy and self-care may improve healthy choices among immigrants with diabetes type 2 .

\section{Effectiveness of an interactive e-Health diabetes medication decision aid $^{85}$}

This RCT included 188 low income Latinos and African Americans with diabetes and low HL, 93 in the EG and 95 in the CG. Participants in the EG received one two-hour session led by a community health worker $(\mathrm{CHW})$, during which a diabetes medication decision aid was delivered via tablet computers. The tablet program, called iDecide (or iDecido in Spanish), provided participants with tailored health information about diabetes, complications and medication. With the help of the CHW, the participants were invited to navigate the program, set goals and develop action plans related to diabetes medication. In addition, they received two printed educational booklets and two follow-up phone calls at three and six weeks to discuss the action plan. The intervention enabled participants to proactively engage with the health information received, improve their communication with their healthcare provider, and negotiate and make informed decisions. Participants in the CG received one session with the CHW, the same evidence-based information using print consumer booklets ${ }^{133,134}$ but without tailoring and goal setting, and also two follow-up phone calls. In the two groups, discussions with the $\mathrm{CHW}$ were based on motivational interviewing principles. At three months, there were significant improvements in diabetes care self-efficacy in the EG compared to the CG $(P=0.05)$. However, no significant differences between groups were found in medication decisional conflict, medication adherence and HbA1c values. Both groups showed significant within-group improvements for all the outcomes, which raises the question of the importance of the modality being used to deliver health information and the intervention. Indeed, the improved diabetes outcomes, irrespective of whether the information was delivered through an interactive tool or by traditional printed education materials, suggest that the motivational interviewing component delivered by CHWs, a common ingredient in both groups, was effective. It is also noted that the only difference found between the groups was in selfefficacy, and not in health-related outcomes. A longer duration between measuring self-efficacy and measuring health-related outcomes may have allowed participants the time to implement their strategies.

\section{Effectiveness of a church-based self-management intervention among Latinos with diabetes ${ }^{83}$}

This RCT included 100 low-income Mexican American adults with diabetes, 50 in the EG and 50 in the CG. Participants in the EG received a multicomponent and tailored diabetes self-management education intervention delivered by lay leaders including: eight group sessions providing information about diabetes, nutrition and physical activity, and addressing goal setting, problem solving, anticipating 
obstacles, exploring behavioral alternatives and stimulus control. Participants in the CG received enhanced usual care, including one diabetes lecture on diabetes self-management by a health educator. At six months follow-up, there was no significant difference between the EG and the CG with regard to HbA1c levels, LDL, blood pressure, waist circumference, diabetes self-empowerment or diabetes knowledge.

\section{Combined findings}

Within the competency of applying health information, the Healthcare domain of the health continuum was addressed in five studies on diabetes selfmanagement ${ }^{74,83,85,86,90}$ and two on medication adherence or safe medication use. ${ }^{72,88}$ On outcomes, a large number of outcomes was explored and mixed results were found. Congruent with the Healthcare domain of the health continuum, outcomes most frequently assessed were clinical outcomes (e.g. HbA1c, blood pressure). Outcomes related to health behaviors were less explored.

For effective interventions, the common component was a person-centered approach including motivational interviewing and tailoring. Active discussions with healthcare providers or lay interventionists seemed to be an important component for mobilizing health information, developing HL skills and adopting healthy behaviors. The cultural appropriateness of the interventions, as well as skills training (such as self-monitoring, and self-care) also appeared to be preferred components for achieving effectiveness. In addition, to facilitate access to health information, interventions should take contextual realities into account and must address structural barriers such as location. Finally, using CHWs might be beneficial as long as they receive sufficient instruction and training to deliver the content of the intervention appropriately and effectively.

\section{Interventions addressing the competency of applying health information in the Disease \\ Prevention domain of the health continuum}

\section{Descriptive summary of interventions}

Effectiveness of a cardiovascular disease prevention program $^{82}$

This RCT included 88 low-income communitydwelling elderly people, aged 65 years or over with hypertension, 42 in the EG and 46 in the CG. Participants in the EG received a home cardiovascular disease prevention program led by nurses, including: i) eight home sessions during which the nurse assessed the participants' cardiovascular risks, delivered feedback, gave oral and written information about hypertension and healthy lifestyles, and encouraged them to set goals and develop an action plan to follow healthy lifestyles; and ii) four followup phone calls. Participants in the CG received usual care. At post-test, there were no significant differences between the groups for any of the outcomes, except diastolic blood pressure $(P=0.018)$.

\section{Effectiveness of a HIV risk reduction intervention ${ }^{80}$}

This RCT included 548 community-dwelling adult Hispanic women reporting sexual activity in the three months prior to the study (274 in the EG and 274 in the CG). Participants in the EG received a culturally specific peer group intervention including: i) five group sessions addressing HIV risk reduction topics (sexually transmitted infections, prevention, communication and negotiation with the partner, partner violence and substance use) by means of PowerPoint presentations, skills demonstrations and exercises, role play, videos and discussions; and ii) one booster session. Participants in the CG received a condensed delayed intervention (one session) 12 months later. At six months, no significant differences were found between both groups with regard to the outcomes. At 12 months, there was a significant difference between groups in condom use, with a higher proportion of participants in the EG reporting condom use than in the CG $(P=0.01)$. The cultural adaptation of the intervention, as well as the participatory approach used, were strengths of this intervention. The participatory approach enabled the participants to collect information, appraise it and make positive health choices, as shown by the significant positive long-term results in condom use. The increased proportion of participants using condoms in the long term may have reflected an improvement in critical thinking skills and the ability to assess risks over time.

\section{Effectiveness of influenza vaccine text message reminders ${ }^{91}$}

This RCT included 1153 low-income women initiating prenatal care, 576 of whom participated in the EG and 577 in the CG. Participants in the EG received health information and health education about influenza during pregnancy through five weekly text messages. The text messages covered 
various topics such as risk of influenza for the pregnant woman and fetus, vaccine safety and vaccine recommendations. Participants in the CG received usual care. At four months follow-up, there was a higher rate of vaccination in the EG than in the CG $(P=0.048)$. Text messages are a simple, convenient and cost-effective tool to send specific health information to a large number of people simultaneously. ${ }^{21}$ Text messages can be an effective tool for delivering health information and encouraging the adoption of positive health behaviors within a population with limited access to health information.

\section{Effectiveness of a health education intervention for} promoting colorectal cancer screening ${ }^{81}$

This RCT included 210 low income Chinese Americans aged 50 to 78 years, 105 in the EG and 105 in the CG. Participants in the EG received a culturally adapted education program promoting FOBT screening from a bicultural Chinese American health educator just before or after a medical visit, according to the patient's preference. Participants viewed a motivational video about colorectal cancer (CRC) screening and received printed educational pamphlets, and a FOBT kit. Participants in the CG received usual care. At six months follow-up, the incidence of FOBT screening were higher in the EG compared to the CG $(\mathrm{OR}=5.98,95 \% \mathrm{CI}=3.29$ $10.85)$, suggesting that a linguistically appropriate education intervention delivered by a health educator and including educational video and print materials was effective for improving CRC screening among ethnic minorities. The cultural adaptation of health information and educational materials, as well as the delivery of the intervention by a health educator from an ethnic minority, may also have contributed to the effectiveness of the intervention. Another key component which probably increased the effectiveness of the intervention was that participants were provided with a tool to implement the health decision (in this case, the FOBT kit).

\section{Effectiveness of a low-literacy intervention for promoting discussion of prostate cancer ${ }^{79}$}

This RCT included 250 men, mainly African Americans, aged 45 to 70 years (86 in $\mathrm{EG}_{1}, 83$ in $\mathrm{EG}_{2}$, and 81 in the CG). Participants in $\mathrm{EG}_{1}$ received a colored two-sided, high-detail patient education handout, including information about prostate cancer screening and other related prostate cancer issues in the waiting room before the medical visit. This handout encouraged participants to ask the doctor for more information as a concluding message. This highdetail handout followed the recommendations for the development of low-literacy educational materials and was written with large characters, at a $6^{\text {th }}$ grade reading level, with simple text, illustrations and highlighting the most important information. Also while in the waiting room before the medical visit, participants in $\mathrm{EG}_{2}$ received a one-sided lowdetail handout about prostate cancer, with the statement "Ask your doctor about prostate cancer today!" (with the word "today" highlighted). This handout simply encouraged them to talk to the doctor about prostate cancer, without any information about screening. This low-detail handout was written at a 5th grade reading level. Participants in the CG received a handout showing a food pyramid. At post-test, the frequency of discussions about prostate cancer with the doctor was significantly higher in $\mathrm{EG}_{2}$ than in the CG $(P=0.008)$. No significant differences in communication were found between $\mathrm{EG}_{1}$ and the CG. In addition, rate of PSA tests ordered was also significantly higher in $\mathrm{EG}_{1}(P=0.02)$ and $\mathrm{EG}_{2}$ $(P=0.03)$ than in the $C G$, with higher rates in $\mathrm{EG}_{1}$ than in $E_{2}$. No significant differences were found between the groups for digital rectal examination (DRE). As pointed out by the authors, the results of this study suggested that handouts that were too long and containing too much information were not useful and did not allow immediate assimilation of the essential message. Conversely, a simple handout containing clear, short and unique messages was an effective way to empower people to discuss preventive health topics with their healthcare provider. ${ }^{17}$ The illustrations included in the handout, which allowed a clear and easy association of the population with the health message, may also have contributed to its effectiveness. Moreover, the positive results could also be explained by the fact that the risk message called for a unique behavior.

\section{Effectiveness of a community-based breast cancer screening promotion program delivered by cosmetologists ${ }^{71}$ \\ This RCT included 984 African American women,} 481 in the EG and 503 in the CG. Participants in the EG received The Black Cosmetologists Promoting Health Program delivered in beauty salons. 'Participants were placed in a HL-friendly environment. 
Cosmetologists initiated proactive discussions with their clients about the importance of early breast cancer detection and adherence to breast cancer screening guidelines using various techniques (e.g. storytelling) and educational materials (e.g. articles from lay newspapers and magazines, binders containing health information about breast cancer, breast cancer model, posters and brochures). The intervention provided participants with culturally appropriate health information regarding breast cancer screening and enabled them to make informed health choices. Participants in the CG received an equivalent training program about diabetes. Outcomes were assessed in the subgroup of participants aged 40 years and over, including 232 participants (112 in the EG and 120 in the CG). At six months follow-up, the odds of adhering to mammography screening were 2.0 times higher in participants in the EG than participants in the CG $(P<0.01)$. Creating a HL-friendly environment seemed to be an effective strategy to disseminate health information about a specific health topic in a population with limited access and low exposure to health information. Several other factors may also have contributed to the effectiveness of the intervention, including the community-based participatory approach, the place-based strategy that was used to reach people and deliver health messages (information delivered locally and in a familiar place), the use of lay interventionists, and the delivery of culturally appropriate health information.

\section{Combined findings}

Within the competency of applying health information, the Disease Prevention domain of the health continuum was addressed in two studies on risk reduction ${ }^{80,82}$ and in four studies on risk messages. ${ }^{71,79,81,91}$ On outcomes, a large number of outcomes were again explored. Mostly, HL interventions in the Disease Prevention domain of the health continuum were effective for improving preventive health behaviors and practices such as vaccination and screenings. On risk reduction, a participatory approach and congruent application of the theoretical foundations seem to lead to effectiveness. Regarding risk messages, effective strategies for implementing education in deprived communities are to deliver simple, short, targeted health messages focusing on only one specific action at a time, with essential health information easily and clearly understood. Creating HL-friendly settings, providing the tools or means to implement the health decision, and cultural appropriateness of the intervention are also components that can contribute to effectiveness.

\section{Interventions addressing the competency of applying health information in the Health Promotion domain of the health continuum Effectiveness of a computer-based CD-ROM nutri- tion behavior-change program ${ }^{84}$}

This RCT included 481 low-income participants aged 40 to 65 years (162 in $\mathrm{EG}_{1}, 160$ in $\mathrm{EG}_{2}$, and 159 in the CG). Participants in $\mathrm{EG}_{1}$ received: i) a 15 to 20-minute computer-based CD-ROM nutrition education session, with different modules delivering tailored interactive nutritional information and tips to increase fruit and vegetable consumption; the participants had to choose goals to increase consumption as suggested by the program; ii) handouts and educational materials to take home, and iii) two reminder phone calls after two months. Participants in $\mathrm{EG}_{2}$ received the same computer-based intervention, but without the two reminder phone calls. Participants in the CG received a 15- to 20-minute computer-based stress management CR-ROM program. At post-test, a significantly higher intake of fruit and vegetables was noted for $\mathrm{EG}_{1}$ compared to the $\mathrm{CG}(P=0.016)$. A subgroup analysis by educational levels revealed that participants from $\mathrm{EG}_{1}$ with a low education level (high school or less) showed a greater increase of fruit and vegetable intake than those from the CG $(P=0.01)$. This suggests that an interactive computer program with tailoring and goal setting is an effective way to increase fruit and vegetable intake among a low-income population. However, due to the multicomponent design of the intervention, it is difficult to determine which component was the most effective (the interactive aspect of the program, tailored feedback and health messages, goal setting or educational printed materials).

\section{Effectiveness of a lifestyle intervention for improv- ing diabetes outcomes ${ }^{87}$}

This RCT included 200 rural adult African American women with type 2 diabetes (100 in the EG and 100 in the CG). Participants in the EG received a culturally appropriate phone-based diabetes selfmanagement intervention in the form of lifestyle coaching led by a CHW. The intervention included information about diabetes, materials for 
self-monitoring and goal setting. During the 16 sessions, the CHW helped participants to set and review small change goals, discussed successes, challenges and barriers, and gave information on topics such as self-monitoring, time management, modifiable practice and problem solving. Participants in the CG were included in a mail-based education group and received 16 mailings of diabetes education materials, including information about diet selection, healthy snacking, managing medications, monitoring blood glucose, and engaging in physical activity. The results indicated that there were no differences between the EG and CG at post-test for $\mathrm{HbA} 1 \mathrm{c}$, systolic and diastolic blood pressure, self-care scores, medication adherence, empowerment or self-efficacy. However, participants in the EG had a moderate but significantly greater weight loss than participants in the CG $(P=0.046)$. Therefore, conclusions about the effectiveness of using the telephone for delivering an intervention aimed at changing health behaviors are limited and further studies are needed to demonstrate their effectiveness in $\mathrm{HL}$ interventions.

\section{Effectiveness of a preventive lifestyle behavior inter- vention for reducing risk factors for cardiovascular disease $e^{78}$}

This RCT included 223 overweight and underserved low-income immigrant Latinas (111 in the EG and 112 in the CG). Participants in the EG received a lifestyle behavior change intervention (Mujeres Sanas y Precavidas [Healthy Women Prepared for Life]), including: i) eight culturally relevant group educational sessions led by promotoras (female community health workers) and delivered in Spanish. The education contained information about various cardiovascular topics, diabetes, hypertension, healthy behaviors, nutrition and physical activity; and ii) eight individual teaching and coaching sessions from the promotora (by phone or home visits) to reinforce class content, and to help participants set personal goals for lifestyle changes. Participants in the CG received a safety/disaster preparedness group educational program. At nine months follow up, there was a significant difference in physical activity (average daily step count) between the EC and CG $(P=0.04)$ due to a significant decrease in physical activity levels in the CG, as well as a small significant decrease in waist circumference in the EG $(P=0.04)$, but no significant differences in the average daily duration for moderate physical activity, weight, BMI, cholesterol (total cholesterol, HLD and LDL), triglycerides and blood glucose. These mixed results could be explained by the fact that the intervention aimed at several behavior change goals at a time, whereas motivational interview theories posit that it is better to work on one goal at a time. Moreover, the use of non-validated measurement tools (the data from which were not taken into account for this review) made it difficult to draw definite conclusions. Nevertheless, the community-based participatory approach as well as use of lay facilitators can be strategies to consider for the promotion of healthy lifestyles in future interventions.

\section{Effects of a multimedia teaching and counseling tool on diet and physical activity during pregnancy ${ }^{77}$}

This RCT included 321 low-income ethnically diverse pregnant women (158 in the EG and 163 in the CG). Prior to the medical visit, participants in the $\mathrm{EG}$ received one session (10 to 15 minutes) with a computerized, multimedia interactive "Video Doctor" tool that provided tailored counseling and educational messages about healthy diets, physical activity and weight gain during pregnancy. At the end of the session, the program provided the participant with an educational worksheet, and the clinician with a cueing sheet, with tailored counseling statements to be used during the consultation. Participants in the CG received usual care. At four weeks follow-up, no significant differences were observed between the groups with regard to the proportion of women gaining weight above Institute of Medicine guidelines or mean weight gain. Nevertheless, this computer program could be a useful tool to improve the effectiveness of medical consultation and communication between patients and providers, and to help patients receive individualized, targeted and needs-focused health information. Further testing of this type of interactive tool in future studies to demonstrate its effectiveness in facilitating change in behavior is therefore warranted.

Effectiveness of a postpartum weight loss Internetbased program for low income postpartum women ${ }^{73}$ This RCT included 370 low-income overweight postpartum women, 174 of who participated in the EG and 196 in the CG. Participants in the EG received two interventions. The first was an internet-based, 
weight-loss program in English and Spanish. This program, including weekly lessons, a diary, automated feedback, educational videos and motivational messages, provided health information about weight loss, nutrition and physical activity. The program also provided tailored calorie goals, and goals to increase physical activity, as well as physical activity trackers to help participants achieve their goals. The second intervention was 12 monthly face-to-face group sessions. Participants in the CG received standard Woman and Infant Care (WIC) services, as well as six newsletters delivered every two months with information about weight control, exercise, nutrition and wellness. At post-test, there was a significantly greater weight loss in the EG than in the CG $(P<0.001)$, as well as a significantly greater reduction in waist circumference $(P<0.001)$, a significantly greater percentage weight loss $(P<0.002)$, a significant greater proportion of women achieving 5\% $\quad(P=0.005)$ and $10 \%$ $(P=0.007)$ or more weight loss, and a significantly higher proportion of women returning to preconception weight or below $(P<0.001)$. No significant differences between the groups were found for physical activity levels and dietary intake. Hence, the intervention helped women to make decisions and renew their commitment on a weekly basis based on information and feedback received. As the intervention had many components, it was not possible to know which one contributed the most to the positive outcome. Nevertheless, the results indicated that an evidence-informed internet weight-loss program may decrease the need for face-to-face contact, thus facilitating access to and adherence by low-income women to the program. Access to the internet must be evaluated prior to choosing this type of program. It is unclear if an internet-based program may be recommended to increase physical activity.

\section{Combined findings}

Within the competency of applying health information, the Health Promotion domain of the health continuum was addressed in five studies. ${ }^{73,77,78,84,87}$ All of these, except one, ${ }^{77}$ were found to be effective for healthy lifestyle outcomes (such as heathy eating and physical activity) or health-related outcomes (such as weight loss). Their results suggested that strategies leading to effectiveness seem to include tailoring of health information delivered, active discussion using motivational interviewing techniques, skills training and goal setting. In addition, interventions should be informed by validated behavior change theories such as the Social Cognitive Theory, ${ }^{77,112-114}$ with the aim of achieving a single objective. Again, the cultural appropriateness of the intervention, use of community-based participatory principles and use of lay interventionists appear to be effective approaches for the development of future HL interventions.

\section{Discussion}

The purpose of this systematic review was to identify and synthesize the best available information on effective HL intervention strategies that increase health-related outcomes for socioeconomically disadvantaged people.

This review found mixed results. Most of the included studies $(62 \%)$ showed effectiveness for health outcomes, even if partially. Regarding the three studies addressing the competency of understanding health information, ${ }^{75,76,89}$ no effectiveness was found for the outcomes considered in this review. In two studies, the absence of significant result could be due to the short follow-up period ${ }^{89}$ or the high attrition rate. ${ }^{76}$ The lack of significant results also suggests that interventions testing the effectiveness of meaningful communication formats (using for example plain language, illustrations, pictograms and icons) should perhaps assess the understanding of health information directly rather than through clinical or behavioral outcomes. As such, this type of intervention requires further study, particularly in the context of chronic medication use among socioeconomically disadvantaged people. Eighteen studies out of 21 addressed the competency of applying health information. This seems logical and congruent with the theoretical framework of Sorensen et al., ${ }^{3}$ with decision-making, communication and implementation of health information being the final outcomes of an HL process. Although almost half of the included studies were in the Healthcare domain of the health continuum, the most effective interventions were those in the Disease Prevention and Health Promotion domains. Within interventions, evaluated outcomes were congruent with the health continuum domain addressed. Thus, effective interventions in the Healthcare domain had positive effects on clinical outcomes (such as HbA1c), self-efficacy and knowledge; effective interventions in the Disease Prevention domain had positive effects on a variety of preventive health practices and behaviors, and effective interventions 
in the Health Promotion domain had positive effects on health behaviors and health outcomes directly related to behavior change. Among studies that did not demonstrate any effect, the lack of significant result could be partly due to: i) high attrition rates, ${ }^{83,88}$ which itself could be attributed to contextual or implementation problems (e.g. personnel and infrastructure) - this highlights the importance of context, which needs to be favorable and conducive to the intervention; ii) inadequate duration of the interventions, which was not in line with the objectives of the intervention; iii) too short follow-up periods; or iv) insufficient training of lay or peer trainers delivering the intervention, if any.

Among included studies, data provided were not sufficient for identifying clear theoretical patterns for effective interventions. How theories were used and incorporated within each intervention was not described in detail. However, theory-based interventions appeared to be more effective than atheoretical ones. Moreover, the use of an appropriate theory, congruent with the aim of the intervention, emerged as an important factor for successful interventions. Our results identified three main behavior change theories and models: i) the Social Cognitive Theory and the key concept of self-efficacy, ${ }^{112,113}$ useful for the development of the HL competency of applying health information, when health decisions need to be made and implemented; ii) the Transtheoretical Model of behavior change, ${ }^{118}$ useful for assessing the readiness level of participants and helping them implement and maintain a desired health behavior; and iii) the Health Belief Model ${ }^{120}$ that enables health professionals to elicit beliefs, barriers and expectations of the client. The use of a specific theory leads to the selection of specific intervention strategies and operational tools. ${ }^{135}$ This can lead in turn to better health outcomes and greater effectiveness. Therefore, the use of an appropriate behavior change theory should be a critical issue for the development of future HL interventions. Another theoretical foundation highlighted by our results was the use of participatory designs, such as community-based participatory research. ${ }^{136,137}$ Community-based participatory research is an ecological approach that seems particularly useful at the community level for the development of an intervention, and is defined as "a partnership approach to research that equitably involves community members, practitioners and academic researchers in all aspects of the process, enabling all partners to contribute their expertise and share responsibility and ownership."138(p.2094) The involvement of community members as research partners at all stages of the research process presents several advantages: i) development of an intervention (including intervention content, modalities and materials) tailored to the target group and corresponding to its needs, preferences, values, beliefs and relevant health issues, and taking into account the available community resources as well as the context; ${ }^{139,140}$ ii) improved recruitment, retention, participation and motivation, especially in hardto-reach populations; ${ }^{121,141}$ and iii) improved effectiveness of the intervention for health-related and behavioral outcomes, with more sustainable effects. ${ }^{139,141,142}$ Community-based participatory research has been described as an approach that is particularly adapted to address health disparities $^{138,142}$ and suitable for disadvantaged groups. ${ }^{141}$ Therefore, community-based participatory research seems to be a promising approach for the development of HL skills among socioeconomically disadvantaged people, and for the development of group-specific appropriate HL interventions.

Among effective included studies, the results allowed the authors to identify some operational components that could be seen as key to the success of HL interventions in socioeconomically disadvantaged people. These operational components included appropriateness of the content in terms of culture and literacy levels of the participants, tailoring, skills training, goal setting, and individual or group discussions.

Cultural appropriateness was identified as a key operational component of HL interventions, as demonstrated by nine RCTs. ${ }^{71,73,74,78,80,81,86,87,91} \mathrm{Cul}$ tural appropriateness refers to a group-specific intervention that is adapted to the needs, preferences, attitudes, norms and cultural values of the target group. ${ }^{143}$ As highlighted in a recent systematic review, ${ }^{144}$ culturally appropriate interventions are more successful than standardized interventions in changing health outcomes because they identify and address systemic barriers (such as financial, geographical and communication barriers), and increase community engagement by the involvement of community members in the development and implementation phases of an intervention. Furthermore, such interventions are relevant to the cultural context, 
values, needs and perspectives of the target population. Conversely, a mismatch between the intervention and the context and target population may limit the effectiveness of the intervention. For example, interventions that are not congruent with the language spoken by participants can lead to problems in understanding the intervention's content; interventions that are not congruent with the ethnicity can lead to resistance to the intervention due to conflicts in beliefs, values and norms; a lack of congruence with the participants' socioeconomic status may be a barrier to accessing social resources and can lead to culturally different life experiences; and interventions that do not take the place of residence (urban versus rural) into account can lead to a lack of participation or adherence due to geographical and environmental barriers. ${ }^{145}$ To be effective, an intervention must therefore be appropriate to the target group, in terms of both its content and form of delivery. ${ }^{145}$ In this regard, Kreuter et al ${ }^{146}$ describe five types of strategy that can help make health interventions culturally appropriate: i) peripheral strategies, such as creating intervention materials with a visual style relevant to the target group (e.g. by using specific colors, pictures, illustrations or declarative titles) and reflecting "the social and cultural world of the audience"146(p.135); ii) evidential strategies, such as providing information and evidence (e.g. epidemiological data, risk factor data) specific to the target population in order to increase the perceived relevance of health messages; iii) linguistic strategies, such as adapting an intervention's content and materials to the language of the target population; iv) constituent-involving strategies based on the experience of (lay) community members and their participation in designing, planning and implementing the intervention; and v) sociocultural strategies, such as incorporating the values, beliefs, behaviors, context, and other social and cultural characteristics of the target population in building the intervention. ${ }^{146}$ Our conclusions are consistent with other systematic reviews that also concluded that health interventions were more effective when they were culturally appropriate. A systematic review focusing on socially disadvantaged groups concluded that cultural appropriateness was one feature amongst others that contributed to the effectiveness of interventions to improve diabetes care. ${ }^{147}$ Another systematic review focusing on ethnic minority groups found that culturally appropriate health education interventions were more effective than standardized interventions for type 2 diabetes. ${ }^{148}$

Tailoring was found to be an effective strategy as demonstrated in nine studies. ${ }^{73,74,78,80,82,84-87}$ Tai- $^{-}$ loring is defined as "creating communications in which information about a given individual is used to determine what specific content he or she will receive, the contexts or frames surrounding the content, by whom it will be presented and even through which channels it will be delivered." ${ }^{\text {149(p.1) }}$ Tailoring allows the delivery of individualized health information in accordance with the participants' needs and preferences. ${ }^{149}$ It can be viewed as a client centered approach. ${ }^{150}$ Tailoring health information provides individuals with more meaningful messages that are more likely to be read and thus increase the recall of health information and relevance of an intervention. ${ }^{149}$ Various systematic reviews and meta-analyses have shown that tailored interventions are more effective than generic interventions for changing health behaviors. ${ }^{151,152}$ Therefore, the results of this review suggest that, in addition to cultural appropriateness of the intervention for a specific group, future HL interventions must also be tailored and oriented to the individual needs of participants.

The development of specific skills useful to a HL process, also called skills training, was found to be an effective component in seven studies. ${ }^{72,74,78,80,82,86,87}$ In addition to the four main HL competencies, HL can be viewed as a "constellation of skills,",153 including, but not limited to, decision-making, problemsolving, critical thinking, communication and self-management. These are considered critical to the application of health information and adequate functioning in the health system. ${ }^{3}$ Our results showed the importance of supporting socioeconomically disadvantaged people in the development of specific skills throughout the HL process, enabling them to apply health information and achieve behavioral change. Making a health decision must be followed by developing the self-efficacy needed to successfully implement a behavior. Skill-building interventions enhance and increase self-efficacy, which in turn foster behavior change. ${ }^{113}$

Congruent with tailoring, goal setting is another operational component found to be effective in six studies. ${ }^{74,78,82,84,85,87}$ Goals "refer to inherently valued, futuristic outcomes that are derived from a level of dissatisfaction with a present condition or circumstance." $154(\mathrm{p} .33)$ As a means to translate health 
information into actual health behaviors, this person-centered approach ${ }^{155}$ supports health behavioral change ${ }^{156}$ and is therefore a strategy that can be used to improve health-related outcomes among socioeconomically disadvantaged people. Although first applied in clinical settings, ${ }^{156}$ our review showed that helping people to set specific and realistic goals was also used in disease prevention and health promotion. As such, personalized goal setting can be viewed as a means to enabling individuals to improve and increase control over their own health. ${ }^{157}$

Individual and/or group discussions with either a professional or a lay interventionist also appear to be a preferred operational component to develop HL

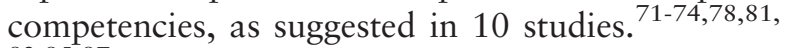
82,85-87 This is congruent with the use of tailoring and goal setting. Active discussions are a personcentered communication method that can be seen as a strategy that enhances the usability of health information. Indeed, through interactions with the intervention provider, questions can be asked, clarifications sought, and feedback provided. Moreover, discussions provide an opportunity to review HL materials, if any, and to ensure good understanding using, for example, teach-back techniques. The teach-back method has been defined as a "technique in which the clinician asks the patient to restate or demonstrate the knowledge or technique just taught,"158(p.3) and has been found as an effective strategy for transmitting clear and understandable information to people. ${ }^{159}$

Our systematic review failed to clearly identify intervention modalities that are most likely to have an impact on effectiveness. For the Healthcare domain of the health continuum, effective interventions took the form of individual or group health education sessions delivered by an interventionist. For the Disease Prevention and the Health Promotion domains, no clear trend could be identified, with effective interventions taking various forms, such as health education sessions, phone sessions, print-based interventions, HL-friendly environment interventions and eHealth interventions. However, complex or multifaceted interventions, combining both a medium of information transfer (such as print materials, interactive tools or videos) and contact with an interventionist (either led by a health professional or trained peer, via either individual, group or phone sessions) appear to be more effective than single modality interventions. Regarding the person delivering the intervention, peer support or the use of peer leaders could be a promising strategy for HL intervention conducted in a community setting, as suggested in five of the included studies. ${ }^{71,74,78,85,87}$ Peer support is defined as support provided by a member of the community sharing the same cultural characteristics as the target population, with experiential knowledge related to a specific health issue, ${ }^{160}$ and good knowledge of community and local resources. ${ }^{88}$ As shown in the included studies, trained peers could facilitate behavior change during interactions with the participant by providing information and knowledge, emotional support, and social support $^{78,160}$ through mutual exchange and discussion of key health issues, thereby increasing the motivation of participants. ${ }^{78}$ Moreover, trained peers could help and strengthen the development of various skills useful to a HL process such as self-efficacy, problemsolving, self-care and self-monitoring, coping, goal setting, communication skills or navigating the healthcare system. ${ }^{161}$ However, due to the multicomponent nature of interventions using lay interventionists, the results of our review did not provide evidence that peer support is an effective modality of a HL intervention. Therefore, the use of lay interventionists needs further studies to assess its effectiveness in a HL context. Finally, interventions seemed more effective if they included recurrent contacts, multiple sessions and follow-up activities such as follow-up phone calls, as shown in nine studies. $^{72-74,78,82,84-87}$ This suggest that a doseresponse relation existed between the number of contacts and the effect of HL interventions, and that the learning effect was enhanced by this process.

\section{Limitations of the review}

Due to the substantial heterogeneity of HL interventions between the included studies, and due to the large number of health-related outcomes addressed, comparisons between studies were challenging, which limited the drawing of conclusions about effectiveness and prevented the authors from performing a meta-analysis. The authors were limited in their access to studies. They were also unable to contact the authors of two potentially eligible studies for additional information, and therefore, these studies could not be included in this systematic review. However, in spite of these limitations, the conclusions of this systematic review provide the 
best evidence available on the effectiveness of HL interventions specifically addressed to socioeconomically disadvantaged people.

Eighty-five percent of the studies were conducted in the USA, with the majority of those identifying socioeconomically disadvantaged subjects with the PROGRESS factor Race, thus favoring mono-cultural interventions. However, if tailoring does not take into account individual life trajectories that may vary considerably in terms of cultural creolization, it may neglect key determinants of health behavior. ${ }^{162}$

The included studies mostly focused on individual skills and behavior change. However, accessing information may be a skill that is best developed using a participatory approach with an ecological and population focus. ${ }^{136}$ From that perspective, outcomes of health behavior may be replaced by Quality of Life measures, ${ }^{136,137}$ and studies of effectiveness may be more useful at the end of the HL process where health outcomes can be measured. Both research methodology and outcome should be congruent with the HL competence that is addressed.

\section{Conclusion}

In conclusion, this systematic review highlights some important features of effective HL interventions among socioeconomically disadvantaged people. Health literacy interventions are more likely to be successful if they are theory-based. The interventions need to be designed in congruence with tested and competence appropriate theories and models. It is clear that a person-centered approach contributes to better health-related outcomes through the use of five essential operational components, including group-specific appropriateness of the intervention, tailoring, skills training, goal setting and active discussions (individual or in group) with the intervention provider. With intervention modalities, multifaceted interventions combining both a communication medium and contact with an interventionist appear to be more effective than single modality interventions. Finally, repetition of health information through recurrent contacts and multiple sessions, as well as follow-up activities are important aspects to consider in HL interventions.

\section{Recommendations for practice}

Based on the JBI Grades of Recommendation, ${ }^{163}$ this systematic review has level B evidence, indicating that the recommendations are "weak." Future HL interventions must be culturally appropriate or group-specific, while being person-centered. This makes it possible to take into account both the context, particularities and characteristics at the community level, and characteristics at the individual level. Future interventions must be able to combine these two complementary approaches - a participatory approach and tailoring - in order to reach greater effectiveness. In the same vein, future HL interventions should adopt an ecological perspective, transversal to all HL competencies, in order to take into account the multiple factors influencing health, HL and HL interventions, and thus achieve more sustainable effects. ${ }^{164}$ And finally, future HL interventions must be theory-based, with solid theoretical foundations consistent with the goals and objectives of the intervention.

\section{Recommendations for research}

Future research on HL interventions must be cognizant of the fact that HL is a process. Future research focusing on the terminal skills of an HL process, such as decision-making and use of health information, must first ensure that skills in accessing and understanding are effectively developed. As described by the Sorensen's definition of $\mathrm{HL}^{3}$ maintaining or improving quality of life is the ultimate goal of an HL process. As such, and in addition to behavioral outcomes, future research on HL interventions must also measure quality of life outcomes.

The research design, as well as intervention modalities, must be adapted to the HL competency addressed. In the same way, tools and measuring instruments must be congruent with the HL skills developed. This is particularly important for the competencies of accessing, understanding and appraising, for which more effectiveness studies are needed. Moreover, this review highlights the importance of using reliable and validated measurement tools in future research on HL interventions.

More studies conducted in various countries are needed to test the effectiveness of interventions in various cultural and socioeconomic contexts.

\section{Acknowledgments}

Blanche Kiszio, librarian at the Institut et Haute Ecole de la Santé La Source in Lausanne, Switzerland, for her guidance with the research equations and retrieval of studies. 


\section{Funding}

This review was funded by the Commission Scientifique du Domaine Santé de la Haute Ecole de Santé de Suisse Occidentale (HES-SO). The funder had no role in the development of this systematic review.

\section{References}

1. Kickbush IS. Health literacy: addressing the health and education divide. Health Promot Int 2001;16(3):289-97.

2. Parker RM. Health literacy: a challenge for American patients and their health care providers. Health Promot Int 2000;15(4):277-91.

3. Sorensen K, Van den Broucke S, Fullam J, Doyle G, Pelikan J, Slonska Z, et al. For (HLS-EU) Consortium Health Literacy Project European. Health literacy and public health: a systematic review and integration of definitions and models. BMC Public Health 2012;12:80.

4. Nutbeam D. Health literacy as a public health goal: a challenge for contemporary health education and communication strategies into the 21st century. Health Promot Int 2000;15(3):259-67.

5. McCray AT. Promoting health literacy. J Am Med Inform Assoc 2005;12(2):152-63.

6. Kickbusch I, Wait S, Maag D. Navigating health. The role of health literacy. Londron: Alliance for Health and the Future; 2005.

7. Kickbusch I, Maag D. Health Literacy. In: Heggenhougen K, Qah S, editors. International encyclopedia of public health. 1st ed. San Diego: Academic Press, 2008;204-11.

8. Bo A, Friis K, Osborne RH, Maindal HT. National indicators of health literacy: ability to understand health information and to engage actively with healthcare providers - a population-based survey among Danish adults. BMC Public Health 2014;14:1095.

9. Ishikawa $\mathrm{H}$, Yano E. Patient health literacy and participation in the health-care process. Health Expect 2008;11(2): 113-22.

10. Mancuso CA, Rincon M. Asthma patients' assessments of health care and medical decision making: the role of health literacy. J Asthma 2006;43(1):41-4.

11. Bohanny W, Wu SF, Liu CY, Yeh SH, Tsay SL, Wang TJ. Health literacy, self-efficacy, and self-care behaviors in patients with type 2 diabetes mellitus. J Am Assoc Nurse Pract 2013;25(9):495-502.

12. Cha E, Kim KH, Lerner HM, Dawkins CR, Bello MK, Umpierrez $\mathrm{G}$, et al. Health literacy, self-efficacy, food label use, and diet in young adults. Am J Health Behav 2014;38(3):331 -9.

13. Geboers B, de Winter AF, Luten KA, Jansen CJ, Reijneveld SA. The association of health literacy with physical activity and nutritional behavior in older adults, and its social cognitive mediators. J Health Commun 2014;19(Suppl 2):61-76.
14. Lee S, Arozullah A, Cho Y. Health Literacy, social support, and health: a research agenda. Soc Sci Med 2004;58(7):1309-21.

15. Osborn CY, Paasche-Orlow MK, Bailey SC, Wolf MS. The mechanisms linking health literacy to behavior and health status. Am J Health Behav 2011;35(1):118-28.

16. Adams RJ, Piantadosi C, Ettridge K, Miller C, Wilson C, Tucker $\mathrm{G}$, et al. Functional health literacy mediates the relationship between socio-economic status, perceptions and lifestyle behaviors related to cancer risk in an Australian population. Patient Educ Couns 2013;91(2):206-12.

17. Sun X, Shi Y, Zeng Q, Wang Y, Du W, Wei N, et al. Determinants of health literacy and health behavior regarding infectious respiratory diseases: a pathway model. BMC Public Health 2013;12:261.

18. Tsai HM, Cheng CY, Chang SC, Yang YM, Wang HH. Health literacy and health-promoting behaviors among multiethnic groups of women in Taiwan. J Obstet Gynecol Neonatal Nurs 2014;43(1):117-29.

19. von Wagner C, Knight K, Steptoe A, Wardle J. Functional health literacy and health-promoting behaviour in a national sample of British adults. J Epidemiol Community Health 2007;61(12):1086-90.

20. Bennett IM, Chen J, Soroui JS, White S. The contribution of health literacy to disparities in self-rated health status and preventive health behaviors in older adults. Ann Fam Med 2009;7(3):204-11.

21. Mitic W, Rootman I. Une approche intersectorielle pour améliorer la littératie en santé des Canadiens et Canadiennes. Victoria, British Columbia: Public Health Association of BC; 2012; French.

22. Sentell T, Braun KL, Davis J, Davis T. Colorectal cancer screening: low health literacy and limited English proficiency among Asians and Whites in California. J Health Commun 2013;18(Suppl 1):242-55.

23. Eichler K, Wieser S, Brügger U. The costs of limited health literacy: a systematic review. Int J Public Health 2009;54(5):313-24.

24. Conseil Canadien Sur L'Apprentissage. [Health literacy in Canada: initial results from the International Adult Literacy and Skills Survey] Ottawa: Conseil Canadien sur l'apprentissage; 2007; French.

25. Kutner M, Greenberg E, Jin Y, Paulsen C. The health literacy of america's adults: results from the 2003 National Assessment of Adult Literacy (NCES 2006-483) Washington: National Center for Education Statistics; 2006.

26. HLS-EU Consortium. Pelikan JM, Röthlin F, Ganahl K. Comparative report of Health literacy in eight EU member states. The European Health Literacy survey HLS-EU Maastricht 2012.

27. Berkman ND, Sheridan SL, Donahue KE, Halpern DJ, Crotty K. Low health literacy and health outcomes: an updated systematic review. Ann Intern Med 2011;155(2):97-107. 
28. Cho YI, Lee SYD, Arozullah AM, Crittenden KS. Effects of health literacy on health status and health service utilization amongst the elderly. Soc Sci Med 2008;66(8):1809-16.

29. Lee SYD, Tsai TI, Tsai YW, Kuo KN. Health Literacy, health status, and healthcare utilization of Taiwanese adults: results from a national survey. BMC Public Health 2010;10:614.

30. Paasche-Orlow MK, Wilson EAH, McCormack L. The evolving field of health literacy research. J Health Commun 2010;15(Suppl2):5-8.

31. Sentell T, Baker KK, Onaka A, Braun K. Low health literacy and poor health status in Asian Americans and Pacific Islanders in Hawai'i. J Health Commun 2011;16(Suppl3):279-94.

32. Sorensen K, Brand H. Health literacy - a strategic asser for corporate social responsibility in Europe. J Health Commun 2011;16(Suppl3):322-7.

33. Commission on Social Determinants of Health. Closing the gap in one generation: health equity through action on the social determinants of health. Final report of the Commission on Social Determinants of Health. Geneva: World Health Organization; 2008.

34. Nielsen-Bohlman L, Panzer A, Kindig D. Heath literacy: a prescription to end confusion Washington DC: The National Academic Press; 2004.

35. Nutbeam D. The evolving concept of health literacy. Soc Sci Med 2008;67(12):2072-8.

36. Edwards M, Wood F, Davies M, Edwards A. The development of health literacy in patients with a long-term health condition: the health literacy pathway model. BMC Public Health 2012;12:130.

37. Paasche-Orlow MK, Wolf MS. The causal pathway linking health literacy to health outcomes. Am J Health Behav 2007;31(Suppl1):S19-26.

38. Squiers L, Peinado S, Berkman N, Boudewyns V, McCormack L. The health literacy skills framework. J Health Commun 2012;17(Suppl3):30-54.

39. Freedman DA, Bess KD, Tucker HA, Boyd DL, Tuchman AM, Wallston KA. Public health literacy defined. Am J Prev Med 2009;36(5):446-51.

40. Van Der Heide I, Rademakers J, Schipper M, Droomers M, Sorensen K, Uiters E. Health literacy of Dutch adults: a cross sectional survey. BMC Public Health 2013;13:179.

41. Garcia SF, Hahn EA, Jacobs EA. Addressing low literacy and health literacy in clinical oncology practice. J Support Oncol 2010;8(2):64-9.

42. Braveman $P$. What are health disparities and health equity? We need to be clear. Public Health Rep 2014;129(Suppl2): 5-8.

43. Braveman P, Gruskin S. Defining equity in health. J Epidemiol Community Health 2003;57(4):254-8.

44. Whitehead $M$. The concept and principles of equity and health. Health Promot Int 1991;6(3):217-28.

45. National Center for Health Statistics. Healthy People 2010 Final Review. Hyattsville: Government Printing Office; 2010
46. Paasche-Orlow MK, Wolf MS. Promoting health literacy research to reduce health disparities. J Health Commun 2010;15(Suppl2):34-41.

47. Al Sayah F, Majumdar SR, Williams B, Robertson S, Johnson JA. Health literacy and health outcomes in diabetes: a systematic review. J Gen Intern Med 2012;28(3):444-52.

48. Clement S, Ibrahim S, Crichton N, Wolf M, Rowlands G. Complex interventions to improve the health of people with limited literacy: a systematic review. Patient Educ Couns 2009;75(3):340-51.

49. Pignone M, DeWalt DA, Sheridan S, Berkman N, Lohr N. Interventions to improve health outcomes for patients with low literacy - a systematic review. J Gen Intern Med 2005;20(2):185-92.

50. Berkman ND, Sheridan SL, Donahue KE, Halpern DJ, Viera A, Crotty K, et al. Health literacy interventions and outcomes: an updated systematic review. Evid Rep Technol Assess (199):2011:1-941.

51. Taggart J, Williams A, Dennis S, Newall A, Shortus T, Zwar N, et al. A systematic review of interventions in primary care to improve health literacy for chronic disease behavioral risk factors. BMC Fam Pract 2012;13:49.

52. Stormacq C, Wosinski J, Van den Broucke S. The effectiveness of health literacy interventions on health-related outcomes among socioeconomically disadvantaged adults living in the community: a systematic review protocol. JBI Database System Rev Implement Rep 2016;14(2):49-63.

53. O'Neill J, Tabish H, Welch V, Petticrew M, Pottie K, Clarke M, et al. Applying an equity lens to interventions: using PROGRESS ensures consideration of socially stratifying factors to illuminate inequities in health. J Clin Epidemiol 2014;67(1):56-64.

54. Glanz K, Rimer BK, Viswanath K. Health behavior and health education theory, research, and practice. 4th ed. San Fransisco: Jossey-Bass; 2008.

55. World Health Organization. The ecological framework [Internet]. 2015 [cited 6 Apr 2015]. Available from: http://www.who.int/violenceprevention/approach/ecol ogy/en/.

56. Higgins W, Begoray D, MacDonald M. A social ecological framework for understanding adolescent health literacy in the health education classroom. Am J Community Psychol 2009;44(3-4):350-62.

57. Manafo E, Wong S. Health literacy programs for older adults: a systematic literature review. Health Educ Res 2012;27(6):947-60.

58. Cochrane Consumers and Communication Review Group. Outcomes of interest to the Cochrane Consumers and Review Group [Internet]. 2012 [updated 2012 Jan; cited 30 Mar 2015]. Available from: https://cccrg.cochrane.org/ sites/cccrg.cochrane.org/files/uploads/Outcomes.pdf.

59. Ware JE, Sherbourne CD. The MOS 36-Item Short-Form Health Survey (SF-36). I. Conceptual framework and item selection. Med Care 1992;30(6):473-83. 
60. Szende A, Oppe M, Devlin N. EQ-5D value sets: inventory, comparative review and user guide London: Springer; 2007.

61. Diener E, Emmons RA, Larsen RJ, Griffin S. The Satisfaction with Life Scale. J Pers Assess 1985;49(1):71-5.

62. Sherer M, Maddux JE, Mercandante B. The Self-Efficacy Scale: Construction and Validation. Psychol Rep 1982;51(2): 663-71.

63. McWhinnie JR. Disability assessment in population surveys: results of the OECD Common Development Effort. Rev Epidemiol Sante Publique 1981;29(4):413-9.

64. Walker SN, Sechrist KR, Pender NJ. The Health-Promoting Lifestyles Profile: development and psychometric characteristics. Nurs Res 1987;36(2):76-81.

65. Chen J, Hou F. Unmet needs for health care. Health Rep 2002;13(2):23-34.

66. Tufanaru C, Munn Z, Aromataris E, Campbell J, Hopp L. Chapter 3: Systematic reviews of effectiveness. In: Aromataris E, Munn Z, editors. JBI reviewer's manual [Internet]. Adelaide: JBI, 2017. [cited 13 June 2017]. Available from: https://reviewersmanual.joannabriggs.org/.

67. Liberati A, Altman DG, Tetzlaff J, Mulrow C, Gøtzsche PC, loannidis JP, et al. The PRISMA statement for reporting systematic reviews and meta-analyses of studies that evaluate health care interventions: explanation and elaboration. PLoS Med 2009;6(7):e1000100.

68. Moher D, Liberati A, Tetzlaff J, Altman DG. Preferred reporting items for systematic reviews and meta-analyses: the PRISMA statement. J Clin Epidemiol 2009;62(10):1006-12.

69. Aromataris E, Munn Z. JBI reviewer's manual [Internet]. Adelaide: JBI; 2017; [cited 13 June 2017]. Available from: https://reviewersmanual.joannabriggs.org/.

70. Schünemann H, Brożek J, Guyatt G, Oxman A. GRADE Handbook. Handbook for grading the quality of evidence and the strength of recommendations using the GRADE approach [Internet]. 2013 [cited 14 Apr 2018]. Available from: http://gdt.guidelinedevelopment.org/app/handbook/ handbook.html.

71. Sadler GR, Ko CM, Wu P, Alisangco J, Castañeda SF, Kelly C. A cluster randomized controlled trial to increase breast cancer screening among African American women: the black cosmetologists promoting health program. J Natl Med Assoc 2011;103(8):735-45.

72. Park M. Effects of interactive pictorial education on community dwelling older adult's self-efficacy and knowledge for safe medication. J Korean Acad Nurs 2011;41(6):795-804.

73. Phelan S, Hagobian T, Brannen A, Hatley KE, Schaffner A, Muñoz-Christian $\mathrm{K}$, et al. Effect of an internet-based program on weight loss for low-income postpartum women: a randomized clinical trial. JAMA 2017;317(23):2381-91.

74. Samuel-Hodge CD, Keyserling TC, Park S, Johnston LF, Gizlice Z, Bangdiwala SI. A randomized trial of a churchbased diabetes self-management program for African Americans with type 2 diabetes. Diabetes Educ 2009;35(3): 439-54.
75. Kripalani S, Schmotzer B, Jacobson TA. Improving medication adherence through graphically enhanced interventions in coronary heart disease (IMAGE-CHD): a randomized controlled trial. J Gen Intern Med 2012;27(12): 1609-17.

76. Gopalan A, Tahirovic E, Moss H, Troxel AB, Zhu J, Loewenstein $\mathrm{G}$, et al. Translating the hemoglobin $\mathrm{A} 1 \mathrm{C}$ with more easily understood feedback: a randomized controlled trial. J Gen Intern Med 2014;29(7):996-1003.

77. Jackson RA, Stotland NE, Caughey AB, Gerbert B. Improving diet and exercise in pregnancy with video doctor counseling: a randomized trial. Patient Educ Couns 2011;83(2):203-9.

78. Koniak-Griffin D, Brecht ML, Takayanagi S, Villegas J, Melendrez M, Balcázar H. A community health worker-led lifestyle behavior intervention for Latina (Hispanic) women: feasibility and outcomes of a randomized controlled trial. Int J Nurs Stud 2015;52(1):75-87.

79. Kripalani S, Sharma J, Justice E, Justice J, Spiker C, Laufman $\mathrm{LE}$, et al. Low-literacy interventions to promote discussion of prostate cancer: a randomized controlled trial. Am J Prev Med 2007;33(2):83-90.

80. Peragallo N, Gonzalez-Guarda RM, McCabe BE, Cianelli R. The efficacy of an HIV risk reduction intervention for Hispanic women. AIDS Behav 2012;16(5):1316-26.

81. Tu SP, Taylor V, Yasui Y, Chun A, Yip MP, Acorda E, et al. Promoting culturally appropriate colorectal cancer screening through a health educator: a randomized controlled trial. Cancer 2006;107(5):959-66.

82. Yang SO, Kim SJ, Lee SH. Effects of a South Korean community-based cardiovascular disease prevention program for low-income elderly with hypertension. J Community Health Nurs 2016;33(3):154-67.

83. Baig AA, Benitez A, Locklin CA, Gao Y, Lee SM, Quinn MT, et al. Picture good health: a church-based self-management intervention among Latino adults with diabetes. J Gen Intern Med 2015;30(10):1481-90.

84. Block G, Wakimoto P, Metz D, Fujii ML, Feldman N, Mandel $\mathrm{R}$, et al. A randomized trial of the Little by Little CD-ROM: demonstrated effectiveness in increasing fruit and vegetable intake in a low-income population. Prev Chronic Dis 2004;1(3):A08.

85. Heisler M, Choi H, Palmisano G, Mase R, Richardson C, Fagerlin $A$, et al. Comparison of community health worker-led diabetes medication decision-making support for low-income Latino and African American adults with diabetes using e-health tools versus print materials: a randomized, controlled trial. Ann Intern Med 2014;161(10 Suppl):S13-22.

86. Kim MT, Han HR, Song HJ, Lee JE, Kim J, Ryu JP, et al. A community-based, culturally tailored behavioral intervention for Korean Americans with type 2 diabetes. Diabetes Educ 2009;35(6):986-94.

87. Lutes LD, Cummings DM, Littlewood K, Dinatale E, Hambidge „A community health worker-delivered intervention 
in African American women with type 2 diabetes: a 12month randomized trial. Obesity (Silver Spring) 2017;25(8):1329-35.

88. Martin MY, Kim Y, Kratt P, Litaker MS, Kohler CL, Schoenberger $\mathrm{YM}$, et al. Medication adherence among rural, lowincome hypertensive adults: a randomized trial of a multimedia community-based intervention. Am J Health Promot 2011;25(6):372-8.

89. Mohan A, Riley B, Schmotzer B, Boyington DR, Kripalani S. Improving medication understanding among Latinos through illustrated medication lists. Am J Manag Care 2014;20(12):e547-55.

90. Muchiri JW, Gericke GJ, Rheeder P. Effect of a nutrition education programme on clinical status and dietary behaviours of adults with type 2 diabetes in a resourcelimited setting in South Africa: a randomised controlled trial. Public Health Nutr 2016;19(1):142-55.

91. Stockwell MS, Westhoff C, Kharbanda EO, Vargas CY, Camargo S, Vawdrey DK, et al. Influenza vaccine text message reminders for urban, low-income pregnant women: a randomized controlled trial. Am J Public Health 2014;104(Suppl 1):e7-12.

92. Jacobson A, Barofsky I, Cleary P, Rand L. The DCCT Research Group. Reliability and validity of a diabetes quality-of-life measure for the diabetes control and complications trial (DCCT). Diabetes Care 1988;11(9):725-32.

93. Elasy TA, Samuel-Hodge CD, DeVellis RF, Skelly AH, Ammerman AS, Keyserling TC. Development of a health status measure for older African-American women with type 2 diabetes. Diabetes Care 2000;23(3):325-9.

94. McHorney CA, Ware JE Jr, Raczek AE. The MOS 36-Item Short-Form Health Survey (SF-36): II. psychometric and clinical tests of validity in measuring physical and mental health constructs. Med Care 1993;31(3):247-63.

95. Radloff LS. The CES-D scale: a self-report depression scale for research in the general population. Appl Psychol Meas 1977;1(3):385-401.

96. Kim MT. Measuring depression in Korean Americans: development of the Kim depression scale for Korean Americans. J Transcult Nurs 2002;13(2):109-17.

97. Kirkpatrick SI, Subar AF, Douglass D, Zimmerman TP, Thompson FE, Kahle LL, et al. Performance of the Automated Self-Administered 24-hour Recall relative to a measure of true intakes and to an intervieweradministered 24-h recall. Am J Clin Nutr 2014;100(1): 233-40.

98. Morisky DE, Green LW, Levine DM. Concurrent and predictive validity of a self-reported measure of medication adherence. Med Care 1986;24(1):67-74.

99. Steiner JF, Prochazka AV. The assessment of refill compliance using pharmacy records: methods, validity, and applications. J Clin Epidemiol 1997;50(1):105-16.

100. Kripalani S, Risser J, Gatti ME, Jacobson TA. Development and evaluation of the Adherence to Refills and Medications
Scale (ARMS) among low-literacy patients with chronic disease. Value Health 2009;12(1):118-23.

101. Lorig A, Stewart A, Ritter P, Gonzalez V, Laurent D, Lynch J. Outcome measures for health education and other health care interventions. Thousand Oaks, CA: Sage; 1996.

102. Risser J, Jacobson TA, Kripalani S. Development and psychometric evaluation of the Self-efficacy for Appropriate Medication Use Scale (SEAMS) in low-literacy patients with chronic disease. J Nurs Meas 2007;15(3):203-19.

103. Garcia AA, Villagomez ET, Brown SA, Kouzekanani K, Hanis CL. The Starr County Diabetes Education Study: development of the Spanish-language diabetes knowledge questionnaire. Diabetes Care 2001;24(1):16-21.

104. Fitzgerald JT, Funnell MM, Hess GE, Barr PA, Anderson RM, Hiss RG, et al. The reliability and validity of a brief diabetes knowledge test. Diabetes Care 1998;21(5):706-10.

105. Dunn SM, Bryson JM, Hoskins PL, Alford JB, Handelsman DJ, Turtle JR. Development of the diabetes knowledge (DKN) scales: forms DKNA, DKNB, and DKNC. Diabetes Care 1984;7(1):36-41.

106. Anderson RM, Fitzgerald JT, Gruppen LD, Funnell MM, Oh MS. The Diabetes Empowerment Scale-Short Form (DESSF). Diabetes Care 2003;26(5):1641-2.

107. Toobert DJ, Hampson SE, Glasgow RE. The summary of diabetes self-care activities measure: results from 7 studies and a revised scale. Diabetes Care 2000;23(7):943-50.

108. O'Connor AM. Validation of a decisional conflict scale. Med Decis Making 1995;15(1):25-30.

109. Catania JA, Binson D, Dolcini MM, Stall R, Choi K-H, Pollack $\mathrm{LM}$, et al. Risk factors for HIV and other sexually transmitted diseases and prevention practices among US heterosexual adults: changes from 1990 to 1992. Am J Public Health 1995;85(11):1492-9.

110. Kickbusch I, Pelikan JM, Apfel F, Tsouros AD. Health Literacy: the Solid Facts Copenhagen: World Health Organization; 2013.

111. Kalichman SC, Cherry C, Cain D, Pope H, Kalichman M, Eaton $\mathrm{L}$, et al. Internet-based health information consumer skills intervention for people living with HIV/AIDS. J Consult Clin Psychol 2006;74(3):545-54.

112. Bandura A. Social Foundations of Thought and Action: A Social Cognitive Theory Englewood Cliffs, NJ: Prentice-Hall; 198.6

113. Bandura A. Self-efficacy: The exercise of control New York: Freeman; 1997.

114. Bandura A. Social learning theory. Englewood Cliffs, NJ: Prentice Hall; 1977.

115. Glanz K, Rimer BK, Lewis FM. Health behavior and health education: theory, research and practice. San Francisco, CA: Jossey-Bass; 2002.

116. Prochaska JO. A transtheoretical model of behavior change: implications for diet interventions. Dans: Henderson $M$, Bowen D, DeRoos K, (Editors). Promoting dietary change in communities: applying existing models of dietary change to 
population-based interventions. Seattle (WA): Fred Hutchinson Cancer Research Center; 1992. p. 37-50.

117. Prochaska JO, DiClemente CC. Stages and processes of selfchange of smoking: toward an integrative model of change. J Consult Clin Psychol 1983;51(3):390-5.

118. Prochaska JO, DiClemente CC. The transtheoretical approach: crossing the traditional boundaries of therapy. Homewood: Dow Jones-Irwin; 1984.

119. Janz NK, Becker MH. The Health Belief Model: a decade later. Health Educ Q 1984;11(1):1-47.

120. Rosenstock IM. Historical origins of the health belief model. Health Educ Monographs 1974;2(4):328-35.

121. Viswanathan $M$, Ammerman A, Eng E, Gartlehner G, Lohr $\mathrm{KN}$, Griffith D, et al. Community-based participatory research: assessing the evidence. Evid Rep Technol Assess (Summ) (99):2004:1-8.

122. Israel BA, Eng E, Schulz AJ, Parker EA, Satcher D. Methods in community-based participatory research for health. San Francisco, CA: Jossey-Bass; 2005.

123. Ryan RM, Deci EL. Self-determination theory and the facilitation of intrinsic motivation, social development, and well-being. Am Psychol 2000;55(1):68-78.

124. Baranowski T, Cullen KW, Nicklas T, Thompson D, Baranowski J. Are current health behavioral change models helpful in guiding prevention of weight gain efforts? Obes Res 2003;11 Suppl:23S-43S.

125. Freire P. Pedagogy of the oppressed. New York, NY: Continuum; 1970.

126. Knowles MS. The adult learner: a neglected species. Houston, TX: Gulf; 1990.

127. Lutes LD, Steinbaugh EK. Theoretical models for pedometer use in physical activity interventions. Phys Ther Rev 2010;15(3):143-53.

128. Lutes LD, Winett RA, Barger SD, Wojcik JR, Herbert WG, Nickols-Richardson SM, et al. Small changes in nutrition and physical activity promote weight loss and maintenance: 3-month evidence from the ASPIRE randomized trial. Ann Behav Med 2008;35(3):351-7.

129. Damschroder L, Lutes LD, Goodrich DE, Gillon L, Lowery JC. A small-change approach delivered via telephone promotes weight loss in veterans: results from the ASPIRE-VA pilot study. Patient Educ Couns 2010;79(2):262-6.

130. Hill JO, Wyatt HR, Reed GW, Peters JC. Obesity and the environment: where do we go from here? Science 2003;299(5608):853-5.

131. Lutes LD, Daiss SR, Barger SD, Read M, Steinbaugh E, Winett RA. Small changes approach promotes initial and continued weight loss with a phone-based follow-up: nine-month outcomes from ASPIRES II. Am J Health Promot 2012;26(4):235-8.

132. Institute of Medicine. Standardizing medication labels: confusing patients less, workshop summary Washington, DC: The National Academies Press; 2008.

133. Goei M, Schechtel M, Meyer S, Stewart J, Nicolai R, King V, et al. Premixed insulin for type 2 diabetes. Effective health care. Rockville, MD: Agency for Healthcare Research and Quality; 2009.

134. Robinson S, Rugge B, Schechtel M, King V, Bianco T, Hickam D. Pills for Type 2 Diabetes. Effective health care. Rockville, MD: Agency for Healthcare Research and Quality; 2007.

135. Prestwich A, Sniehotta FF, Whittington C, Dombrowski SU, Rogers $L$, Michie $S$. Does theory influence the effectiveness of health behavior interventions? Meta-analysis. Health Psychol 2014;33(5):465-74.

136. Porter CM. Revisiting Precede-Proceed: A leading model for ecological and ethical health promotion. Health Educ J 2015;75(6):753-64.

137. Bartholomew Eldredge LK, Markham CM, Ruiter RAC, Fernández ME, Kok G, Parcel GS. Planning health promotion programs: an intervention mapping approach. 4th ed. San Francisco: Jossey-Bass; 2016.

138. Israel BA, Coombe CM, Cheezum RR, Schulz AJ, McGranaghan RJ, Lichtenstein R, et al. Community-based participatory research: a capacity-building approach for policy advocacy aimed at eliminating health disparities. Am J Public Health 2010;100(11):2094-102.

139. Ginossar T, Nelson S. Reducing the health and digital divides: a model for using community-based participatory research approach to e-health interventions in low-income Hispanic communities. J Comput Mediat Commun 2010;15:530-51.

140. Israel BA, Schulz AJ, Parker EA, Becker AB. Communitybased participatory research: policy recommendations for promoting a partnership approach in health research. Educ Health 2001;14(2):182-97.

141. De las Nueces D, Hacker K, DiGirolamo A, Hicks LS. A systematic review of community-based participatory research to enhance clinical trials in racial and ethnic minority groups. Health Serv Res 2012;47(3 Pt 2):1363-86.

142. Bogart LM, Uyeda K. Community-based participatory research: partnering with communities for effective and sustainable behavioral health interventions. Health Psychol 2009;28(4):391-3.

143. Marin G. Defining culturally appropriate community interventions: Hispanics as a case study. J Community Psychol 1993;21(2):149-61.

144. Healey P, Stager ML, Woodmass K, Dettlaff AJ, Vergara A, Janke $R$, et al. Cultural adaptations to augment health and mental health services: a systematic review. BMC Health Serv Res 2017;17(1):8.

145. Castro FG, Barrera M Jr, Martinez CR Jr. The cultural adaptation of prevention interventions: resolving tensions between fidelity and fit. Prev Sci 2004;5(1):41-5.

146. Kreuter MW, Lukwago SN, Bucholtz RD, Clark EM, SandersThompson V. Achieving cultural appropriateness in health promotion programs: targeted and tailored approaches. Health Educ Behav 2003;30(2):133-46.

147. Glazier RH, Bajcar J, Kennie NR, Willson K. A systematic review of interventions to improve diabetes care in socially 
disadvantaged populations. Diabetes Care 2006;29(7): 1675-88.

148. Hawthorne K, Robles Y, Cannings-John R, Edwards AG. Culturally appropriate health education for Type 2 diabetes in ethnic minority groups: a systematic and narrative review of randomized controlled trials. Diabet Med 2010;27(6):613-23.

149. Hawkins RP, Kreuter M, Resnicow K, Fishbein M, Dijkstra A. Understanding tailoring in communicating about health. Health Educ Res 2008;23(3):454-66.

150. Cuevas AG, O'Brien K, Saha S. What is the key to culturally competent care: reducing bias or cultural tailoring? Psychol Health 2017;32(4):493-507.

151. Neville LM, O'Hara B, Milat AJ. Computer-tailored dietary behaviour change interventions: a systematic review. Health Educ Res 2009;24(4):699-720.

152. Noar SM, Benac CN, Harris MS. Does tailoring matter? Metaanalytic review of tailored print health behavior change interventions. Psychol Bull 2007;133(4):673-93.

153. Ad Hoc Committee on Health Literacy for the Council on Scientific Affairs, American Medical Association. Health literacy: report of the Council on Scientific Affairs. JAMA 1999;281(6):552-7.

154. Pearson ES. Goal setting as a health behavior change strategy in overweight and obese adults: a systematic literature review examining intervention components. Patient Educ Couns 2012;87(1):32-42.

155. Miller WR, Rollnick S. Motivational Interviewing. Helping People Change. 3rd ed. New-York: Guilford Press; 2012.

156. Strecher VJ, Seijts GH, Kok GJ, Latham GP, Glasgow R, DeVellis $B$, et al. Goal setting as a strategy for health behavior change. Health Educ Q 1995;22(2): 190-200.

157. Word Health Organization Europe. Ottawa Charter for Health Promotion. Geneva: Word Health Organization; 1986.

158. Sudore RL, Schillinger D. Interventions to improve care for patients with limited health literacy. J Clin Outcomes Manag 2009;16(1):20-9.

159. DeWalt DA, Callahan LF, Hawk VH, Broucksou KA, Hink A, Rudd $\mathrm{R}$, et al. Health literacy universal precautions toolkit. Washington: Agency for Healthcare Research and Quality; 2010.

160. Dennis CL. Peer support within a health care context: a concept analysis. Int J Nurs Stud 2003;40(3):321-32.

161. Heisler M. Overview of peer support models to improve diabetes self-management and clinical outcomes. Diabetes Spectr 2007;20(4):214-21.

162. Desgroseilliers V, Nicolas V. Expérience migratoire et santé: ou comment penser l'altérité et la souffrance identitaire. Aproria 2010;2(2):17-25; French.

163. Joanna Briggs Institute. JBI grades of recommendation [Internet]. 2013 [cited 17 October 2019]. Available from: https://joannabriggs.org/sites/default/files/2019-05/ JBlgrades-of-recommendation_2014.pdf.

164. McCormack L, Thomas V, Lewis MA, Rudd R. Improving low health literacy and patient engagement: a social ecological approach. Patient Educ Couns 2017;100(1):8-13.

165. National Heart, Lung, and Blood Institute. Your heart, your life: a community health educator's manual for the Hispanic community. Bethesda, MD: U.S Department of Health and Human Services; 2008. 


\section{Appendix I: Search strategy}

\section{PubMed (search performed on May 22, 2018)}

\begin{tabular}{|c|c|}
\hline Search & Query \\
\hline$\# 1$ & 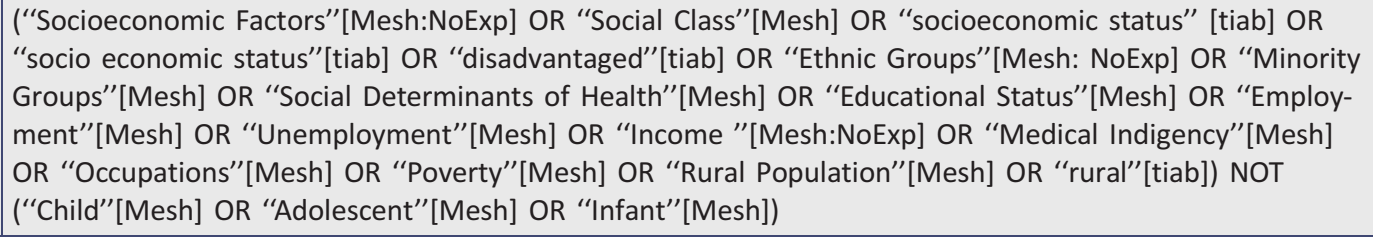 \\
\hline$\# 2$ & 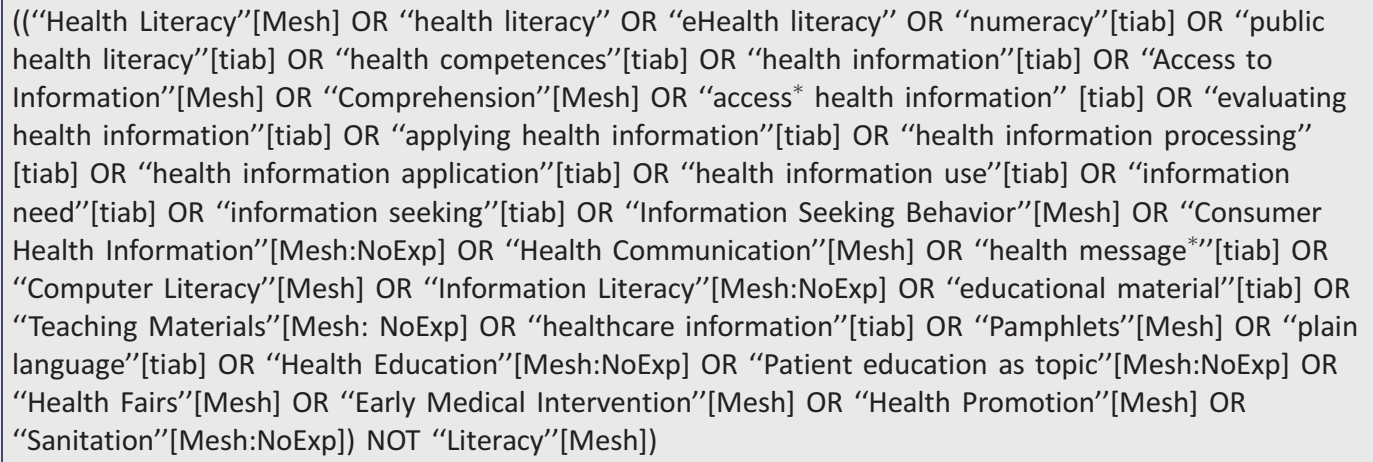 \\
\hline$\# 3$ & 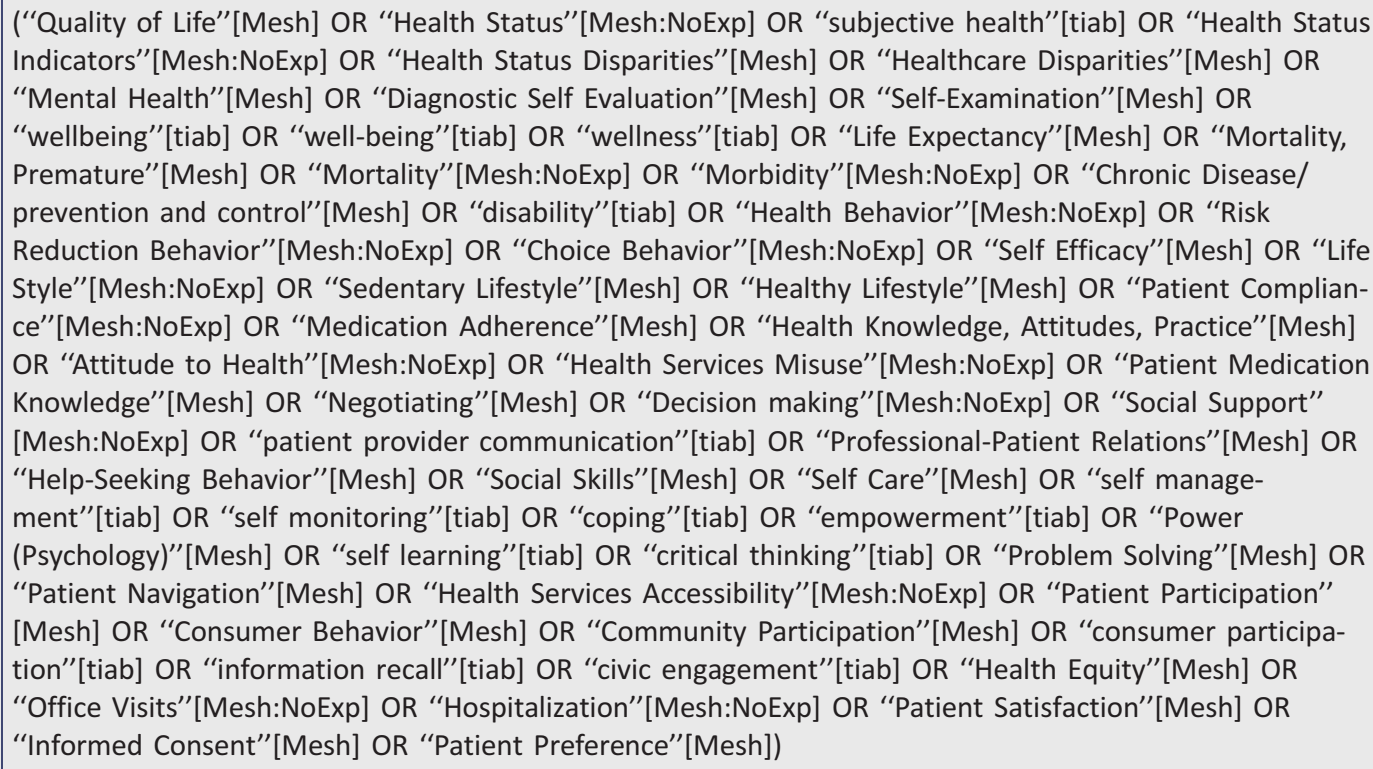 \\
\hline$\# 4$ & $\# 1$ AND \#2 AND \#3 \\
\hline
\end{tabular}




\section{CINAHL (search performed on May 22, 2018)}

\begin{tabular}{|c|c|}
\hline Search & Query \\
\hline$\# 1$ & $\begin{array}{l}\text { (((MM "Socioeconomic Factors") OR (MH "Social Class") OR "socioeconomic status" OR "socio economic } \\
\text { status" OR "disadvantaged" OR (MM "Ethnic Groups") OR (MH "Minority Groups") OR (MH "Social } \\
\text { Determinants of Health") OR (MH "Educational Status") OR (MH "Employment") OR (MH "Unemploy- } \\
\text { ment") OR (MH "Employment Status") OR (MM "Income") OR (MM “Occupations and Professions") OR } \\
\text { (MH "Poverty") OR (MH "Rural Population")) NOT ((MH "Child") OR (MH "Adolescence") OR (MH } \\
\text { "Infant"))) }\end{array}$ \\
\hline$\# 2$ & 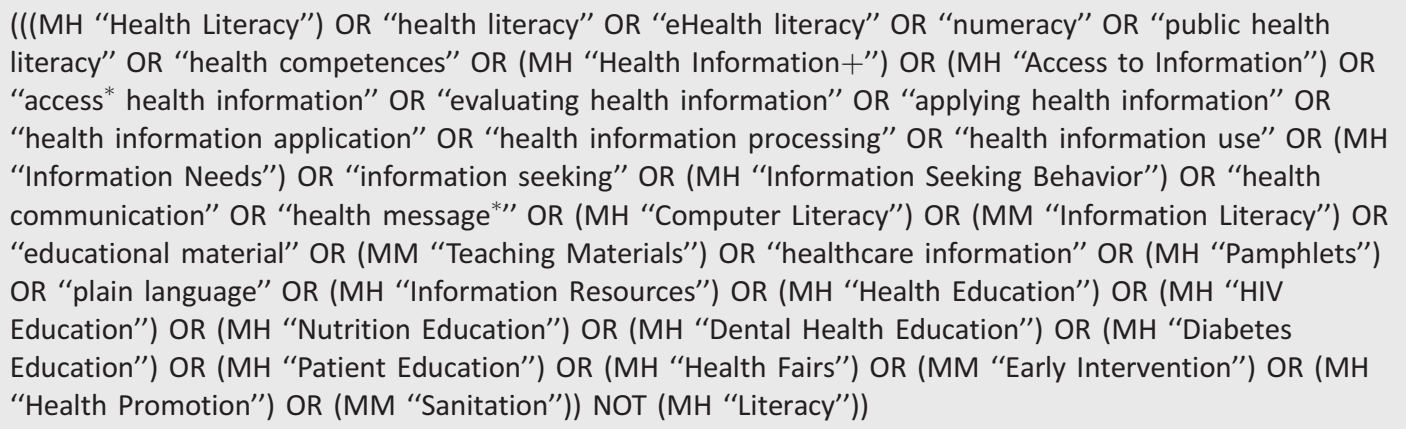 \\
\hline$\# 3$ & 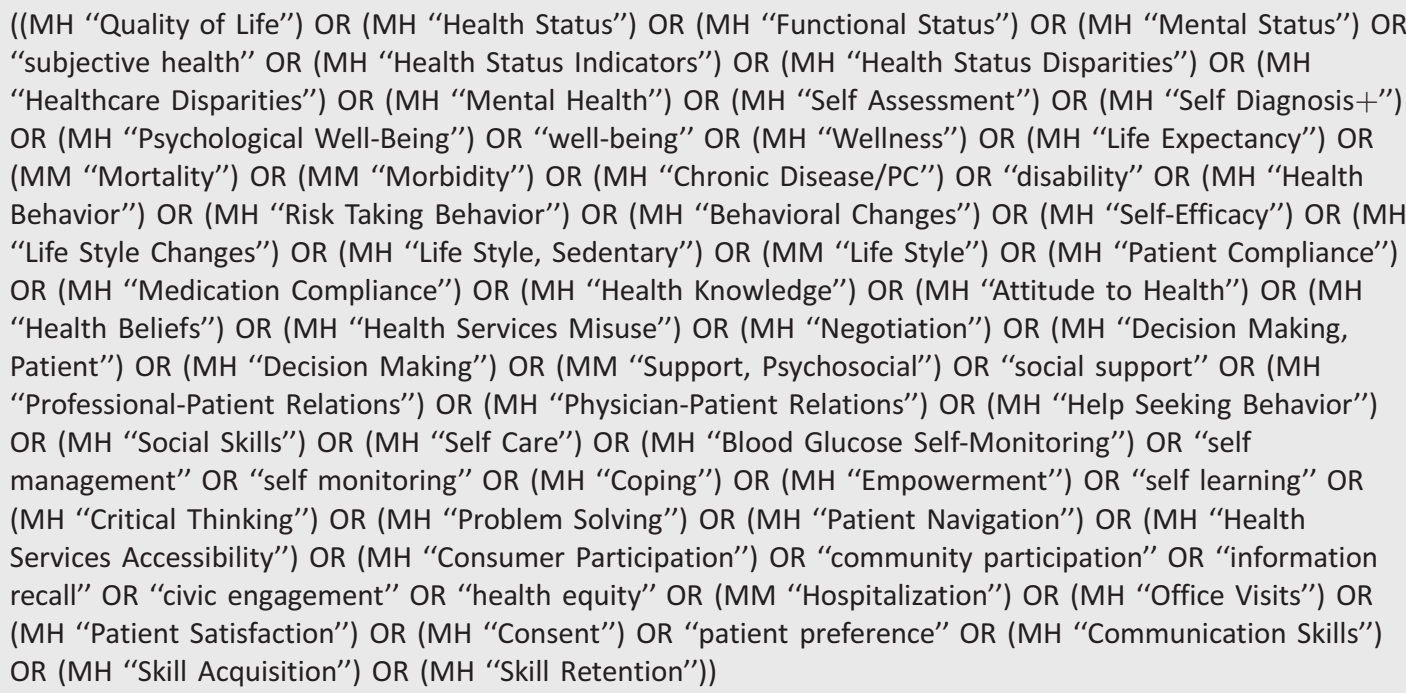 \\
\hline$\# 4$ & $\# 1$ AND \#2 AND \#3 \\
\hline
\end{tabular}




\section{CENTRAL (search performed on May 22, 2018)}

\begin{tabular}{|c|c|}
\hline Search & Query \\
\hline$\# 1$ & 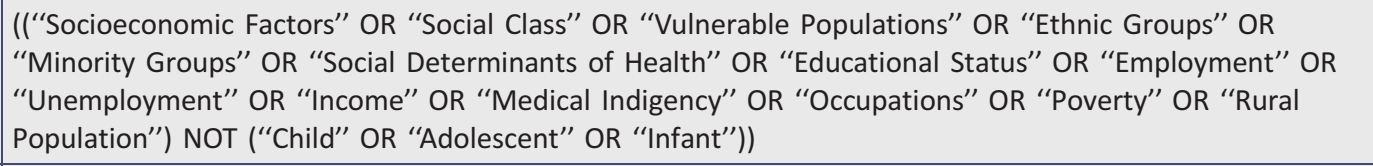 \\
\hline$\# 2$ & $\begin{array}{l}\text { ((Health Literacy OR "eHealth literacy" OR "numeracy" OR "public health literacy" OR "health } \\
\text { competences" OR "health information" OR "Access to Information" OR "Comprehension" OR "access* } \\
\text { health information" OR "evaluating health information" OR "applying health information" OR "health } \\
\text { information processing" OR "health information application" OR "health information use" OR } \\
\text { "information need" OR "information seeking" OR "Information Seeking Behavior" OR "Consumer Health } \\
\text { Information" OR "Health Communication" OR "health message"” OR "Computer Literacy" OR } \\
\text { "Information Literacy" OR "educational material" OR "Teaching Materials" OR "healthcare information" } \\
\text { OR "Pamphlets" OR "plain language" OR "Health Education" OR "Patient education as topic" OR } \\
\text { "Health Fairs" OR "Early Medical Intervention" OR "Health Promotion" OR "Sanitation") NOT "Literacy") }\end{array}$ \\
\hline \#3 & 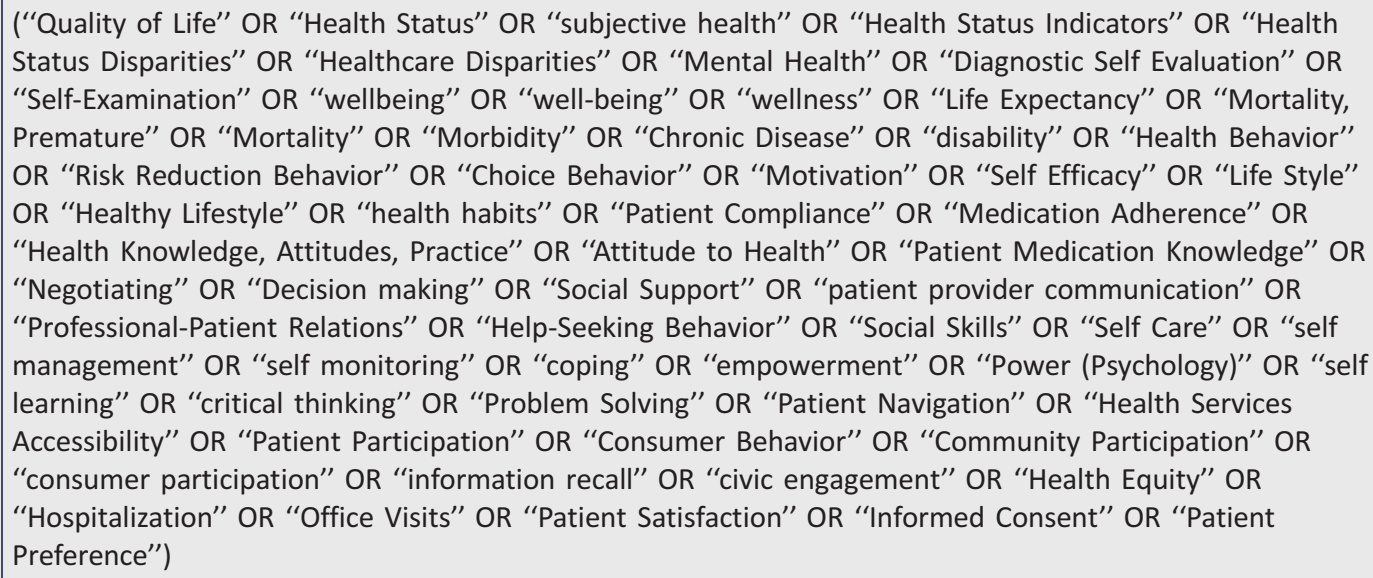 \\
\hline \multirow[t]{2}{*}{$\# 4$} & $\# 1$ AND \#2 AND \#3 \\
\hline & Search all text, limit trials \\
\hline
\end{tabular}




\section{Embase (search performed on May 22, 2018)}

\begin{tabular}{|c|c|}
\hline Search & Query \\
\hline$\# 1$ & $\begin{array}{l}\text { (('socioeconomics'/de OR 'social class'/exp OR 'social status'/exp OR disadvantaged OR 'ethnic group'/de } \\
\text { OR 'minority group'/exp OR 'social determinants of health'/exp OR 'educational status'/exp OR } \\
\text { 'employment'/exp OR 'income'/de OR 'household income'/exp OR 'income group'/exp 'occupation'/de } \\
\text { OR 'poverty'/exp OR 'rural population'/exp) NOT ('child'/exp OR 'adolescent'/exp OR 'infant'/exp)) }\end{array}$ \\
\hline$\# 2$ & $\begin{array}{l}\text { (('health literacy'/br OR 'numeracy'/exp OR 'public health literacy' OR 'health competences' OR 'medical } \\
\text { information'/exp OR 'access to information'/exp OR 'comprehension'/exp OR 'access* health information' } \\
\text { OR 'evaluating health information' OR 'applying health information' OR 'health information processing' } \\
\text { OR 'health information application' OR 'health information use' OR 'information need' OR 'information } \\
\text { seeking'/exp OR 'consumer health information'/exp OR 'health message*' OR 'information literacy'/exp } \\
\text { OR 'educational material' OR 'healthcare information' OR 'plain language' OR 'health education'/de OR } \\
\text { 'diabetes education'/exp OR 'HIV education'/exp OR 'nutrition education'/exp OR 'patient education'/exp } \\
\text { OR 'early intervention'/exp OR 'health promotion'/exp OR 'sanitation'/de OR 'sanitation education'/exp) } \\
\text { NOT ('reading'/exp OR 'literacy programs'/exp)) }\end{array}$ \\
\hline$\# 3$ & $\begin{array}{l}\text { ('health outcomes'/exp OR 'quality of life'/de OR 'health status'/de OR 'functional status'/exp OR 'health } \\
\text { status indicator'/exp OR 'health disparity'/exp OR 'subjective health' OR 'health care disparity'/exp OR } \\
\text { 'mental health'/exp OR 'self evaluation'/exp OR 'self examination'/exp OR 'wellbeing'/exp OR 'subjective } \\
\text { well being/exp' OR 'physical well-being'/exp OR 'psychological well-being'/exp OR 'life expectancy'/exp } \\
\text { OR 'premature mortality'/exp OR 'mortality'/de OR 'mortality rate'/de OR 'morbidity'/de OR 'chronic } \\
\text { disease'/exp OR 'chronic disease prevention and control'/exp OR 'disability'/de OR 'invalidity'/exp OR } \\
\text { 'limited mobility'/exp OR 'physical disability'/exp OR 'work disability'/exp OR 'health behavior'/de OR } \\
\text { 'health belief'/exp OR 'high risk behavior'/exp OR 'risk reduction'/exp OR 'decision making'/de OR } \\
\text { 'patient decision making'/exp OR 'shared decision making'/exp OR 'motivation'/exp OR 'self concept'/de } \\
\text { OR 'lifestyle'/exp OR 'lifestyle modification'/exp OR 'healthy lifestyle'/exp OR 'health habits' OR 'patient } \\
\text { compliance'/exp OR 'medication compliance'/exp OR 'attitude to health'/exp OR 'interpersonal } \\
\text { communication'/de OR 'communication skill'/exp OR 'social support'/exp OR 'help seeking behavior'/exp } \\
\text { OR 'self care'/de OR 'self management'/exp OR 'self monitoring'/exp OR 'coping behavior'/de OR } \\
\text { 'empowerment'/exp OR 'self learning' OR 'critical thinking'/exp OR 'problem solving'/de OR 'navigation'/ } \\
\text { exp OR 'patient participation'/exp OR 'consumer attitude'/exp OR 'community participation'/exp OR } \\
\text { 'information recall' OR 'civic engagement'/exp OR 'health equity'/exp OR 'hospitalization'/exp OR } \\
\text { 'ambulatory care'/exp OR 'patient satisfaction'/exp OR 'informed consent'/exp OR 'patient preference'/ } \\
\text { exp) }\end{array}$ \\
\hline$\# 4$ & $\# 1$ AND \#2 AND \#3 \\
\hline
\end{tabular}




\section{PsyciNFO (search performed on May 22, 2018)}

\begin{tabular}{|c|c|}
\hline Search & Query \\
\hline$\# 1$ & Socioeconomic Status/ \\
\hline \#2 & exp Social Class/ \\
\hline \#3 & "Racial and Ethnic Groups"/ \\
\hline \#4 & Minority Groups/ \\
\hline \#5 & Social Determinants of Health.mp. \\
\hline \#6 & exp Educational Attainment Level/ \\
\hline \#7 & Employment Status/ \\
\hline \#8 & income level/ \\
\hline \#9 & exp Lower Income Level/ \\
\hline \#10 & disadvantaged/ \\
\hline \#11 & poverty/ \\
\hline \#12 & adolescent.mp. \\
\hline \#13 & child.mp. \\
\hline \#14 & infant.mp. \\
\hline \#15 & 1 or 2 or 3 or 4 or 5 or 6 or 7 or 8 or 9 or 10 or 11 \\
\hline \#16 & 12 or 13 or 14 \\
\hline \#17 & 15 not 16 \\
\hline \#18 & exp Health Literacy/ \\
\hline$\# 19$ & eHealth literacy.mp. \\
\hline$\# 20$ & numeracy.mp. \\
\hline \#21 & public health literacy.mp. \\
\hline$\# 22$ & health competences.mp. \\
\hline$\# 23$ & health information.mp. \\
\hline$\# 24$ & Access to Information.mp. \\
\hline \#25 & access* health information.mp. \\
\hline$\# 26$ & evaluating health information.mp. \\
\hline$\# 27$ & applying health information.mp. \\
\hline$\# 28$ & health information processing.mp. \\
\hline$\# 29$ & information need.mp. \\
\hline$\# 30$ & information seeking/ \\
\hline \#31 & information literacy/ \\
\hline$\# 32$ & Health Communication.mp. \\
\hline \#33 & health message*.mp. \\
\hline$\# 34$ & computer literacy/ or computer searching/ \\
\hline \#35 & healthcare information.mp. \\
\hline$\# 36$ & Pamphlet*.mp. \\
\hline \#37 & plain language.mp. \\
\hline
\end{tabular}




\begin{tabular}{|c|c|}
\hline \multicolumn{2}{|c|}{ (Continued) } \\
\hline Search & Query \\
\hline \#38 & health education/ or drug education/ or sex education/ or client education/ \\
\hline \#39 & early intervention/ \\
\hline$\# 40$ & health promotion/ \\
\hline \#41 & literacy/ \\
\hline \#42 & $\begin{array}{l}18 \text { or } 19 \text { or } 20 \text { or } 21 \text { or } 22 \text { or } 23 \text { or } 24 \text { or } 25 \text { or } 26 \text { or } 27 \text { or } 28 \text { or } 29 \text { or } 30 \text { or } 31 \text { or } 32 \text { or } 33 \text { or } 34 \text { or } \\
35 \text { or } 36 \text { or } 37 \text { or } 38 \text { or } 39 \text { or } 40\end{array}$ \\
\hline \#43 & 42 not 41 \\
\hline$\# 44$ & "quality of life"/ \\
\hline \#45 & health status.mp. \\
\hline \#46 & mental health/ \\
\hline \#47 & physical health/ \\
\hline \#48 & health disparities/ \\
\hline \#49 & health knowledge/ \\
\hline$\# 50$ & well being/ \\
\hline \#51 & self-evaluation/ \\
\hline$\# 52$ & wellness.mp. \\
\hline \#53 & life expectancy/ \\
\hline \#54 & "death and dying"/ \\
\hline$\# 55$ & chronic illness/ \\
\hline \#56 & health behavior/ \\
\hline \#57 & risk perception/ \\
\hline \#58 & risk taking/ \\
\hline \#59 & choice behavior/ \\
\hline$\# 60$ & self-efficacy/ \\
\hline$\# 61$ & lifestyle/ or lifestyle changes/ \\
\hline$\# 62$ & Healthy Lifestyle.mp. \\
\hline$\# 63$ & treatment compliance/ \\
\hline$\# 64$ & decision making/ \\
\hline$\# 65$ & negotiation/ \\
\hline \#66 & disabilities/ \\
\hline$\# 67$ & social support/ \\
\hline \#68 & help seeking behavior/ \\
\hline$\# 69$ & health care seeking behavior/ \\
\hline \#70 & social skills/ \\
\hline \#71 & self-care skills/ \\
\hline \#72 & self-management/ \\
\hline \#73 & behavior modification/ \\
\hline \#74 & self-monitoring/ \\
\hline
\end{tabular}




\begin{tabular}{|l|l|}
\hline (Continued) & \multicolumn{2}{|l|}{} \\
\hline Search & Query \\
\hline$\# 75$ & coping behavior/ \\
\hline$\# 76$ & empowerment/ \\
\hline$\# 77$ & critical thinking/ \\
\hline$\# 78$ & problem solving/ \\
\hline$\# 79$ & client participation/ \\
\hline$\# 80$ & community involvement/ \\
\hline$\# 81$ & information recall.mp. \\
\hline$\# 82$ & health equity.mp. \\
\hline$\# 83$ & disease management/ \\
\hline$\# 84$ & client satisfaction/ \\
\hline$\# 85$ & informed consent/ \\
\hline$\# 86$ & Patient Preference.mp. \\
\hline$\# 87$ & $\begin{array}{l}44 \text { or } 45 \text { or } 46 \text { or } 47 \text { or } 48 \text { or } 49 \text { or } 50 \text { or } 51 \text { or } 52 \text { or } 53 \text { or } 54 \text { or } 55 \text { or } 56 \text { or } 57 \text { or } 58 \text { or } 59 \text { or } 60 \text { or } \\
61 \text { or } 62 \text { or } 63 \text { or } 64 \text { or } 65 \text { or } 66 \text { or } 67 \text { or } 68 \text { or } 69 \text { or } 70 \text { or } 71 \text { or } 72 \text { or } 73 \text { or } 74 \text { or } 75 \text { or } 76 \text { or } 77 \text { or } \\
78 \text { or } 79 \text { or } 80 \text { or } 81 \text { or } 82 \text { or } 83 \text { or } 84 \text { or } 85 \text { or } 86\end{array}$ \\
\hline$\# 88$ & 17 and 43 and 87 \\
\hline
\end{tabular}




\section{TROPHI (search performed on May 22, 2018)}

\begin{tabular}{|c|c|}
\hline Search & Query \\
\hline$\# 1$ & Freetext: "Socioeconomic Factors" \\
\hline$\# 2$ & Freetext: "Social Class" \\
\hline \#3 & Freetext: "socioeconomic status" \\
\hline \#4 & Freetext: "socio economic status" \\
\hline \#5 & Freetext: disadvantaged \\
\hline \#6 & Freetext: "Ethnic Groups" \\
\hline \#7 & Freetext: "Minority Groups" \\
\hline \#8 & Freetext: "Social Determinants of Health" \\
\hline \#9 & Freetext: "Educational Status" \\
\hline \#10 & Freetext: "Educational attainment" \\
\hline \#11 & Freetext: Employment \\
\hline \#12 & Freetext: Unemployment \\
\hline \#13 & Freetext: Income \\
\hline \#14 & Freetext: Occupation \\
\hline \#15 & Freetext: Poverty \\
\hline \#16 & Freetext: rural \\
\hline$\# 17$ & Freetext: "Rural Population" \\
\hline \#18 & 1 OR 2 OR 3 OR 4 OR 5 OR 6 OR 7 OR 8 OR 9 OR 10 OR 11 OR 12 OR 13 OR 14 OR 15 OR 16 OR 17 \\
\hline$\# 19$ & Freetext: "Health Literacy" \\
\hline$\# 20$ & Freetext: "eHealth literacy" \\
\hline \#21 & Freetext: numeracy \\
\hline$\# 22$ & Freetext: "public health literacy" \\
\hline$\# 23$ & Freetext: "health competences" \\
\hline$\# 24$ & Freetext: "health information" \\
\hline$\# 25$ & Freetext: Comprehension \\
\hline \#26 & Freetext: "information need" \\
\hline$\# 27$ & Freetext: "information seeking" \\
\hline \#28 & Freetext: "Health Communication" \\
\hline$\# 29$ & Freetext: "health message" \\
\hline$\# 30$ & Freetext: "health messages" \\
\hline \#31 & Freetext: "Computer Literacy" \\
\hline$\# 32$ & Freetext: "Information Literacy" \\
\hline \#33 & Freetext: "educational material" \\
\hline \#34 & Freetext: "Teaching Materials" \\
\hline \#35 & Freetext: "healthcare information" \\
\hline$\# 36$ & Freetext: Pamphlets \\
\hline \#37 & Freetext: "plain language" \\
\hline
\end{tabular}




\begin{tabular}{|c|c|}
\hline \multicolumn{2}{|c|}{ (Continued) } \\
\hline Search & Query \\
\hline \#38 & Freetext: "Health Education" \\
\hline \#39 & Freetext: "Patient education" \\
\hline$\# 40$ & Freetext: "Health Fairs" \\
\hline$\# 41$ & Freetext: "Health Promotion" \\
\hline \#42 & Freetext: Sanitation \\
\hline$\# 43$ & $\begin{array}{l}19 \text { OR } 20 \text { OR } 21 \text { OR } 22 \text { OR } 23 \text { OR } 24 \text { OR } 25 \text { OR } 26 \text { OR } 27 \text { OR } 28 \text { OR } 29 \text { OR } 30 \text { OR } 31 \text { OR } 32 \text { OR } 33 \text { OR } \\
34 \text { OR } 35 \text { OR } 36 \text { OR } 37 \text { OR } 38 \text { OR } 39 \text { OR } 40 \text { OR } 41 \text { OR } 42\end{array}$ \\
\hline$\# 44$ & Freetext: “Quality of Life” \\
\hline$\# 45$ & Freetext: "Health Status" \\
\hline \#46 & Freetext: "subjective health" \\
\hline$\# 47$ & Freetext: "Health Status Indicators" \\
\hline$\# 48$ & Freetext: "Health Status Disparities" \\
\hline \#49 & Freetext: "Healthcare Disparities" \\
\hline \#50 & Freetext: disparities \\
\hline \#51 & Freetext: inequalities \\
\hline \#52 & Freetext: inequities \\
\hline \#53 & Freetext: "Mental Health" \\
\hline \#54 & Freetext: Self-Examination \\
\hline \#55 & Freetext: wellbeing \\
\hline \#56 & Freetext: well-being \\
\hline \#57 & Freetext: wellness \\
\hline$\# 58$ & Freetext: "Life Expectancy" \\
\hline \#59 & Freetext: Mortality \\
\hline$\# 60$ & Freetext: Morbidity \\
\hline \#61 & Freetext: "Chronic Disease" \\
\hline$\# 62$ & Freetext: disability \\
\hline \#63 & Freetext: disabilities \\
\hline$\# 64$ & Freetext: "Health Behavior" \\
\hline \#65 & Freetext: "Risk Reduction Behavior" \\
\hline \#66 & Freetext: "Self Efficacy" \\
\hline$\# 67$ & Freetext: "Life Style" \\
\hline \#68 & Freetext: "Healthy Lifestyle" \\
\hline$\# 69$ & Freetext: "Patient Compliance" \\
\hline$\# 70$ & Freetext: "Medication Adherence" \\
\hline$\# 71$ & Freetext: "Attitude to Health" \\
\hline \#72 & Freetext: "Patient Medication Knowledge" \\
\hline$\# 73$ & Freetext: Negotiating \\
\hline \#74 & Freetext: "Decision making" \\
\hline
\end{tabular}




\begin{tabular}{|c|c|}
\hline \\
\hline \multicolumn{2}{|c|}{\begin{tabular}{l|l}
\multicolumn{2}{l}{$($ Continued) } \\
Search & Query
\end{tabular}} \\
\hline \multicolumn{2}{|r|}{ Freetext: "Social Support" } \\
\hline \multicolumn{2}{|r|}{ Freetext: "patient provider communication" } \\
\hline \multicolumn{2}{|r|}{ Freetext: "Help-Seeking Behavior" } \\
\hline & Freetext: "Social Skills" \\
\hline \multicolumn{2}{|r|}{ Freetext: "Self Care" } \\
\hline \multicolumn{2}{|r|}{ Freetext: "self management" } \\
\hline \multicolumn{2}{|r|}{ Freetext: "self monitoring" } \\
\hline \multicolumn{2}{|r|}{ Freetext: coping } \\
\hline \multicolumn{2}{|r|}{ Freetext: empowerment } \\
\hline \multicolumn{2}{|r|}{ Freetext: "self learning" } \\
\hline$\# 85$ & Freetext: "critical thinking" \\
\hline \multicolumn{2}{|r|}{ Freetext: "Problem Solving" } \\
\hline \multicolumn{2}{|r|}{ Freetext: "Patient Navigation" } \\
\hline \multicolumn{2}{|r|}{ Freetext: Navigation } \\
\hline & Freetext: "Patient Participation" \\
\hline \multicolumn{2}{|r|}{ Freetext: "Consumer Behavior" } \\
\hline \multicolumn{2}{|r|}{ Freetext: "Community Participation" } \\
\hline \multicolumn{2}{|r|}{ Freetext: "consumer participation" } \\
\hline \multicolumn{2}{|r|}{ Freetext: "information recall” } \\
\hline$\# 94$ & Freetext: "civic engagement" \\
\hline \multicolumn{2}{|r|}{ Freetext: "Health Equity" } \\
\hline \multicolumn{2}{|r|}{ Freetext: Hospitalization } \\
\hline \multicolumn{2}{|r|}{ Freetext: "Office Visits" } \\
\hline \multicolumn{2}{|r|}{ Freetext: "Patient Satisfaction" } \\
\hline \#99 & Freetext: "Informed Consent" \\
\hline$\# 100$ & Freetext: "Patient Preference" \\
\hline$\# 101$ & $\begin{array}{l}44 \text { OR } 45 \text { OR } 46 \text { OR } 47 \text { OR } 48 \text { OR } 49 \text { OR } 50 \text { OR } 51 \text { OR } 52 \text { OR } 53 \text { OR } 54 \text { OR } 55 \text { OR } 56 \text { OR } 57 \text { OR } 58 \text { OR } \\
59 \text { OR } 60 \text { OR } 61 \text { OR } 62 \text { OR } 63 \text { OR } 64 \text { OR } 65 \text { OR } 66 \text { OR } 67 \text { OR } 68 \text { OR } 69 \text { OR } 70 \text { OR } 71 \text { OR } 72 \text { OR } 73 \text { OR } \\
74 \text { OR } 75 \text { OR } 76 \text { OR } 77 \text { OR } 78 \text { OR } 79 \text { OR } 80 \text { OR } 81 \text { OR } 82 \text { OR } 83 \text { OR } 84 \text { OR } 85 \text { OR } 86 \text { OR } 87 \text { OR } 88 \text { OR } \\
89 \text { OR } 90 \text { OR } 91 \text { OR } 92 \text { OR } 93 \text { OR } 94 \text { OR } 95 \text { OR } 96 \text { OR } 97 \text { OR } 98 \text { OR } 99 \text { OR } 100\end{array}$ \\
\hline$\# 102$ & 18 AND 43 AND 101 \\
\hline
\end{tabular}




\section{Web of Science (search performed on May 22, 2018)}

\begin{tabular}{|c|c|}
\hline Search & Query \\
\hline$\# 1$ & $\begin{array}{l}\text { ((“Socioeconomic Factors" OR "Social Class" OR "socioeconomic status" OR "socio economic status" OR } \\
\text { "disadvantaged" OR "Ethnic Groups" OR "Minority Groups" OR "Social Determinants of Health" OR } \\
\text { "Educational Status" OR "Employment" OR "Unemployment" OR "Income" OR "Medical Indigency" OR } \\
\text { "Occupations" OR "Poverty" OR "Rural Population" OR "rural”) NOT (“Child" OR "Adolescent" OR } \\
\text { "Infant")) }\end{array}$ \\
\hline$\# 2$ & $\begin{array}{l}\text { (("Health Literacy" OR "eHealth literacy" OR "numeracy" OR "public health literacy" OR "health } \\
\text { competences" OR "health information" OR "Access to Information" OR "Comprehension" OR "access* } \\
\text { health information" OR "evaluating health information" OR "applying health information" OR "health } \\
\text { information processing" OR "health information application" OR "health information use" OR } \\
\text { "information need" OR "information seeking" OR "Information Seeking Behavior" OR "Consumer Health } \\
\text { Information" OR "Health Communication" OR "health message"” OR "Computer Literacy" OR } \\
\text { "Information Literacy" OR "educational material" OR "Teaching Materials" OR "healthcare information" } \\
\text { OR "Pamphlets" OR "plain language" OR "Health Education" OR "Patient education" OR "Health Fairs" } \\
\text { OR "Early Medical Intervention" OR "Health Promotion" OR "Sanitation") NOT "Literacy") }\end{array}$ \\
\hline \#3 & 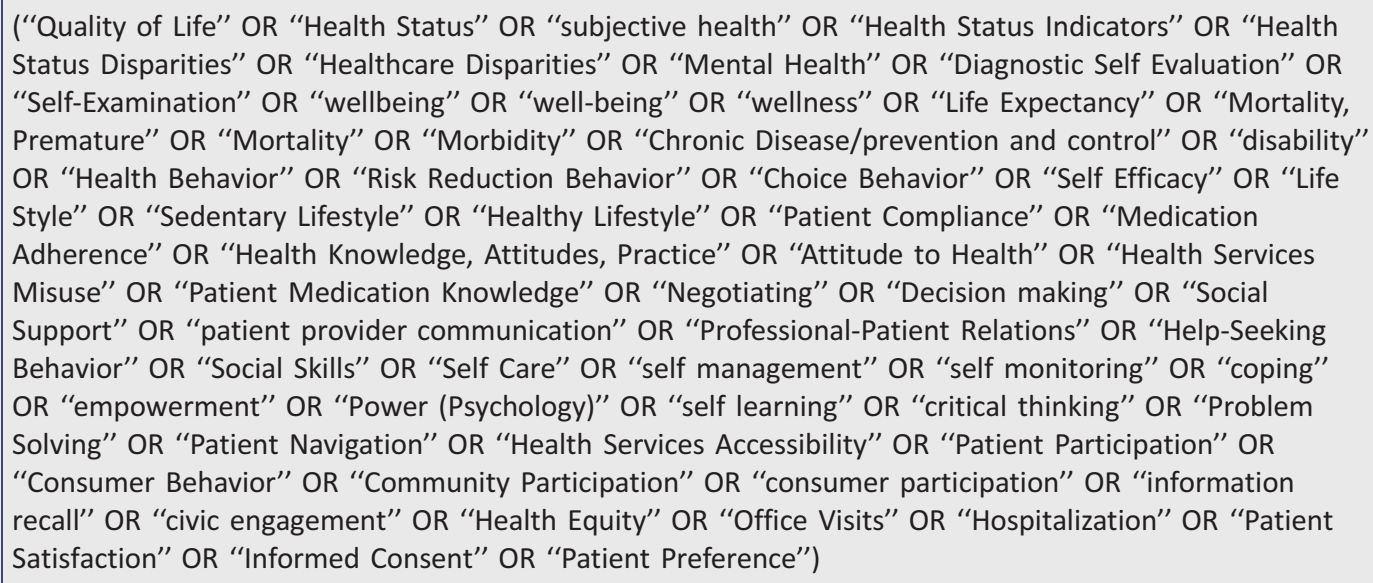 \\
\hline$\# 4$ & $\# 1$ AND \#2 AND \#3 \\
\hline
\end{tabular}




\section{ProQuest Dissertations \& Theses A\&I (search performed on May 22, 2018)}

\begin{tabular}{|c|c|}
\hline Search & Query \\
\hline$\# 1$ & 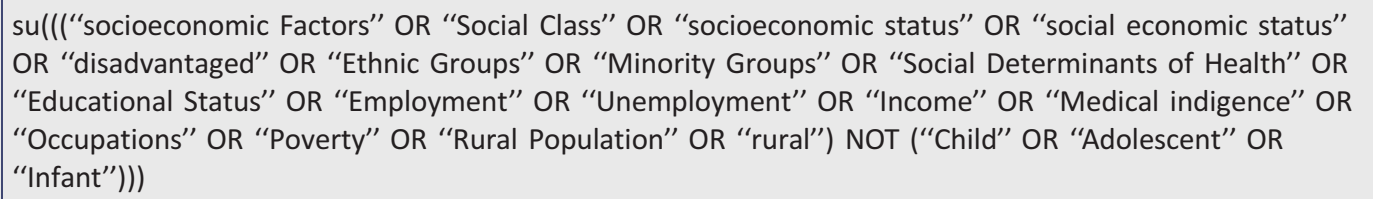 \\
\hline$\# 2$ & $\begin{array}{l}\text { su((("Health Literacy" OR "health literacy" OR "numerary" OR "public health literacy" OR "health } \\
\text { competences" OR "health information" OR "Access to Information" OR "Comprehension" OR "access* } \\
\text { health information" OR "evaluating health information" OR "applying health information" OR "health } \\
\text { information processing" OR "health information application" OR "health information use" OR } \\
\text { "information need" OR "information seeking" OR "Information Seeking Behavior" OR "Consumer Health } \\
\text { Information" OR "Health Communication" OR "health message"” OR "Computer Literacy" OR } \\
\text { "Information Literacy" OR "educational material" OR "Teaching Materials" OR "healthcare information" } \\
\text { OR "Pamphlets" OR "plain language" OR "Health Education" OR "Patient education" OR "Health Fairs" } \\
\text { OR "Early Medical Intervention" OR "Health Promotion" OR "Sanitation") NOT "Literacy")) }\end{array}$ \\
\hline \#3 & 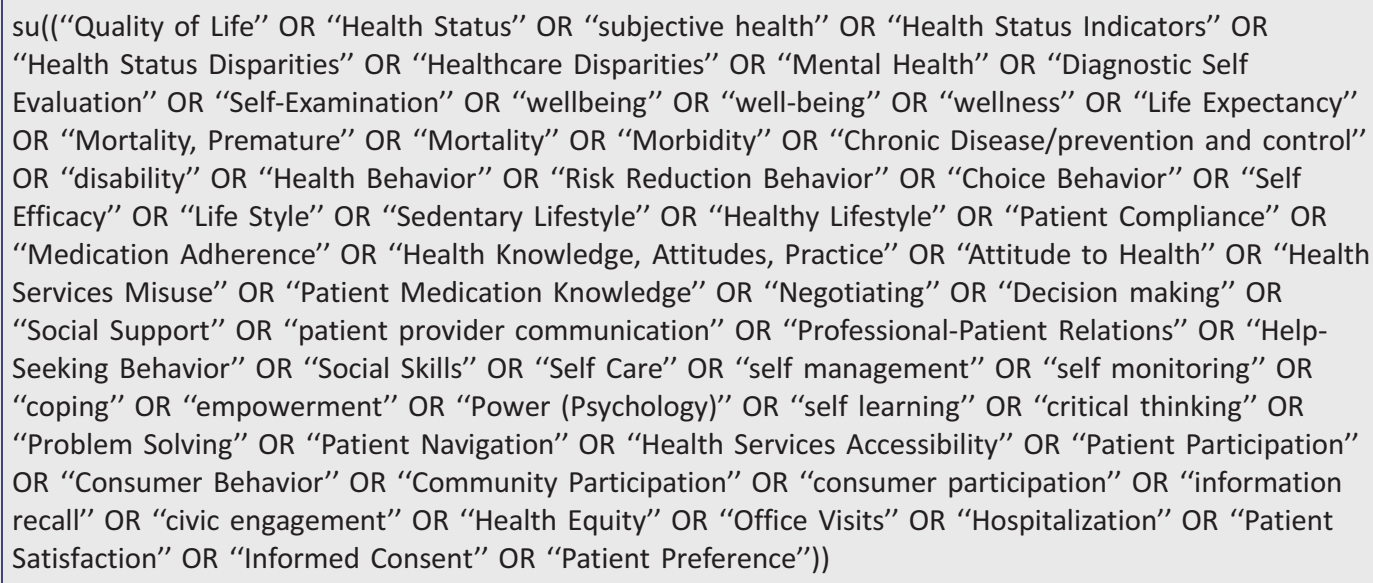 \\
\hline$\# 4$ & $\# 1$ AND \#2 AND \#3 \\
\hline
\end{tabular}




\section{Scopus (search performed on May 22, 2018)}

\begin{tabular}{|c|c|}
\hline Search & Query \\
\hline$\# 1$ & $\begin{array}{l}\text { ((TITLE-ABS(“Socioeconomic Factors") OR TITLE-ABS(“Social Class") OR TITLE-ABS(“socioeconomic status") } \\
\text { OR TITLE-ABS(“socio economic status") OR TITLE-ABS(disadvantaged) OR TITLE-ABS(“Ethnic Groups") OR } \\
\text { TITLE-ABS(“Minority Groups") OR TITLE-ABS(“Social Determinants of Health") OR TITLE-ABS(“Educational } \\
\text { Status") OR TITLE-ABS(“Employment") OR TITLE-ABS(“Unemployment") OR TITLE-ABS(“Income") OR } \\
\text { TITLE-ABS(“Medical Indigency") OR TITLE-ABS(“Occupations") OR TITLE-ABS(“Poverty") OR TITLE-ABS } \\
\text { (“Rural Population") OR TITLE-ABS(rural)) AND NOT (TITLE-ABS(child) OR TITLE-ABS(adolescent) OR TITLE- } \\
\text { ABS(infant))) }\end{array}$ \\
\hline$\# 2$ & 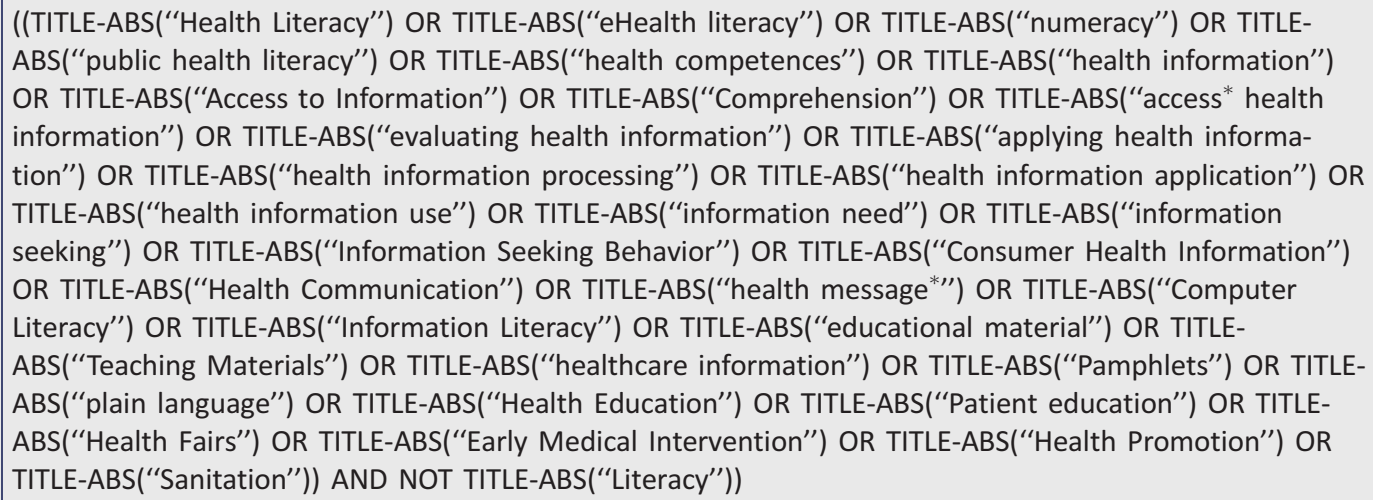 \\
\hline$\# 3$ & 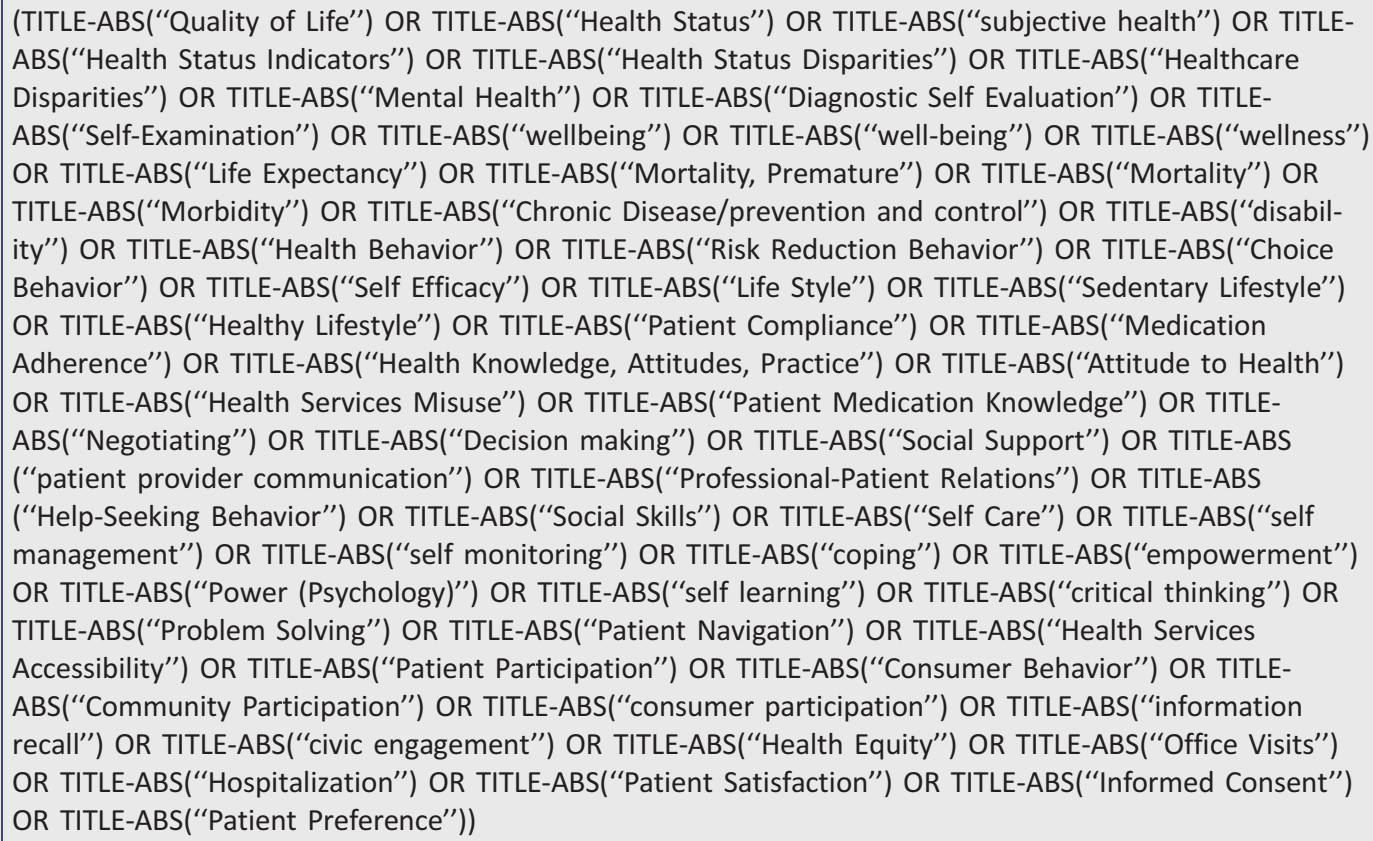 \\
\hline$\# 4$ & $\# 1$ AND \#2 AND \#3 \\
\hline
\end{tabular}




\section{ClinicalTrials.gov (search performed on May 22, 2018)}

\begin{tabular}{|l|l|}
\hline Search & Query \\
\hline$\# 1$ & (“health literacy" OR “health education" OR “health promotion" OR "health information") \\
\hline$\# 2$ & $\begin{array}{l}\text { ("Socioeconomic Factors" OR “Social Class" OR “socioeconomic status" OR “disadvantaged" OR "Ethnic } \\
\text { Groups" OR “Minority Groups") }\end{array}$ \\
\hline$\# 3$ & $\# 1$ AND \#2 \\
\hline & Limit: Trial completed \\
\hline
\end{tabular}

\section{EU Clinical Trial Register (search performed on May 22, 2018)}

\begin{tabular}{|c|c|}
\hline Search & Query \\
\hline$\# 1$ & 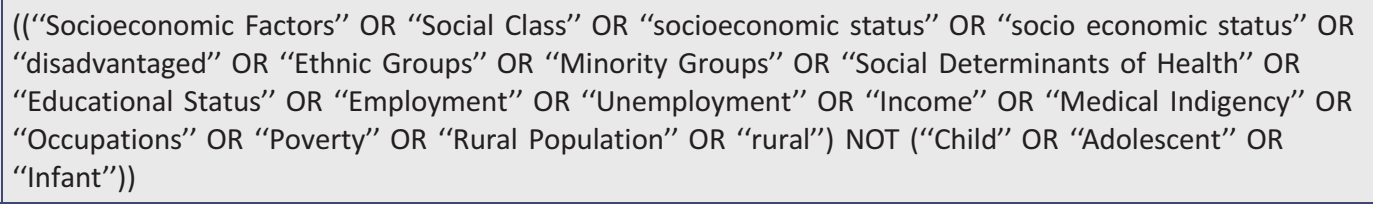 \\
\hline$\# 2$ & $\begin{array}{l}\text { (("Health Literacy" OR "eHealth literacy" OR "numeracy" OR "public health literacy" OR "health } \\
\text { competences" OR "health information" OR "Access to Information" OR "Comprehension" OR "access* } \\
\text { health information" OR "evaluating health information" OR "applying health information" OR "health } \\
\text { information processing" OR "health information application" OR "health information use" OR } \\
\text { "information need" OR "information seeking" OR "Information Seeking Behavior" OR "Consumer Health } \\
\text { Information" OR "Health Communication" OR "health message"” OR "Computer Literacy" OR } \\
\text { "Information Literacy" OR "educational material" OR "Teaching Materials" OR "healthcare information" } \\
\text { OR "Pamphlets" OR "plain language" OR "Health Education" OR "Patient education" OR "Health Fairs" } \\
\text { OR "Early Medical Intervention" OR "Health Promotion" OR "Sanitation") NOT "Literacy") }\end{array}$ \\
\hline$\# 3$ & 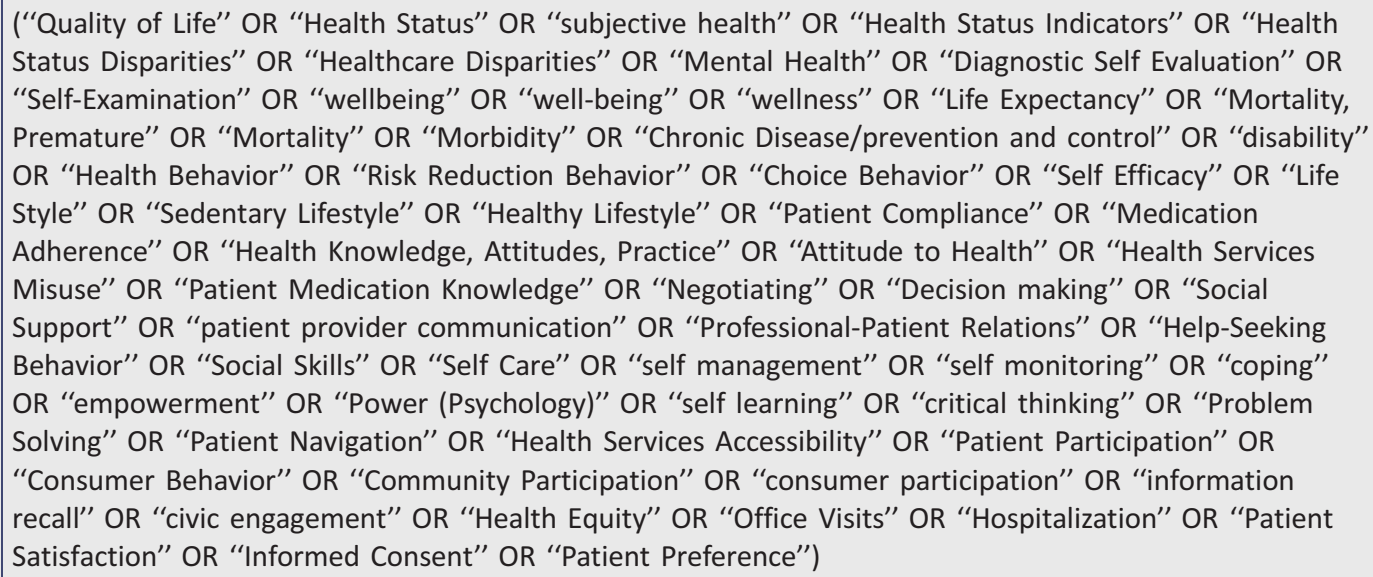 \\
\hline$\# 4$ & $\# 1$ AND \#2 AND \#3 \\
\hline
\end{tabular}




\section{Current Controlled Trials (CCT) (search performed on May 22, 2018)}

\begin{tabular}{|c|c|}
\hline Search & Query \\
\hline$\# 1$ & $\begin{array}{l}\text { ("Socioeconomic Factors" OR "Social Class" OR "socioeconomic status" OR "socio economic status" OR } \\
\text { "disadvantaged" OR "Ethnic Groups" OR "Minority Groups" OR "Social Determinants of Health" OR } \\
\text { "Educational Status" OR "Employment" OR "Unemployment" OR "Income" OR "Medical Indigency" OR } \\
\text { "Occupations" OR "Poverty" OR "Rural Population" OR "rural”) }\end{array}$ \\
\hline \#2 & $\begin{array}{l}\text { ("Health Literacy" OR "eHealth literacy" OR "numeracy" OR "public health literacy" OR "health } \\
\text { competences" OR "health information" OR "Access to Information" OR "Comprehension" OR "access* } \\
\text { health information" OR "evaluating health information" OR "applying health information" OR "health } \\
\text { information processing" OR "health information application" OR "health information use" OR } \\
\text { "information need" OR "information seeking" OR "Information Seeking Behavior" OR "Consumer Health } \\
\text { Information" OR "Health Communication" OR "health message"” OR "Computer Literacy" OR } \\
\text { "Information Literacy" OR "educational material" OR "Teaching Materials" OR "healthcare information" } \\
\text { OR "Pamphlets" OR "plain language" OR "Health Education" OR "Patient education" OR "Health Fairs" } \\
\text { OR "Early Medical Intervention" OR "Health Promotion" OR "Sanitation") }\end{array}$ \\
\hline \#3 & 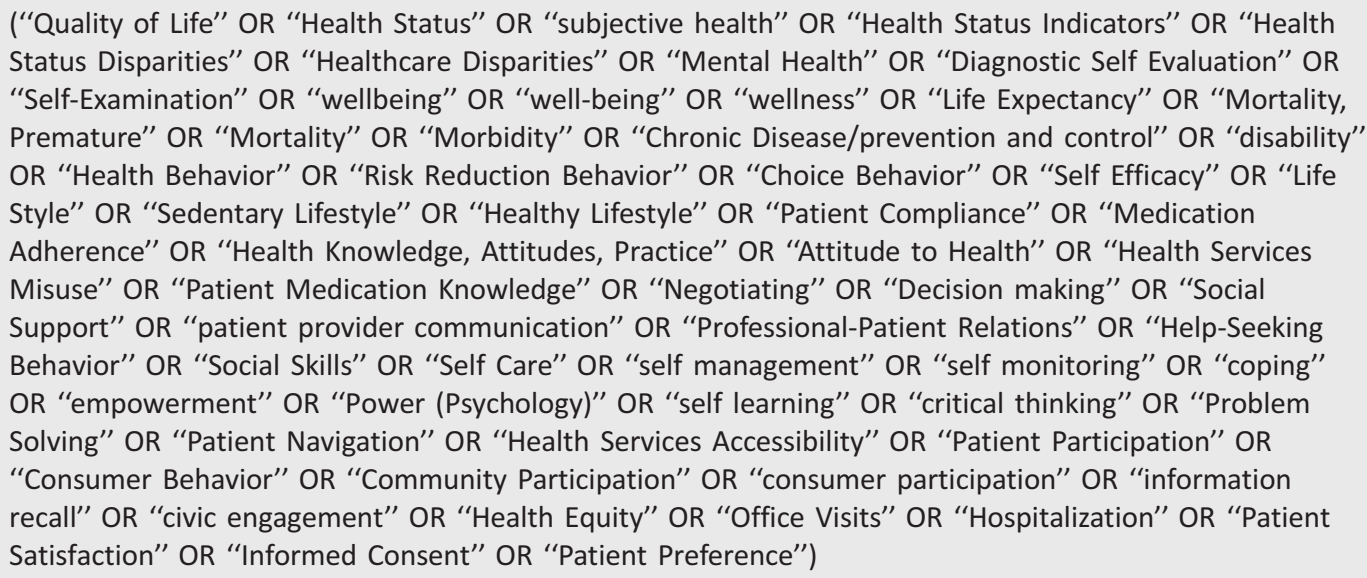 \\
\hline \multirow[t]{2}{*}{$\# 4$} & $\# 1$ AND \#2 AND \#3 \\
\hline & Limit: Trial completed \\
\hline
\end{tabular}




\section{UK Clinical Trials Gateway (search performed on May 22, 2018)}

\begin{tabular}{|l|l|}
\hline Search & Query \\
\hline$\# 1$ & $\begin{array}{l}\text { "Health Literacy" OR "eHealth literacy" OR "numeracy" OR "public health literacy" OR "health } \\
\text { competences" OR "health information" OR "Access to Information" OR "Comprehension" OR "access* } \\
\text { health information" OR "evaluating health information" OR "applying health information" OR "health } \\
\text { information processing" OR "health information application" OR "health information use" OR } \\
\text { "information need" OR "information seeking" OR "Information Seeking Behavior" OR "Consumer Health } \\
\text { Information" OR "Health Communication" OR "health message*" OR "Computer Literacy" OR } \\
\text { "Information Literacy" OR "educational material" OR "Teaching Materials" OR "healthcare information" } \\
\text { OR "Pamphlets" OR "plain language" OR "Health Education" OR "Patient education" OR "Health Fairs" } \\
\text { OR "Early Medical Intervention" OR "Health Promotion" OR "Sanitation" }\end{array}$ \\
\hline Limit: Trial completed
\end{tabular}

\section{DART-Europe E-theses portal (search performed on May 22, 2018)}

\begin{tabular}{|l|l|}
\hline Search & Query \\
\hline$\# 1$ & $\begin{array}{l}\text { ("health literacy" OR "health information" OR "information need" OR "information seeking" OR "health } \\
\text { communication" OR "health education" OR "patient education" OR "health promotion") AND } \\
\text { ("socioeconomic factors" OR "disadvantaged" OR "socioeconomic" OR "rural") }\end{array}$ \\
\hline
\end{tabular}

DOAJ, Google, Google Scholar, MedNar, Worldcat (search performed on May 22, 2018)

\begin{tabular}{|c|c|}
\hline Search & Query \\
\hline$\# 1$ & $\begin{array}{l}\text { ("Socioeconomic Factors" OR "socioeconomic status" OR "socio economic status" OR "disadvantaged" } \\
\text { OR "Ethnic Groups" OR "Minority Groups" OR "Educational Status" OR “Employment" OR "Unemploy- } \\
\text { ment" OR "Income" OR “Occupations" OR "Poverty" OR "Rural Population" OR "rural") AND ("Health } \\
\text { Literacy" OR "health competences" OR "health information" OR "health message" OR "information } \\
\text { need" OR "information seeking" OR "health communication") }\end{array}$ \\
\hline
\end{tabular}




\section{Appendix II: Studies excluded on methodological quality}

\section{Randomized controlled trials}

Agurs-Collins TD, Kumanyika SK, Ten Have TR, Adams-Campbell LL. A randomized controlled trial of weight reduction and exercise for diabetes management in older African-American subjects. Diabetes Care. 1997;20(10):1503-11.

Reason for exclusion: 5 criteria on the critical appraisal checklist for randomized controlled trials not met, leading to a risk of selection, performance, attrition and detection bias that seriously weakened confidence in the results.

Au LE, Whaley SE, Gurzo K, Meza M, Rosen NJ, Ritchie LD. Evaluation of online and in-person nutrition education related to salt knowledge and behaviors among special supplemental nutrition program for women, infants, and children participants. J Acad Nutr Diet. 2017;117(9):1384-95.

Reason for exclusion: 8 criteria on the critical appraisal checklist for randomized controlled trials not met, leading to a risk of selection, performance, attrition and detection bias that seriously weakened confidence in the results.

Auslander W, Haire-Joshu D, Houston C, Rhee C-W, Williams JH. A controlled evaluation of staging dietary patterns to reduce the risk of diabetes in African-American women. Diabetes Care. 2002;25(5):809-14.

Reason for exclusion: 4 criteria on the critical appraisal checklist for randomized controlled trials not met, leading to a risk of selection, performance and detection bias that seriously weakened confidence in the results.

Ayala GX, Baquero B, Laraia BA, Ji M, Linnan L. Efficacy of a store-based environmental change intervention compared with a delayed treatment control condition on store customers' intake of fruits and vegetables. Public Health Nutr. 2013;16(11):1953-60.

Reason for exclusion: 7 criteria on the critical appraisal checklist for randomized controlled trials not met, leading to a risk of selection, performance, attrition and detection bias that seriously weakened confidence in the results.

Balcazar HG, Byrd TL, Ortiz M, Tondapu SR, Chavez M. A randomized community intervention to improve hypertension control among Mexican Americans: using the promotoras de salud community outreach model. J Health Care Poor Underserved. 2009;20(4):1079-94.

Reason for exclusion: 4 criteria on the critical appraisal checklist for randomized controlled trials not met, leading to a risk of selection, performance and detection bias that seriously weakened confidence in the results.

Barton JL, Trupin L, Schillinger D, Evans-Young G, Imboden J, Montori VM, et al. Use of low-literacy decision aid to enhance knowledge and reduce decisional conflict among a diverse population of adults with rheumatoid arthritis: results of a pilot study. Arthritis Care Res. 2016;68(7):889-98.

Reason for exclusion: 5 criteria on the critical appraisal checklist for randomized controlled trials not met, leading to a risk of selection, performance and detection bias that seriously weakened confidence in the results.

Braich PS, Almeida DR, Hollands S, Coleman MT. Effects of pictograms in educating 3 distinct low-literacy populations on the use of postoperative cataract medication. Can J Ophthalmol. 2011;46(3):276-81.

Reason for exclusion: 7 criteria on the critical appraisal checklist for randomized controlled trials not met, leading to a risk of selection, performance, attrition and detection bias that seriously weakened confidence in the results. 
Buller DB, Woodall WG, Zimmerman DE, Slater MD, Heimendinger J, Waters E, et al. Randomized trial on the 5 a day, the Rio Grande Way Website, a web-based program to improve fruit and vegetable consumption in rural communities. J Health Commun. 2008;13(3):230-49.

Reason for exclusion: 7 criteria on the critical appraisal checklist for randomized controlled trials not met, leading to a risk of selection, performance, attrition and detection bias that seriously weakened confidence in the results.

Campbell MK, Honess-Morreale L, Farrell D, Carbone E, Brasure M. A tailored multimedia nutrition education pilot program for low-income women receiving food assistance. Health Educ Res. 1999;14(2):257-67.

Reason for exclusion: 7 criteria on the critical appraisal checklist for randomized controlled trials not met, leading to a risk of selection, performance, attrition and detection bias that seriously weakened confidence in the results.

Campbell MK, James A, Hudson MA, Carr C, Jackson E, Oakes V, et al. Improving multiple behaviors for colorectal cancer prevention among African American church members. Health Psychol. 2004;23(5): 492-502.

Reason for exclusion: 5 criteria on the critical appraisal checklist for randomized controlled trials not met, leading to a risk of selection, performance and detection bias that seriously weakened confidence in the results.

Champion VL, Springston JK, Zollinger TW, Saywell RM, Monahan PO, Zhao Q, et al. Comparison of three interventions to increase mammography screening in low income African American women. Cancer Detect Prev. 2006;30(6):535-44.

Reason for exclusion: 4 criteria on the critical appraisal checklist for randomized controlled trials not met, leading to a risk of selection, performance, attrition and detection bias that seriously weakened confidence in the results.

Consedine NS, Horton D, Magai C, Kukafka R. Breast screening in response to gain, loss, and empowerment framed messages among diverse, low-income women. J Health Care Poor Underserved. 2007;18(3):550-66.

Reason for exclusion: 5 criteria on the critical appraisal checklist for randomized controlled trials not met, leading to a risk of selection, performance and detection bias that seriously weakened confidence in the results.

Cordasco KM, Asch SM, Bell DS, Guterman JJ, Gross-Schulman S, Ramer L, et al. A low-literacy medication education tool for safety-net hospital patients. Am J Prev Med. 2009;37(6):S209-16.

Reason for exclusion: 6 criteria on the critical appraisal checklist for randomized controlled trials not met, leading to a risk of selection, performance and detection bias that seriously weakened confidence in the results.

Davis TC, Berkel HJ, Arnold CL, Nandy I, Jackson RH, Murphy PW. Intervention to increase mammography utilization in a public hospital. J Gen Intern Med. 13(4):230-3.

Reason for exclusion: 4 criteria on the critical appraisal checklist for randomized controlled trials not met, leading to a risk of selection, performance and detection bias that seriously weakened confidence in the results.

Deavenport A, Modeste N, Marshak HH, Neish C. Closing the gap in mammogram screening: an experimental intervention among low-income Hispanic women in community health clinics. Health Educ Behav. 2011;38(5):452-61. 
Reason for exclusion: 5 criteria on the critical appraisal checklist for randomized controlled trials not met, leading to a risk of selection, performance and detection bias that seriously weakened confidence in the results.

Deren S, Davis WR, Beardsley M, Tortu S, Clatts M. Outcomes of a risk-reduction intervention with highrisk populations: the Harlem AIDS project. AIDS Educ Prev. 1995; 7(5):379-90.

Reason for exclusion: 4 criteria on the critical appraisal checklist for randomized controlled trials not met, leading to a risk of selection, performance and detection bias that seriously weakened confidence in the results.

DeWalt DA, Malone RM, Bryant ME, Kosnar MC, Corr KE, Rothman RL, et al. A heart failure selfmanagement program for patients of all literacy levels: a randomized, controlled trial [ISRCTN11535170]. BMC Health Serv Res. 2006;6:30.

Reason for exclusion: 6 criteria on the critical appraisal checklist for randomized controlled trials not met, leading to a risk of selection, performance, attrition and detection bias that seriously weakened confidence in the results.

Dollahite JS, Pijai EI, Scott-Pierce M, Parker C, Trochim W. A randomized controlled trial of a communitybased nutrition education program for low-income parents. J Nutr Educ Behav. 2014;46(2):102-9.

Reason for exclusion: 5 criteria on the critical appraisal checklist for randomized controlled trials not met, leading to a risk of selection, performance, attrition and detection bias that seriously weakened confidence in the results.

Eakin EG, Bull SS, Riley KM, Reeves MM, McLaughlin P, Gutierrez S. Resources for health: a primary-carebased diet and physical activity intervention targeting urban Latinos with multiple chronic conditions. Health Psychol. 2007;26(4):392-400.

Reason for exclusion: 4 criteria on the critical appraisal checklist for randomized controlled trials not met, leading to a risk of selection, performance and detection bias that seriously weakened confidence in the results.

Elder JP, Ayala GX, Slymen DJ, Arredondo EM, Campbell NR. Evaluating psychosocial and behavioral mechanisms of change in a tailored communication intervention. Health Educ Behav. 2009;36(2):366-80.

Reason for exclusion: 6 criteria on the critical appraisal checklist for randomized controlled trials not met, leading to a risk of selection, performance, attrition and detection bias that seriously weakened confidence in the results.

Elder JP, Candelaria J, Woodruff SI, Golbeck AL, Criqui MH, Talavera GA, et al. Initial results of 'Language for Health': cardiovascular disease nutrition education for English-as-a-second-language students. Health Educ Res. 1998;13(4):567-75.

Reason for exclusion: 5 criteria on the critical appraisal checklist for randomized controlled trials not met, leading to a risk of selection, performance and detection bias that seriously weakened confidence in the results.

Elder JP, Candelaria JI, Woodruff SI, Criqui MH, Talavera GA, Rupp JW. Results of language for health: cardiovascular disease nutrition education for Latino English-as-a-second-language students. Health Educ Behav. 2000;27(1):50-63.

Reason for exclusion: 5 criteria on the critical appraisal checklist for randomized controlled trials not met, leading to a risk of selection, performance and detection bias that seriously weakened confidence in the results. 
Ell K, Vourlekis B, Lee P-J, Xie B. Patient navigation and case management following an abnormal mammogram: a randomized clinical trial. Prev Med. 2007;44(1):26-33.

Reason for exclusion: 4 criteria on the critical appraisal checklist for randomized controlled trials not met, leading to a risk of selection, performance and detection bias that seriously weakened confidence in the results.

Friedman LC, Everett TE, Peterson L, Ogbonnaya KI, Mendizabal V. Compliance with fecal occult blood test screening among low-income medical outpatients: a randomized controlled trial using a videotaped intervention. J Cancer Educ. 2001;16(2):85-8.

Reason for exclusion: 10 criteria on the critical appraisal checklist for randomized controlled trials not met, leading to a risk of selection, performance, attrition and detection bias that seriously weakened confidence in the results.

Gans KM, Risica PM, Strolla LO, Fournier L, Kirtania U, Upegui D, et al. Effectiveness of different methods for delivering tailored nutrition education to low income, ethnically diverse adults. Int J Behav Nutr Phys Act. 2009;6:24.

Reason for exclusion: 4 criteria on the critical appraisal checklist for randomized controlled trials not met, leading to a risk of selection and performance bias that seriously weakened confidence in the results.

Gathirua-Mwangi WG, Monahan PO, Stump T, Rawl SM, Skinner CS, Champion VL. Mammography adherence in African-American women: results of a randomized controlled trial. Ann Behav Med. 2016;50(1):70-8.

Reason for exclusion: 4 criteria on the critical appraisal checklist for randomized controlled trials not met, leading to a risk of performance, attrition and detection bias that seriously weakened confidence in the results.

Gerber BS, Brodsky IG, Lawless KA, Smolin LI, Arozullah AM, Smith EV, et al. Implementation and evaluation of a low-literacy diabetes education computer multimedia application. Diabetes Care. 2005;28(7):1574-80.

Reason for exclusion: 4 criteria on the critical appraisal checklist for randomized controlled trials not met, leading to a risk of selection, performance, attrition and detection bias that seriously weakened confidence in the results.

Greenlee H, Gaffney AO, Aycinena AC, Koch P, Contento I, Karmally W, et al. iCocinar para su salud!: randomized controlled trial of a culturally based dietary intervention among Hispanic breast cancer survivors. J Acad Nutr Diet. 2015;115(5):709-23.e3.

Reason for exclusion: 4 criteria on the critical appraisal checklist for randomized controlled trials not met, leading to a risk of selection, performance, attrition and detection bias that seriously weakened confidence in the results.

Grindel CG, Brown L, Caplan L, Blumenthal D. The effect of breast cancer screening messages on knowledge, attitudes, perceived risk, and mammography screening of African American women in the rural South. Oncol Nurs Forum. 2004;31(4):801-8.

Reason for exclusion: 6 criteria on the critical appraisal checklist for randomized controlled trials not met, leading to a risk of selection, performance, attrition and detection bias that seriously weakened confidence in the results.

Han H-R, Kim J, Kim KB, Jeong S, Levine D, Li C, et al. Implementation and success of nurse telephone counseling in linguistically isolated Korean American patients with high blood pressure. Patient Educ Couns. 2010;80(1):130-4. 
Reason for exclusion: 5 criteria on the critical appraisal checklist for randomized controlled trials not met, leading to a risk of selection, performance and detection bias that seriously weakened confidence in the results.

Havas S, Anliker J, Greenberg D, Block G, Block T, Blik C, et al. Final results of the Maryland WIC food for life program. Prev Med. 2003;37(5):406-16.

Reason for exclusion: 5 criteria on the critical appraisal checklist for randomized controlled trials not met, leading to a risk of selection, performance, attrition and detection bias that seriously weakened confidence in the results.

Hayashi T, Farrell MA, Chaput LA, Rocha DA, Hernandez M. Lifestyle intervention, behavioral changes, and improvement in cardiovascular risk profiles in the California WISEWOMAN project. J Womens Health. 2010;19(6):1129-38.

Reason for exclusion: 4 criteria on the critical appraisal checklist for randomized controlled trials not met, leading to a risk of performance, attrition and detection bias that seriously weakened confidence in the results.

Hill-Briggs F, Lazo M, Peyrot M, Doswell A, Chang Y-T, Hill MN, et al. Effect of problem-solving-based diabetes self-management training on diabetes control in a low income patient sample. J Gen Intern Med. 2011;26(9):972-8.

Reason for exclusion: 5 criteria on the critical appraisal checklist for randomized controlled trials not met, leading to a risk of selection, performance and detection bias that seriously weakened confidence in the results.

Holstad MM, DiIorio C, Kelley ME, Resnicow K, Sharma S. Group motivational interviewing to promote adherence to antiretroviral medications and risk reduction behaviors in HIV infected women. AIDS Behav. 2011;15(5):885-96.

Reason for exclusion: 5 criteria on the critical appraisal checklist for randomized controlled trials not met, leading to a risk of selection, performance, attrition and detection bias that seriously weakened confidence in the results.

Howard-Pitney B, Winkleby MA, Albright C, Bruce B, Fortmann SP. The Stanford Nutrition Action Program: a dietary fat intervention for low-literacy adults. Am J Public Health. 1997;87(12):1971-6.

Reason for exclusion: 6 criteria on the critical appraisal checklist for randomized controlled trials not met, leading to a risk of selection, performance and detection bias that seriously weakened confidence in the results.

Hyman DJ, Ho KS, Dunn JK, Simons-Morton D. Dietary intervention for cholesterol reduction in public clinic patients. Am J Prev Med. 1998;15(2):139-45.

Reason for exclusion: 4 criteria on the critical appraisal checklist for randomized controlled trials not met, leading to a risk of selection, performance and detection bias that seriously weakened confidence in the results.

Jacobs AD, Ammerman AS, Ennett ST, Campbell MK, Tawney KW, Aytur SA, et al. Effects of a tailored follow-up intervention on health behaviors, beliefs, and attitudes. J Womens Health. 2004;13(5):557-68.

Reason for exclusion:. 6 criteria on the critical appraisal checklist for randomized controlled trials not met, leading to a risk of selection, performance and detection bias that seriously weakened confidence in the results. 
Jacobson TA, Thomas DM, Morton FJ, Offutt G, Shevlin J, Ray S. Use of a low-literacy patient education tool to enhance pneumococcal vaccination rates: a randomized controlled trial. JAMA. 1999;282(7): 646-50.

Reason for exclusion: 5 criteria on the critical appraisal checklist for randomized controlled trials not met, leading to a risk of selection, performance and detection bias that seriously weakened confidence in the results.

Jandorf L, Cooperman JL, Stossel LM, Itzkowitz S, Thompson HS, Villagra C, et al. Implementation of culturally targeted patient navigation system for screening colonoscopy in a direct referral system. Health Educ Res. 2013;28(5):803-15.

Reason for exclusion: 4 criteria on the critical appraisal checklist for randomized controlled trials not met, leading to a risk of performance, attrition and detection bias that seriously weakened confidence in the results.

Jandorf L, Gutierrez Y, Lopez J, Christie J, Itzkowitz SH. Use of a patient navigator to increase colorectal cancer screening in an urban neighborhood health clinic. J Urban Health. 2005;82(2):216-24.

Reason for exclusion: 4 criteria on the critical appraisal checklist for randomized controlled trials not met, leading to a risk of selection, performance and detection bias that seriously weakened confidence in the results.

Jason LA, Tait E, Goodman D, Buckenberger L, Gruder CL. Effects of a televised smoking cessation intervention among low-income and minority smokers. Am J Community Psychol. 1988;16(6):863-76.

Reason for exclusion: 7 criteria on the critical appraisal checklist for randomized controlled trials not met, leading to a risk of selection, performance, attrition and detection bias that seriously weakened confidence in the results.

Jiamjariyapon T, Ingsathit A, Pongpirul K, Vipattawat K, Kanchanakorn S, Saetie A, et al. Effectiveness of integrated care on delaying progression of stage 3-4 chronic kidney disease in rural communities of Thailand (ESCORT study): a cluster randomized controlled trial. BMC Nephrol. 2017;18(1):83.

Reason for exclusion: 7 criteria on the critical appraisal checklist for randomized controlled trials not met, leading to a risk of selection, performance and detection bias that seriously weakened confidence in the results.

Jibaja ML, Kingery P, Neff NE, Smith Q, Bowman J, Holcomb JD. Tailored, interactive soap operas for breast cancer education of high-risk Hispanic women. J Cancer Educ. 2000;15(4):237-42.

Reason for exclusion: 5 criteria on the critical appraisal checklist for randomized controlled trials not met, leading to a risk of selection, performance and detection bias that seriously weakened confidence in the results.

Juon H-S, Lee S, Strong C, Rimal R, Kirk GD, Bowie J. Effect of a liver cancer education program on hepatitis B screening among Asian Americans in the Baltimore-Washington metropolitan area, 2009-2010. Prev Chronic Dis. 2014;11:130258.

Reason for exclusion: 4 criteria on the critical appraisal checklist for randomized controlled trials not met, leading to a risk of selection, performance and detection bias that seriously weakened confidence in the results.

Kandula NR, Dave S, De Chavez PJ, Bharucha H, Patel Y, Seguil P, et al. Translating a heart disease lifestyle intervention into the community: the South Asian Heart Lifestyle Intervention (SAHELI) study; a randomized control trial. BMC Public Health. 2015;15:1064. 
Reason for exclusion: 4 criteria on the critical appraisal checklist for randomized controlled trials not met, leading to a risk of selection, performance and detection bias that seriously weakened confidence in the results.

Kangovi S, Mitra N, Grande D, Huo H, Smith RA, Long JA. Community health worker support for disadvantaged patients with multiple chronic diseases: a randomized clinical trial. Am J Public Health. 2017;107(10):1660-7.

Reason for exclusion: 5 criteria on the critical appraisal checklist for randomized controlled trials not met, leading to a risk of selection, performance and detection bias that seriously weakened confidence in the results.

Keyserling TC, Hodge CDS, Jilcott SB, Johnston LF, Garcia BA, Gizlice Z, et al. Randomized trial of a clinicbased, community-supported, lifestyle intervention to improve physical activity and diet: the North Carolina enhanced WISEWOMAN project. Prev Med. 2008;46(6):499-510.

Reason for exclusion: 4 criteria on the critical appraisal checklist for randomized controlled trials not met, leading to a risk of selection, performance and detection bias that seriously weakened confidence in the results.

Khare MM, Carpenter RA, Huber R, Bates NJ, Cursio JF, Balmer PW, et al. Lifestyle intervention and cardiovascular risk reduction in the Illinois WISEWOMAN Program. J Womens Health. 2012;21(3): 294-301.

Reason for exclusion: 4 criteria on the critical appraisal checklist for randomized controlled trials not met, leading to a risk of selection, performance and detection bias that seriously weakened confidence in the results.

Khare MM, Cursio JF, Locklin CA, Bates NJ, Loo RK. Lifestyle intervention and cardiovascular disease risk reduction in low-income Hispanic immigrant women participating in the Illinois WISEWOMAN program. J Community Health. 2014;39(4):737-46.

Reason for exclusion: 4 criteria on the critical appraisal checklist for randomized controlled trials not met, leading to a risk of selection, performance and detection bias that seriously weakened confidence in the results.

Kim KB, Han H-R, Huh B, Nguyen T, Lee H, Kim MT. The effect of a community-based self-help multimodal behavioral intervention in Korean American seniors with high blood pressure. Am J Hypertens. 2014;27(9):1199-208.

Reason for exclusion: 5 criteria on the critical appraisal checklist for randomized controlled trials not met, leading to a risk of selection, performance, attrition and detection bias that seriously weakened confidence in the results.

Kim MT, Kim KB, Huh B, Nguyen T, Han H-R, Bone LR, et al. The effect of a community-based self-help intervention: Korean Americans with type 2 diabetes. Am J Prev Med. 2015;49(5):726-37.

Reason for exclusion: 6 criteria on the critical appraisal checklist for randomized controlled trials not met, leading to a risk of selection, performance, attrition and detection bias that seriously weakened confidence in the results.

Kocken PL, Joosten-van Zwanenburg E, de Hoop T. Effects of health education for migrant females with psychosomatic complaints treated by general practitioners: a randomised controlled evaluation study. Patient Educ Couns. 2008;70(1):25-30. 
Reason for exclusion: 4 criteria on the critical appraisal checklist for randomized controlled trials not met, leading to a risk of performance, attrition and detection bias that seriously weakened confidence in the results.

Kopelowicz A, Zarate R, Smith VG, Mintz J, Liberman RP. Disease management in Latinos with schizophrenia: a family-assisted, skills training approach. Schizophr Bull. 2003;29(2):211-28.

Reason for exclusion: 4 criteria on the critical appraisal checklist for randomized controlled trials not met, leading to a risk of selection, performance and attrition bias that seriously weakened confidence in the results.

Kreuter MW, Holmes K, Alcaraz K, Kalesan B, Rath S, Richert M, et al. Comparing narrative and informational videos to increase mammography in low-income African American women. Patient Educ Couns. 2010;81 Suppl:S6-14.

Reason for exclusion: 4 criteria on the critical appraisal checklist for randomized controlled trials not met, leading to a risk of selection, performance and detection bias that seriously weakened confidence in the results.

Kumanyika SK, Adams-Campbell L, Van Horn B, Ten Have TR, Treu JA, Askov E, et al. Outcomes of a cardiovascular nutrition counseling program in African-Americans with elevated blood pressure or cholesterol level. J Am Diet Assoc. 1999;99(11):1380-91.

Reason for exclusion: 5 criteria on the critical appraisal checklist for randomized controlled trials not met, leading to a risk of selection, performance, attrition and detection bias that seriously weakened confidence in the results.

Kumar MS, Sarma PS, Thankappan KR. Community-based group intervention for tobacco cessation in rural Tamil Nadu, India: a cluster randomized trial. J Subst Abuse Treat. 2012;43(1):53-60.

Reason for exclusion: 6 criteria on the critical appraisal checklist for randomized controlled trials not met, leading to a risk of selection, performance and detection bias that seriously weakened confidence in the results.

Larkey LK, Herman PM, Roe DJ, Garcia F, Lopez AM, Gonzalez J, et al. A cancer screening intervention for underserved Latina women by lay educators. J Womens Health. 2012;21(5):557-66.

Reason for exclusion: 5 criteria on the critical appraisal checklist for randomized controlled trials not met, leading to a risk of performance, attrition and detection bias that seriously weakened confidence in the results.

Lee E, Menon U, Nandy K, Szalacha L, Kviz F, Cho Y, et al. The effect of couples intervention to increase breast cancer screening among Korean Americans. Oncol Nurs Forum. 2014;41(3):E185-93.

Reason for exclusion: 4 criteria on the critical appraisal checklist for randomized controlled trials not met, leading to a risk of selection, performance and detection bias that seriously weakened confidence in the results.

Lipkus IM, Lyna PR, Rimer BK. Using tailored interventions to enhance smoking cessation among AfricanAmericans at a community health center. Nicotine Tob Res. 1999;1(1):77-85.

Reason for exclusion: 8 criteria on the critical appraisal checklist for randomized controlled trials not met, leading to a risk of selection, performance, attrition and detection bias that seriously weakened confidence in the results.

Lu C-H, Tang S-T, Lei Y-X, Zhang M-Q, Lin W-Q, Ding S-H, et al. Community-based interventions in hypertensive patients: a comparison of three health education strategies. BMC Public Health. 2015;15:33. 
Reason for exclusion: 4 criteria on the critical appraisal checklist for randomized controlled trials not met, leading to a risk of performance, attrition and detection bias that seriously weakened confidence in the results.

Miller SM, Hui SA, Wen K-Y, Scarpato J, Zhu F, Buzaglo J, et al. Tailored telephone counseling to improve adherence to follow-up regimens after an abnormal pap smear among minority, underserved women. Patient Educ Couns. 2013;93(3):488-95.

Reason for exclusion: 6 criteria on the critical appraisal checklist for randomized controlled trials not met, leading to a risk of selection, performance, attrition and detection bias that seriously weakened confidence in the results.

Navarro AM, Senn KL, McNicholas LJ, Kaplan RM, Roppé B, Campo MC. Por La Vida model intervention enhances use of cancer screening tests among Latinas. Am J Prev Med. 1998;15(1):32-41.

Reason for exclusion: 5 criteria on the critical appraisal checklist for randomized controlled trials not met, leading to a risk of selection, performance and detection bias that seriously weakened confidence in the results.

Nguyen TT, Le G, Nguyen T, Le K, Lai K, Gildengorin G, et al. Breast cancer screening among Vietnamese Americans: a randomized controlled trial of lay health worker outreach. Am J Prev Med. 2009;37(4): 306-13.

Reason for exclusion: 5 criteria on the critical appraisal checklist for randomized controlled trials not met, leading to a risk of selection, performance, attrition and detection bias that seriously weakened confidence in the results.

Nitzke S, Kritsch K, Boeckner L, Greene G, Hoerr S, Horacek T, et al. A stage-tailored multi-modal intervention increases fruit and vegetable intakes of low-income young adults. Am J Health Promot. 2007;22(1):6-14.

Reason for exclusion: 6 criteria on the critical appraisal checklist for randomized controlled trials not met, leading to a risk of selection, performance and detection bias that seriously weakened confidence in the results.

Nuño T, Martinez ME, Harris R, García F. A promotora-administered group education intervention to promote breast and cervical cancer screening in a rural community along the US-Mexico border: a randomized controlled trial. Cancer Causes Control. 2011;22(3):367-74.

Reason for exclusion: 4 criteria on the critical appraisal checklist for randomized controlled trials not met, leading to a risk of selection, performance, attrition and detection bias that seriously weakened confidence in the results.

Okuyemi KS, James AS, Mayo MS, Nollen N, Catley D, Choi WS, et al. Pathways to health: a cluster randomized trial of nicotine gum and motivational interviewing for smoking cessation in low-income housing. Health Educ Behav. 2007;34(1):43-54.

Reason for exclusion: 5 criteria on the critical appraisal checklist for randomized controlled trials not met, leading to a risk of selection, performance and detection bias that seriously weakened confidence in the results.

Osborn CY, Amico KR, Cruz N, O’Connell AA, Perez-Escamilla R, Kalichman SC, et al. A brief culturally tailored intervention for Puerto Ricans with type 2 diabetes. Health Educ Behav. 2010;37(6):849-62.

Reason for exclusion: 4 criteria on the critical appraisal checklist for randomized controlled trials not met, leading to a risk of selection, performance and attrition bias that seriously weakened confidence in the results. 
Paskett E, Tatum C, Rushing J, Michielutte R, Bell R, Foley KL, et al. Randomized trial of an intervention to improve mammography utilization among a triracial rural population of women. J Natl Cancer Inst. 2006;98(17):1226-37.

Reason for exclusion: 4 criteria on the critical appraisal checklist for randomized controlled trials not met, leading to a risk of selection, performance and detection bias that seriously weakened confidence in the results.

Pekmezi DW, Neighbors CJ, Lee CS, Gans KM, Bock BC, Morrow KM, et al. A culturally adapted physical activity intervention for Latinas: a randomized controlled trial. Am J Prev Med. 2009;37(6):495-500.

Reason for exclusion: 4 criteria on the critical appraisal checklist for randomized controlled trials not met, leading to a risk of selection, performance and detection bias that seriously weakened confidence in the results.

Philis-Tsimikas A, Fortmann A, Lleva-Ocana L, Walker C, Gallo LC. Peer-led diabetes education programs in high-risk Mexican Americans improve glycemic control compared with standard approaches: a Project Dulce promotora randomized trial. Diabetes Care. 2011;34(9):1926-31.

Reason for exclusion: 4 criteria on the critical appraisal checklist for randomized controlled trials not met, leading to a risk of performance, attrition and detection bias that seriously weakened confidence in the results.

Reijneveld SA, Westhoff MH, Hopman-Rock M. Promotion of health and physical activity improves the mental health of elderly immigrants: results of a group randomised controlled trial among Turkish immigrants in the Netherlands aged 45 and over. J Epidemiol Community Health. 2003;57(6):405-11.

Reason for exclusion: 4 criteria on the critical appraisal checklist for randomized controlled trials not met, leading to a risk of selection, performance and detection bias that seriously weakened confidence in the results.

Rosal MC, Ockene IS, Restrepo A, White MJ, Borg A, Olendzki B, et al. Randomized trial of a literacysensitive, culturally tailored diabetes self-management intervention for low-income Latinos: Latinos en control. Diabetes Care. 2011;34(4):838-44.

Reason for exclusion: 4 criteria on the critical appraisal checklist for randomized controlled trials not met, leading to a risk of selection, performance and detection bias that seriously weakened confidence in the results.

Ruggiero L, Riley BB, Hernandez R, Quinn LT, Gerber BS, Castillo A, et al. Medical assistant coaching to support diabetes self-care among low-income racial/ethnic minority populations: randomized controlled trial. West J Nurs Res. 2014;36(9):1052-73.

Reason for exclusion: 4 criteria on the critical appraisal checklist for randomized controlled trials not met, leading to a risk of selection, performance, attrition and detection bias that seriously weakened confidence in the results.

Russell KM, Champion VL, Monahan PO, Millon-Underwood S, Zhao Q, Spacey N, et al. Randomized trial of a lay health advisor and computer intervention to increase mammography screening in African American women. Cancer Epidemiol Prev Biomark. 2010;19(1):201-10.

Reason for exclusion: 5 criteria on the critical appraisal checklist for randomized controlled trials not met, leading to a risk of selection and performance bias that seriously weakened confidence in the results.

Sanderson M, Khabele D, Brown CL, Harbi K, Alexander LR, Coker AL, et al. Results of a health education message intervention on HPV knowledge and receipt of follow-up care among Latinas infected with highrisk human papillomavirus. J Health Care Poor Underserved. 2015;26(4):1440-55. 
Reason for exclusion: 6 criteria on the critical appraisal checklist for randomized controlled trials not met, leading to a risk of selection, performance and detection bias that seriously weakened confidence in the results.

Sattin RW, Williams LB, Dias J, Garvin JT, Marion L, Joshua TV, et al. Community trial of a faith-based lifestyle intervention to prevent diabetes among African-Americans. J Community Health. 2016;41(1): $87-96$.

Reason for exclusion: 4 criteria on the critical appraisal checklist for randomized controlled trials not met, leading to a risk of selection and performance bias that seriously weakened confidence in the results.

Scarinci IC, Moore A, Wynn-Wallace T, Cherrington A, Fouad M, Li Y. A community-based, culturally relevant intervention to promote healthy eating and physical activity among middle-aged African American women in rural Alabama: findings from a group randomized controlled trial. Prev Med. 2014;69:13-20.

Reason for exclusion: 5 criteria on the critical appraisal checklist for randomized controlled trials not met, leading to a risk of selection, performance and detection bias that seriously weakened confidence in the results.

Schillinger D, Handley M, Wang F, Hammer H. Effects of self-management support on structure, process and outcomes among vulnerable patients with diabetes: A 3-arm practical clinical Trial. Diabetes Care. 2009;32(4):559-66.

Reason for exclusion: 5 criteria on the critical appraisal checklist for randomized controlled trials not met, leading to a risk of selection, performance, attrition and detection bias that seriously weakened confidence in the results.

Skelly AH, Carlson J, Leeman J, Soward A, Burns D. Controlled trial of nursing interventions to improve health outcomes of older African American women with type 2 diabetes. Nurs Res. 2009;58(6):410-8.

Reason for exclusion: 5 criteria on the critical appraisal checklist for randomized controlled trials not met, leading to a risk of selection, performance and attrition bias that seriously weakened confidence in the results.

Smith SK, Trevena L, Simpson JM, Barratt A, Nutbeam D, McCaffery KJ. A decision aid to support informed choices about bowel cancer screening among adults with low education: randomised controlled trial. BMJ. 2010;341:c5370.

Reason for exclusion: 4 criteria on the critical appraisal checklist for randomized controlled trials not met, leading to a risk of performance and detection bias that seriously weakened confidence in the results.

Spencer MS, Rosland A-M, Kieffer EC, Sinco BR, Valerio M, Palmisano G, et al. Effectiveness of a community health worker intervention among African American and Latino adults with type 2 diabetes: a randomized controlled trial. Am J Public Health. 2011;101(12):2253-60.

Reason for exclusion: 6 criteria on the critical appraisal checklist for randomized controlled trials not met, leading to a risk of selection, performance and detection bias that seriously weakened confidence in the results.

St. Lawrence JS, Wilson TE, Eldridge GD, Brasfield TL, O’Bannon III RE. Community-based interventions to reduce low income, African American women's risk of sexually transmitted diseases: a randomized controlled trial of three theoretical models. Am J Community Psychol. 2001;29(6):937-64.

Reason for exclusion: 8 criteria on the critical appraisal checklist for randomized controlled trials not met, leading to a risk of selection, performance, attrition and detection bias that seriously weakened confidence in the results. 
Stockwell MS, Catallozzi M, Larson E, Rodriguez C, Subramony A, Martinez RA, et al. Effect of a URIrelated educational intervention in early head start on ED visits. Pediatrics. 2014;133(5):e1233-40.

Reason for exclusion: 7 criteria on the critical appraisal checklist for randomized controlled trials not met, leading to a risk of selection, performance and detection bias that seriously weakened confidence in the results.

The National Institute of Mental Health (NIMH) Multisite HIV Prevention Trial Group. The NIMH Multisite HIV Prevention Trial: reducing HIV sexual risk behavior. Science. 1998;280(5371)1889-94.

Reason for exclusion: 5 criteria on the critical appraisal checklist for randomized controlled trials not met, leading to a risk of selection, performance and attrition bias that seriously weakened confidence in the results.

Thapinta D, Skulphan S, Kitsumban V, Longchoopol C. Cognitive behavior therapy self-help booklet to decrease depression and alcohol use among people with alcohol dependence in Thailand. Issues Ment Health Nurs. 2017;38(11):964-70.

Reason for exclusion: 4 criteria on the critical appraisal checklist for randomized controlled trials not met, leading to a risk of selection and performance bias that seriously weakened confidence in the results.

Thorn BE, Eyer JC, Van Dyke BP, Torres CA, Burns JW, Smith LJ, et al. Literacy-adapted cognitive behavioral therapy versus education for chronic pain at low-income clinics. Ann Intern Med. 2018;168(7):471-480.

Reason for exclusion: 4 criteria on the critical appraisal checklist for randomized controlled trials not met, leading to a risk of selection, performance and detection bias that seriously weakened confidence in the results.

Tian M, Ajay V, Dunzhu D, Hameed S, Li X, Liu Z, et al. A cluster-randomized controlled trial of a simplified multifaceted management program for individuals at high cardiovascular risk (SimCard Trial) in Rural Tibet, China, and Haryana, India. Circulation. 2015;132(9):815-24.

Reason for exclusion: 7 criteria on the critical appraisal checklist for randomized controlled trials not met, leading to a risk of selection, performance and detection bias that seriously weakened confidence in the results.

Trento M, Passera P, Bajardi M, Tomalino M, Grassi G, Borgo E, et al. Lifestyle intervention by group care prevents deterioration of Type II diabetes: a 4-year randomized controlled clinical trial. Diabetologia. 2002;45(9):1231-9.

Reason for exclusion: 5 criteria on the critical appraisal checklist for randomized controlled trials not met, leading to a risk of selection, performance and detection bias that seriously weakened confidence in the results.

Tuthill EL, Butler LM, Pellowski JA, McGrath JM, Cusson RM, Gable RK, et al. Exclusive breast-feeding promotion among HIV-infected women in South Africa: an Information-Motivation-Behavioural Skills model-based pilot intervention. Public Health Nutr. 2017;20(8):1481-90.

Reason for exclusion: 3 criteria on the critical appraisal checklist for randomized controlled trials not met, leading to a risk of performance, attrition and detection bias that seriously weakened confidence in the results.

Walker EA, Shmukler C, Ullman R, Blanco E, Scollan-Koliopoulus M, Cohen HW. Results of a successful telephonic intervention to improve diabetes control in urban adults: a randomized trial. Diabetes Care. 2011;34(1):2-7. 
Reason for exclusion: 4 criteria on the critical appraisal checklist for randomized controlled trials not met, leading to a risk of selection, performance, attrition and detection bias that seriously weakened confidence in the results.

Wiens L, Chandavimol M, Ignaszewski A. Randomized trial of an individualized coronary risk factor intervention in patients from rural communities undergoing percutaneous coronary revascularization. $\mathrm{J}$ Cardiopulm Rehabil Prev. 2004;24(4):259-63.

Reason for exclusion: 4 criteria on the critical appraisal checklist for randomized controlled trials not met, leading to a risk of selection, performance and attrition bias that seriously weakened confidence in the results.

Willard-Grace R, Chen EH, Hessler D, DeVore D, Prado C, Bodenheimer T, et al. Health coaching by medical assistants to improve control of diabetes, hypertension, and hyperlipidemia in low-income patients: a randomized controlled trial.

Reason for exclusion: 4 criteria on the critical appraisal checklist for randomized controlled trials not met, leading to a risk of selection, performance and detection bias that seriously weakened confidence in the results.

Wu D, Ma GX, Zhou K, Zhou D, Liu A, Poon AN. The effect of a culturally tailored smoking cessation for Chinese American smokers. Nicotine Tob Res. 2009;11(12):1448-57.

Reason for exclusion: 4 criteria on the critical appraisal checklist for randomized controlled trials not met, leading to a risk of selection, performance, attrition and detection bias that seriously weakened confidence in the results.

Yancey AK, McCARTHY WJ, Harrison GG, Wong WK, Siegel JM, Leslie J. Challenges in improving fitness: results of a community-based, randomized, controlled lifestyle change intervention. J Womens Health. $2006 ; 15(4): 412-29$.

Reason for exclusion: 4 criteria on the critical appraisal checklist for randomized controlled trials not met, leading to a risk of selection, performance, attrition and detection bias that seriously weakened confidence in the results.

Yuan X, Tao Y, Zhao JP, Liu XS, Xiong WN, Xie JG, et al. Long-term efficacy of a rural community-based integrated intervention for prevention and management of chronic obstructive pulmonary disease: a cluster randomized controlled trial in China's rural areas. Braz J Med Biol Res. 2015;48(11):1023-31.

Reason for exclusion: 7 criteria on the critical appraisal checklist for randomized controlled trials not met, leading to a risk of selection, performance, attrition and detection bias that seriously weakened confidence in the results.

\section{Quasi-experimental studies}

El-Hadad ARM. Effect of a supportive educational intervention on cervical cancer screening for minority women [dissertation]. Los Angeles: University of California; 1996.

Reason for exclusion: 3 criteria on the critical appraisal checklist for quasi experimental studies not met, leading to a risk of performance and detection bias that seriously weakened confidence in the results.

Erwin DO, Spatz TS, Stotts RC, Hollenberg JA. Increasing mammography practice by African American women. Cancer Pract. 1999;7(2):78-85.

Reason for exclusion: 5 criteria on the critical appraisal checklist for quasi experimental studies not met, leading to a risk of performance, attrition and detection bias that seriously weakened confidence in the results. 
Faller H, Koch GF, Reusch A, Pauli P, Allgayer H. Effectiveness of education for gastric cancer patients: a controlled prospective trial comparing interactive vs. lecture-based programs. Patient Educ Couns. 2009;76(1):91-8.

Reason for exclusion: 3 criteria on the critical appraisal checklist for quasi experimental studies not met, leading to a risk of performance, attrition and detection bias that seriously weakened confidence in the results.

Ferris DG, Condorhuaman WSG, Waller J, Lilienthal A. Impact of a video intervention for rural Peruvian women with cervical neoplasia before loop excisional procedures. J Low Genit Tract Dis. 2015;19(3):224-8.

Reason for exclusion: 5 criteria on the critical appraisal checklist for quasi experimental studies not met, leading to a risk of performance, attrition and detection bias that seriously weakened confidence in the results.

Huang S, Hu X, Chen H, Xie D, Gan X, Wu Y, et al. The positive effect of an intervention program on the hypertension knowledge and lifestyles of rural residents over the age of 35 years in an area of China. Hypertens Res. 2011;34(4):503-8.

Reason for exclusion: 3 criteria on the critical appraisal checklist for quasi experimental studies not met, leading to a risk of attrition bias that seriously weakened confidence in the results.

Jenkins CN, McPhee SJ, Bird JA, Pham GQ, Nguyen BH, Nguyen T, et al. Effect of a media-led education campaign on breast and cervical cancer screening among Vietnamese-American women. Prev Med. 1999;28(4):395-406.

Reason for exclusion: 3 criteria on the critical appraisal checklist for quasi experimental studies not met, leading to a risk of performance, attrition and detection bias that seriously weakened confidence in the results.

Kim KH, Linnan L, Kramish Campbell M, Brooks C, Koenig HG, Wiesen C. The WORD (wholeness, oneness, righteousness, deliverance): a faith-based weight-loss program utilizing a community-based participatory research approach. Health Educ Behav. 2008;35(5):634-50.

Reason for exclusion: 5 criteria on the critical appraisal checklist for quasi experimental studies not met, leading to a risk of selection, performance, attrition and detection bias that seriously weakened confidence in the results.

Kuhns-Hastings J, Brakey MR, Marshall IA. Effectiveness of a comprehensive breast cancer-screening class for women residing in rural areas. Appl Nurs Res. 1993;6(2):71-9.

Reason for exclusion: 3 criteria on the critical appraisal checklist for quasi experimental studies not met, leading to a risk performance, attrition and detection bias that seriously weakened confidence in the results.

Peña-Purcell NC, Boggess MM, Jimenez N. An empowerment-based diabetes self-management education program for Hispanic/Latinos: a quasi-experimental pilot study. Diabetes Educ. 2011;37(6):770-9.

Reason for exclusion: 3 criteria on the critical appraisal checklist for quasi experimental studies not met, leading to a risk of performance and detection bias that seriously weakened confidence in the results.

Ratanawongsa N, Handley MA, Sarkar U, Quan J, Pfeifer K, Soria C, et al. Diabetes health information technology innovation to improve quality of life for health plan members in urban safety net. J Ambulatory Care Manage. 2014;37(2):127-37.

Reason for exclusion: 3 criteria on the critical appraisal checklist for quasi experimental studies not met, leading to a risk of performance and detection bias that seriously weakened confidence in the results. 
Ries AV, Blackman LT, Page RA, Gizlice Z, Benedict S, Barnes K, et al. Goal setting for health behavior change: evidence from an obesity intervention for rural low-income women. Rural Remote Health. 2014;14:2682.

Reason for exclusion: 4 criteria on the critical appraisal checklist for quasi experimental studies not met, leading to a risk of performance, attrition and detection bias that seriously weakened confidence in the results.

Sauaia A, Min S, Byers T, Lack D, Apodaca C, Osuna D, et al. Church-based breast cancer screening education: impact of two approaches on Latinas enrolled in public and private health insurance plans. Prev Chronic Dis. 2007;4(4):A99.

Reason for exclusion: 4 criteria on the critical appraisal checklist for quasi experimental studies not met, leading to a risk of performance and detection bias that seriously weakened confidence in the results.

Tussing-Humphreys L, Thomson J. A church-based, diet and supervised physical activity intervention for rural, southern African American adults improves diet quality, physical activity, and blood lipids (251.6). FASEB J. 2014;28 Suppl:251-6.

Reason for exclusion: 6 criteria on the critical appraisal checklist for quasi experimental studies not met, leading to a risk of selection, performance and detection bias that seriously weakened confidence in the results.

Van Servellen G, Carpio F, Lopez M, Garcia-Teague L, Herrera G, Monterrosa F, et al. Program to enhance health literacy and treatment adherence in low-income HIV-infected Latino men and women. AIDS Patient Care STDS. 2003;17(11):581-94.

Reason for exclusion: 3 criteria on the critical appraisal checklist for quasi experimental studies not met, leading to a risk of performance, attrition and detection bias that seriously weakened confidence in the results.

Van Servellen G, Nyamathi A, Carpio F, Pearce D, Garcia-Teague L, Herrera G, et al. Effects of a treatment adherence enhancement program on health literacy, patient-provider relationships, and adherence to HAART among low-income HIV-positive Spanish-speaking Latinos. AIDS Patient Care STDS. 2005;19(11):745-59.

Reason for exclusion: 3 criteria on the critical appraisal checklist for quasi experimental studies not met, leading to a risk of performance, attrition and detection bias that seriously weakened confidence in the results.

Wang X, Fang C, Tan Y, Liu A, Ma GX. Evidence-based intervention to reduce access barriers to cervical cancer screening among underserved Chinese American women. J Womens Health. 2010;19(3):463-9.

Reason for exclusion: 3 criteria on the critical appraisal checklist for quasi experimental studies not met, leading to a risk of performance and detection bias that seriously weakened confidence in the results. 


\section{Appendix III: Characteristics of included studies}

\section{Randomized controlled trials}

\begin{tabular}{|c|c|c|c|c|c|c|c|c|}
\hline \multirow[b]{2}{*}{ Study } & \multirow[b]{2}{*}{ Country } & \multirow[b]{2}{*}{ Setting/context } & \multicolumn{3}{|l|}{ Participant characteristics } & \multirow[t]{2}{*}{ Intervention } & \multirow[t]{2}{*}{$\begin{array}{l}\text { Outcomes } \\
\text { measured and } \\
\text { follow-up }\end{array}$} & \multirow[t]{2}{*}{$\begin{array}{l}\text { Description of main } \\
\text { results }\end{array}$} \\
\hline & & & & EG & CG & & & \\
\hline \multirow[t]{9}{*}{$\begin{array}{l}\text { Baig et al., } \\
2005^{83}\end{array}$} & \multirow[t]{9}{*}{ USA } & \multirow[t]{9}{*}{$\begin{array}{l}\text { In the commu- } \\
\text { nity } \\
\text { Participants } \\
\text { recruited from } \\
\text { churches }\end{array}$} & $\begin{array}{l}100 \text { low-income Mexican } \\
\text { American adults aged } 18 \\
\text { years or older, English or } \\
\text { Spanish speaking, with a } \\
\text { diagnosis of diabetes }\end{array}$ & & & \multirow{9}{*}{$\begin{array}{l}\text { EG: "Picture Good Health/Imagínate una Buena } \\
\text { Salud": church-based diabetes self-manage- } \\
\text { ment intervention } \\
\text { Aim: to improve diabetes self-management and } \\
\text { diabetes outcomes } \\
\text { Intervention delivered by: trained lay leaders } \\
\text { with diabetes, or with a family member with } \\
\text { diabetes } \\
\text { Eight weekly 90-min group sessions } \\
\text { Sessions included: } 1 \text { ) information about diabe- } \\
\text { tes, nutrition and physical activity; } 2 \text { ) photo- } \\
\text { voice exercises (use of photographs and } \\
\text { storytelling); } 3 \text { ) learning healthy recipes; } 4 \text { ) } \\
\text { assistance from patient navigators in finding a } \\
\text { primary care provider if necessary } \\
\text { CG: enhanced usual care: one } 90-\text {-min diabetes } \\
\text { lecture on diabetes self-management by a } \\
\text { health educator }+ \text { assistance from patient } \\
\text { navigators in finding a primary care provider }+ \\
\text { delayed minimal intervention }\end{array}$} & \multirow{9}{*}{$\begin{array}{l}\text { HbA1c } \\
\text { Direct LDL } \\
\text { Blood pressure } \\
\text { Waist circumfer- } \\
\text { ence } \\
\text { DKQ-24 } \\
\text { DES } \\
\text { Measurements at } \\
\text { baseline, post- } \\
\text { test (3m.) \& } 6 \mathrm{~m} \text {. }\end{array}$} & \multirow{9}{*}{$\begin{array}{l}\text { Post-test: } \\
\text { - No significant differ- } \\
\text { ence between groups in } \\
\text { HbA1c levels, LDL, blood } \\
\text { pressure and waist cir- } \\
\text { cumference } \\
6 \mathrm{~m} \text {. follow-up: } \\
\text { - No significant differ- } \\
\text { ence between groups in } \\
\text { HbA1c levels, LDL, blood } \\
\text { pressure, waist circum- } \\
\text { ference, DES scores and } \\
\text { DKQ-24 scores }\end{array}$} \\
\hline & & & $\mathrm{N}$ & 50 & 50 & & & \\
\hline & & & Mean age in $y$. & 52 & 55 & & & \\
\hline & & & Men (n) & 9 & 10 & & & \\
\hline & & & Women $(n)$ & 41 & 40 & & & \\
\hline & & & Education $\leq 8$ th grade $(\%)$ & 62 & 46 & & & \\
\hline & & & Latino ethnicity (\%) & 96 & 100 & & & \\
\hline & & & Income $<\$ 30,000(\%)$ & 94 & 79 & & & \\
\hline & & & Health insurance (\%) & 46 & 52 & & & \\
\hline \multirow[t]{26}{*}{$\begin{array}{l}\text { Block et al., } \\
2004^{84}\end{array}$} & \multirow[t]{26}{*}{ USA } & \multirow{26}{*}{$\begin{array}{l}\text { In the commu- } \\
\text { nity } \\
\text { Participants } \\
\text { recruited } \\
\text { through flyers } \\
\text { from commu- } \\
\text { nity-based orga- } \\
\text { nizations, pro- } \\
\text { grams providing } \\
\text { services to a } \\
\text { low-income } \\
\text { population, and } \\
\text { other social ser- } \\
\text { vices programs }\end{array}$} & $\begin{array}{l}481 \text { low-income women } \\
\text { aged } 40 \text { to } 65 \text { years old }\end{array}$ & & & \multirow{26}{*}{$\begin{array}{l}\text { EGs: "Little by Little": CD-ROM nutrition } \\
\text { behavior-change program } \\
\text { Aim: to increase fruit and vegetable consump- } \\
\text { tion } \\
\text { Intervention delivered by: computer-based } \\
\text { EG }_{1} \text { : One-time experience with the CD-ROM } \\
\text { nutrition behavior-change program during } 15 \\
\text { to } 20 \text { minutes } \\
\text { Intervention components: } \\
\text { - dietary screening (brief assessment of fruit } \\
\text { and vegetable intake) and immediate } \\
\text { feedback } \\
\text { - flexibility: participants could choose among } \\
\text { different modules, according to their interest. } \\
\text { Modules provided participants with nutritional } \\
\text { messages and tips to increase fruits and } \\
\text { vegetables intake, suggestions for specific situa- } \\
\text { tions (eating out, packing lunch, cooking at } \\
\text { home) and tips for barriers to healthy eating } \\
\text { - goal setting: the program suggested several } \\
\text { goals to work toward } \\
\text { - take-home handouts and educational } \\
\text { materials } \\
-2 \text { reminder phone calls } 2 \text { months after using } \\
\text { the computer program } \\
\text { EG } 2 \text { : same one-time experience with the Little } \\
\text { by Little CD-ROM computer program, but } \\
\text { without reminder phone calls } \\
\text { CG: computer-based stress management CR- } \\
\text { ROM program for } 15 \text { to } 20 \text { minutes }\end{array}$} & \multirow{26}{*}{\begin{tabular}{|l|} 
Fruit and vegeta- \\
ble intake \\
Measurements at \\
baseline \& post- \\
test $(2 \mathrm{~m})$.
\end{tabular}} & \multirow{26}{*}{$\begin{array}{l}\text { Post-test: } \\
\text { - Significantly higher } \\
\text { fruit and vegetable } \\
\text { intake in the } \mathrm{EG}_{1}(\mathrm{MD} \\
\mathrm{EG} 1=1.32 ; \mathrm{MD} \mathrm{CG}= \\
1.20 ; \mathrm{p}=0.016) \text { com- } \\
\text { pared to the } \mathrm{CG} \\
\text { - No significant differ- } \\
\text { ence in fruit and vege- } \\
\text { table intake in the } \mathrm{EG}_{2} \\
\text { compared to the } \mathrm{CG} \\
\text { Subgroups analysis by } \\
\text { educational levels: } \\
\text { - Among participants } \\
\text { with a low educational } \\
\text { attainment (HS or less): } \\
\text { significantly greater } \\
\text { increase in fruits and } \\
\text { vegetables among parti- } \\
\text { cipants from the } \mathrm{EG}_{1} \\
\text { (MD } \mathrm{EG}=1.22 ; \mathrm{MD}_{1}= \\
\mathrm{CG}=-0.04 ; \mathrm{p}=0.01 \text { ); } \\
\text { and no significant differ- } \\
\text { ence between the } \mathrm{EG}_{2} \\
\text { and the } \mathrm{CG}\end{array}$} \\
\hline & & & $\mathrm{N}$ & $162^{\mathrm{a}}$ & 159 & & & \\
\hline & & & & $160^{\mathrm{b}}$ & & & & \\
\hline & & & Mean age in $y$. & $51^{\mathrm{a}}$ & 50 & & & \\
\hline & & & & $50^{b}$ & & & & \\
\hline & & & Ethnicity (n) & & & & & \\
\hline & & & African American & $76^{\mathrm{a}}$ & 80 & & & \\
\hline & & & & $77^{b}$ & & & & \\
\hline & & & White non-Hispanic & $86^{\mathrm{a}}$ & 79 & & & \\
\hline & & & & $83^{b}$ & & & & \\
\hline & & & $\begin{array}{l}\text { Poverty Index Ratio } \\
\text { category (n) }\end{array}$ & & & & & \\
\hline & & & Below poverty & $109^{\mathrm{a}}$ & 105 & & & \\
\hline & & & & $113^{b}$ & & & & \\
\hline & & & $100-185 \%$ of poverty & $41^{\mathrm{a}}$ & 41 & & & \\
\hline & & & & $36^{\mathrm{b}}$ & & & & \\
\hline & & & Above $185 \%$ of poverty & $12^{\mathrm{a}}$ & 13 & & & \\
\hline & & & & $11^{\mathrm{b}}$ & & & & \\
\hline & & & Education $(n)$ & & & & & \\
\hline & & & Elementary school only & $1^{\mathrm{a}}$ & 1 & & & \\
\hline & & & & $1^{\mathrm{b}}$ & & & & \\
\hline & & & Junior high only & $2^{a}$ & 4 & & & \\
\hline & & & & $4^{b}$ & 4 & & & \\
\hline & & & HS graduate & $58^{\mathrm{a}}$ & & & & \\
\hline & & & & $39^{\mathrm{b}}$ & 52 & & & \\
\hline & & & More than HS & $101^{a}$ & & & & \\
\hline & & & & $116^{\mathrm{b}}$ & 102 & & & \\
\hline
\end{tabular}




\begin{tabular}{|c|c|c|c|c|c|c|c|c|}
\hline \multicolumn{9}{|c|}{ (Continued) } \\
\hline \multirow[b]{2}{*}{ Study } & \multirow[b]{2}{*}{ Country } & \multirow[b]{2}{*}{ Setting/context } & \multicolumn{3}{|l|}{ Participant characteristics } & \multirow[t]{2}{*}{ Intervention } & \multirow[t]{2}{*}{$\begin{array}{l}\text { Outcomes } \\
\text { measured and } \\
\text { follow-up }\end{array}$} & \multirow[t]{2}{*}{$\begin{array}{l}\text { Description of main } \\
\text { results }\end{array}$} \\
\hline & & & & EG & CG & & & \\
\hline \multirow[t]{34}{*}{$\begin{array}{l}\text { Gopalan } \\
\text { et al., } \\
2013^{76}\end{array}$} & \multirow[t]{34}{*}{ USA } & \multirow[t]{34}{*}{$\begin{array}{l}\text { Clinical setting } \\
\text { Participants } \\
\text { recruited from } \\
\text { urban, academic } \\
\text { internal medi- } \\
\text { cine practices }\end{array}$} & $\begin{array}{l}177 \text { adult patients with } \\
\text { poorly controlled diabetes, } \\
\text { with recent } \mathrm{HbA1c} \text { value } \\
\text { greater than } 8 \% \text { (majority } \\
\text { of African American women } \\
\text { with low numeracy) }\end{array}$ & & & \multirow{34}{*}{$\begin{array}{l}\text { EGs: two formats for communicating diabetes } \\
\text { control: letter grades (A through F) vs. faces } \\
\text { expressing representative emotions } \\
\text { Aim: to improve the understanding of informa- } \\
\text { tion about diabetes control and disease man- } \\
\text { agement } \\
\text { EG }_{1} \text { : one mailed individualized information } \\
\text { about current glycemic control using a "diabe- } \\
\text { tes report card" containing letter grades rang- } \\
\text { ing from A to F (From Grade "A" (best grade) } \\
\text { for HbA1c } \leq 7 \% \text {, to Grade "F" for HbA1c value } \\
\text { over } 10 \% \text { ) + one updated report card } 3 \\
\text { months after. } \\
\text { EG } \\
\text { current mailed individualized information about } \\
\text { containing faces whose emotion a report card } \\
\text { rent glycemic control (From "happlected cur- } \\
\text { (symbol) for HbA1c } \leq 7 \% \text {, to "crying face" for } \\
\text { HbA1c value over } 10 \% \text { ) } \\
\text { CG: standard care: mailed individualized infor- } \\
\text { mation about current glycemic control using a } \\
\text { report card containing the actual HbA1c value }\end{array}$} & \multirow[t]{34}{*}{$\begin{array}{l}\text { HbA1c } \\
\text { Measurements at } \\
\text { baseline, and } \\
6 \mathrm{~m} \text {. }\end{array}$} & \multirow[t]{34}{*}{$\begin{array}{l}6 \mathrm{~m} .: \\
\text { - No significant differ- } \\
\text { ence between groups in } \\
\text { HbA1c levels }\end{array}$} \\
\hline & & & $\mathrm{N}$ & $58^{a}$ & 58 & & & \\
\hline & & & & $61^{b}$ & & & & \\
\hline & & & Mean age in $y$. & $58^{a}$ & 57 & & & \\
\hline & & & & $55^{b}$ & & & & \\
\hline & & & Ethnicity (\%) & & & & & \\
\hline & & & African-American & $87^{a}$ & 84 & & & \\
\hline & & & & $79^{b}$ & & & & \\
\hline & & & White & $3^{a}$ & 4 & & & \\
\hline & & & & $7^{b}$ & & & & \\
\hline & & & Other & $10^{\mathrm{a}}$ & 12 & & & \\
\hline & & & & $15^{\mathrm{b}}$ & & & & \\
\hline & & & Women (\%) & $22^{\mathrm{a}}$ & 29 & & & \\
\hline & & & & $28^{\mathrm{b}}$ & & & & \\
\hline & & & Education Level (\%) & & & & & \\
\hline & & & Some HS & $14^{\mathrm{a}}$ & 24 & & & \\
\hline & & & & $15^{\mathrm{b}}$ & & & & \\
\hline & & & Completed HS & $41^{\mathrm{a}}$ & 29 & & & \\
\hline & & & & $41^{b}$ & & & & \\
\hline & & & Some college & $26^{\mathrm{a}}$ & 26 & & & \\
\hline & & & & $18^{\mathrm{b}}$ & & & & \\
\hline & & & College degree & $12^{\mathrm{a}}$ & 10 & & & \\
\hline & & & & $20^{\mathrm{b}}$ & & & & \\
\hline & & & $>$ college & $7^{\mathrm{a}}$ & 10 & & & \\
\hline & & & & $7^{b}$ & & & & \\
\hline & & & Income (\%) & & & & & \\
\hline & & & $<\$ 20,000$ & $57^{\mathrm{a}}$ & 61 & & & \\
\hline & & & & $41^{\mathrm{b}}$ & & & & \\
\hline & & & $\$ 20,000-\$ 50,000$ & $29^{\mathrm{a}}$ & 28 & & & \\
\hline & & & & $46^{b}$ & & & & \\
\hline & & & $\$ 50,000-\$ 80,000$ & $11^{\mathrm{a}}$ & 7 & & & \\
\hline & & & & $9^{b}$ & & & & \\
\hline & & & $>\$ 80,000$ & $4^{a}$ & 4 & & & \\
\hline & & & & $5^{b}$ & & & & \\
\hline
\end{tabular}




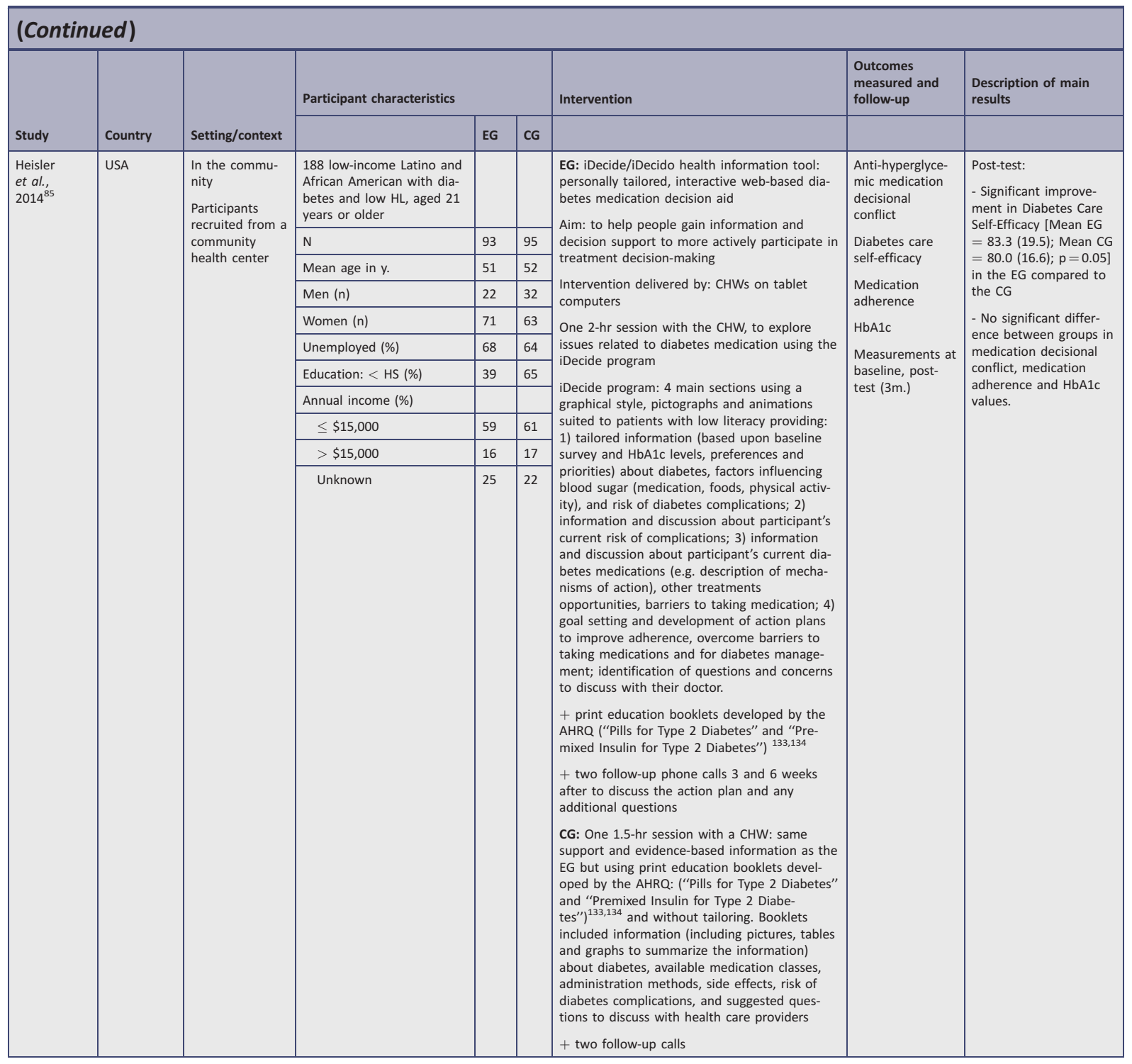




\begin{tabular}{|c|c|c|c|c|c|c|c|c|}
\hline \multicolumn{9}{|c|}{ (Continued) } \\
\hline \multirow[b]{2}{*}{ Study } & \multirow[b]{2}{*}{ Country } & \multirow[b]{2}{*}{ Setting/context } & \multicolumn{3}{|l|}{ Participant characteristics } & \multirow[t]{2}{*}{ Intervention } & \multirow[t]{2}{*}{$\begin{array}{l}\text { Outcomes } \\
\text { measured and } \\
\text { follow-up }\end{array}$} & \multirow[t]{2}{*}{$\begin{array}{l}\text { Description of main } \\
\text { results }\end{array}$} \\
\hline & & & & EG & CG & & & \\
\hline \multirow[t]{14}{*}{$\begin{array}{l}\text { Jackson } \\
\text { et al., } \\
2011^{77}\end{array}$} & \multirow[t]{14}{*}{ USA } & \multirow{14}{*}{$\begin{array}{l}\text { Clinical setting } \\
\text { Participants } \\
\text { recruited from } \\
\text { prenatal care } \\
\text { practices (public } \\
\text { hospitals, aca- } \\
\text { demic practices, } \\
\text { and community } \\
\text { hospital) }\end{array}$} & $\begin{array}{l}321 \text { low-income ethnically } \\
\text { diverse pregnant women } \\
\text { aged } 18 \text { years or older and } \\
\text { less than } 26 \text { weeks of ges- } \\
\text { tation }\end{array}$ & & & \multirow{14}{*}{$\begin{array}{l}\text { EG: Keep Fit program: Video Doctor counseling } \\
\text { (computerized, multimedia interactive Video } \\
\text { Doctor tool) } \\
\text { Aim: to deliver targeted counseling messages } \\
\text { on nutrition, exercise, and weight gain during } \\
\text { pregnancy } \\
\text { Computer-based intervention } \\
3 \text { components: } \\
\text { - One } 10-15 \text { min Video Doctor session prior to } \\
\text { the prenatal care appointment with the clini- } \\
\text { cian, including: a) a behavioral risk assessment } \\
\text { (food intake, physical activity, knowledge about } \\
\text { diet during pregnancy); and b) tailored } \\
\text { counseling and education messages: in the } \\
\text { manner of a confidential face-to-face discus- } \\
\text { sion with a health care provider (based on } \\
\text { principles of motivational interviewing), using } \\
\text { an actor-portrayed Video Doctor, brief mes- } \\
\text { sages, and video clips on nutrition, exercise } \\
\text { and weight gain. Topics included information } \\
\text { about healthy diet (increasing intake of fruits } \\
\text { and vegetables, whole grains, healthful fats, } \\
\text { and decreasing sugary foods) and physical } \\
\text { activity } \\
\text { - Cueing Sheet for the clinician printed at the } \\
\text { end of the session with the Video Doctor: } \\
\text { including a summary of the patient's risk profile } \\
\text { and suggestions for counseling } \\
\text { statements during the medical visit } \\
\text { - Educational Worksheet for the patient, includ- } \\
\text { ing information presented by the Video Doctor } \\
\text { and questions for self-reflection } \\
\text { cG: usual care }\end{array}$} & \multirow{14}{*}{$\begin{array}{l}\text { Weight gain at } \\
\text { term delivery } \\
\text { Weight gain } \\
\text { above the IOM } \\
\text { guidelines } \\
\text { Measurements at } \\
\text { baseline \& } 4 \mathrm{w} \text {. }\end{array}$} & \multirow{14}{*}{$\begin{array}{l}4 \text { w.: } \\
\text { - No significant differ- } \\
\text { ence between groups in } \\
\text { the proportion of } \\
\text { women gaining weight } \\
\text { above IOM guidelines, } \\
\text { and in mean weight } \\
\text { gain }\end{array}$} \\
\hline & & & $\mathrm{N}$ & 158 & 163 & & & \\
\hline & & & Mean age in $y$. & 26 & 27 & & & \\
\hline & & & Race/ethnicity (\%) & & & & & \\
\hline & & & Hispanic & 39 & 42 & & & \\
\hline & & & African-American & 24 & 23 & & & \\
\hline & & & Asian & 16 & 13 & & & \\
\hline & & & White, non-Hispanic & 12 & 13 & & & \\
\hline & & & Other/mixed & 9 & 8 & & & \\
\hline & & & Education (\%) & & & & & \\
\hline & & & $<\mathrm{HS}$ & 20 & 28 & & & \\
\hline & & & HS graduate & 28 & 17 & & & \\
\hline & & & College and above & 52 & 55 & & & \\
\hline & & & Medicaid (\%) & 85 & 85 & & & \\
\hline \multirow[t]{9}{*}{$\begin{array}{l}\text { Kim et al., } \\
2009^{86}\end{array}$} & \multirow[t]{9}{*}{ USA } & \multirow{9}{*}{$\begin{array}{l}\text { In the commu- } \\
\text { nity } \\
\text { Participants } \\
\text { recruited from } \\
\text { ethnic media, } \\
\text { ethnic Korean } \\
\text { churches, and } \\
\text { Korean grocery } \\
\text { stores }\end{array}$} & $\begin{array}{l}83 \text { Korean American immi- } \\
\text { grants aged } 30 \text { years or } \\
\text { older, with diabetes and an } \\
\text { uncontrolled glucose level } \\
\text { (HbA1c } \geq 7.5 \% \text { ) }\end{array}$ & & & \multirow{9}{*}{$\begin{array}{l}\text { EG: community-based self-help intervention } \\
\text { program for type } 2 \text { diabetes (SHIP-DM): cultur- } \\
\text { ally tailored behavioral intervention program } \\
\text { Aim: to achieve better glycemic control, to } \\
\text { empower patients with greater diabetes- } \\
\text { related knowledge, self-efficacy, and } \\
\text { self-help skills } \\
\text { Intervention delivered by: a bilingual nurse + a } \\
\text { nutritionist } \\
3 \text { components: } \\
\text { - } 6 \text { weekly psycho-behavioral education ses- } \\
\text { sions in groups (nurse + nutritionist). Aim: } \\
\text { improving diabetes knowledge and promoting } \\
\text { diabetes self-care behaviors for glucose control. } \\
\text { Sessions included information about diabetes } \\
\text { and diabetes management guidelines, compli- } \\
\text { cations, healthy eating, food labels reading, } \\
\text { medications and interactions, problem-solving } \\
\text { skills, and communication skills with physicians. } \\
\text { - home glucose and blood pressure } \\
\text { telemonitoring, with monthly reports sent to } \\
\text { the participants } \\
\text { - monthly individualized telephone counseling } \\
\text { by a nurse for } 24 \text { weeks (10-25 min): to } \\
\text { reinforce knowledge, discuss problems and } \\
\text { barriers, overcome barriers, and for emotional } \\
\text { support } \\
\text { CG: delayed intervention }\end{array}$} & \multirow{9}{*}{$\begin{array}{l}\text { DKT } \\
\text { Stanford Chronic } \\
\text { Disease Self-Effi- } \\
\text { cacy scale } \\
\text { SDSCA } \\
\text { KDSKA } \\
\text { DQOL } \\
\text { HbA1C } \\
\text { FBG } \\
\text { Lipid: HDL, LDL, } \\
\text { triglyceride } \\
\text { Systolic blood } \\
\text { pressure } \\
\text { Diastolic blood } \\
\text { pressure } \\
\text { BMI } \\
\text { Measurements at } \\
\text { baseline, \& post- } \\
\text { test (30 w.) }\end{array}$} & \multirow{9}{*}{ 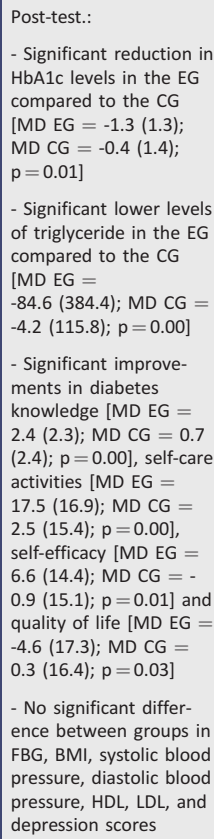 } \\
\hline & & & $\mathrm{N}$ & 41 & 42 & & & \\
\hline & & & Mean age in $y$. & 56 & 576 & & & \\
\hline & & & Men (\%) & 62 & 49 & & & \\
\hline & & & Women (\%) & 37 & 51 & & & \\
\hline & & & Married (\%) & 90 & 85 & & & \\
\hline & & & Employed (\%) & 6 & 80 & & & \\
\hline & & & High education level (\%) & 52 & 44 & & & \\
\hline & & & $\begin{array}{l}\text { Family income }>\$ 40,000 \\
(\%)\end{array}$ & 63 & 55 & & & \\
\hline
\end{tabular}




\begin{tabular}{|c|c|c|c|c|c|c|c|c|}
\hline \multicolumn{9}{|c|}{ (Continued) } \\
\hline \multirow[b]{2}{*}{ Study } & \multirow[b]{2}{*}{ Country } & \multirow[b]{2}{*}{ Setting/context } & \multicolumn{3}{|l|}{ Participant characteristics } & \multirow[t]{2}{*}{ Intervention } & \multirow[t]{2}{*}{$\begin{array}{l}\text { Outcomes } \\
\text { measured and } \\
\text { follow-up }\end{array}$} & \multirow[t]{2}{*}{$\begin{array}{l}\text { Description of main } \\
\text { results }\end{array}$} \\
\hline & & & & EG & CG & & & \\
\hline \multirow[t]{16}{*}{$\begin{array}{l}\text { Koniak- } \\
\text { Griffin et al., } \\
2015^{78}\end{array}$} & \multirow[t]{16}{*}{ USA } & \multirow{16}{*}{$\begin{array}{l}\text { In the commu- } \\
\text { nity } \\
\text { Participants } \\
\text { recruited from } \\
\text { parent educa- } \\
\text { tion centers, } \\
\text { churches, } \\
\text { laundromats, } \\
\text { and organiza- } \\
\text { tions providing } \\
\text { basic services to } \\
\text { children and } \\
\text { families }\end{array}$} & \begin{tabular}{|l}
223 under-served low- \\
income immigrant Latinas, \\
aged 35 to 64 years, over- \\
weight (BMI $\geq 25$ ) \\
\end{tabular} & & & \multirow{16}{*}{$\begin{array}{l}\text { EG: 6-month Lifestyle Behavior Intervention } \\
\text { "Mujeres Sanas y Precavidas" (Healthy Women } \\
\text { Prepared for Life) } \\
\text { Aim: to promote healthy lifestyle behaviors } \\
\text { (diet and physical activity) for reduction of } \\
\text { cardiovascular disease risk } \\
\text { Intervention delivered by: CHWs } \\
\text { (promotoras) } \\
\text { - } 8 \text { group education sessions based on the } \\
\text { "Your Heart, Your Life " (Su Corazó, Su Vida) } \\
\text { program (promotora-led educational program } \\
\text { for Latinos), }{ }^{165} \text { led by promotoras. Participants } \\
\text { received health information and education } \\
\text { about heart functioning, heart attack symp- } \\
\text { toms, heart-healthy eating, physical activity, } \\
\text { cholesterol, living smoke free, diabetes and } \\
\text { hypertension using a variety of approaches to } \\
\text { motivate behavioral changes such as videos, } \\
\text { role plays, and low-literacy culturally adapted } \\
\text { brochures } \\
\text { - } 8 \text { Individual Teaching and Coaching sessions } \\
\text { (4 home visits plus } 4 \text { telephone calls) from the } \\
\text { promotora: to reinforce class content, to help } \\
\text { participants setting personal goals for lifestyle } \\
\text { changes, offer support and help them to } \\
\text { overcome barriers to lifestyle change. } \\
\text { - pedometer to promote self-monitoring }+ \\
\text { physical activity DVD + culturally } \\
\text { appropriate recipes } \\
\text { CG: safety/disaster preparedness group educa- } \\
\text { tional program (8 sessions during } 6 \text { m.) led by } \\
\text { promotoras + } 8 \text { sessions of individual teaching } \\
\text { and coaching for more in-depth discussion } \\
\text { about class content }\end{array}$} & \multirow{16}{*}{$\begin{array}{l}\text { Physical activity: } \\
\text { accelerometer } \\
\text { Weight } \\
\text { BMI } \\
\text { Waist circumfer- } \\
\text { ence } \\
\text { Blood pressure } \\
\text { Total serum cho- } \\
\text { lesterol } \\
\text { HDL cholesterol } \\
\text { LDL cholesterol } \\
\text { Triglycerides } \\
\text { Blood glucose } \\
\text { Measurements at } \\
\text { baseline \& 9m. }\end{array}$} & \multirow{16}{*}{$\begin{array}{l}9 \text { m.: } \\
\text { - Significant difference } \\
\text { in average daily steps } \\
\text { count (physical activity) } \\
\text { (MD EG =-2; MD } \\
C G=-1130 ; p=0.04 \text { ) } \\
\text { due to a significant } \\
\text { decrease in the CG } \\
\text { - Significant decrease in } \\
\text { waist circumference in } \\
\text { the EG (MD EG = } \\
-2.99 ; \text { MD CG }= \\
-0.71 ; p=0.04 \text { ) in the } \\
\text { EG compared to the CG } \\
- \text { No significant differ- } \\
\text { ence in average daily } \\
\text { minute in moderate } \\
\text { physical activity } \\
\text { between groups, as well } \\
\text { as in weight, BMI, cho- } \\
\text { lesterol (total choles- } \\
\text { terol, HLD and LDL), } \\
\text { triglycerides, and blood } \\
\text { glucose }\end{array}$} \\
\hline & & & $\mathrm{N}$ & 111 & 112 & & & \\
\hline & & & \begin{tabular}{|l} 
Mean age in $y$. \\
\end{tabular} & 43 & 46 & & & \\
\hline & & & Education (n) & & & & & \\
\hline & & & $\leq 8$ th grade & 57 & 60 & & & \\
\hline & & & 9th-12th grade & 37 & 38 & & & \\
\hline & & & $\geq 13$ years & 16 & 12 & & & \\
\hline & & & Marital status (n) & & & & & \\
\hline & & & Married/with partner & 84 & 77 & & & \\
\hline & & & Divorced/ widowed/single & 27 & 35 & & & \\
\hline & & & Income (n) & & & & & \\
\hline & & & $\leq \$ 20,000$ & 57 & 65 & & & \\
\hline & & & $\$ 20,001-\$ 40,000$ & 32 & 32 & & & \\
\hline & & & $\$ 40,001-\$ 75,000$ & 22 & 15 & & & \\
\hline & & & Unemployed (n) & 78 & 87 & & & \\
\hline & & & No health insurance (n) & 78 & 74 & & & \\
\hline \multirow[t]{23}{*}{$\begin{array}{l}\text { Kripalani } \\
\text { et al., } \\
2007^{79}\end{array}$} & \multirow[t]{23}{*}{ USA } & \multirow{23}{*}{$\begin{array}{l}\text { Primary care } \\
\text { clinical setting } \\
\text { Participants } \\
\text { recruited from } \\
\text { primary care } \\
\text { clinics }\end{array}$} & $\begin{array}{l}250 \text { men, mainly African } \\
\text { Americans, aged between } \\
45 \text { to } 70 \text { years. }\end{array}$ & & & \multirow{23}{*}{$\begin{array}{l}\text { EGs: handouts about prostate cancer } \\
\text { Aim: to empower men to discuss prostate } \\
\text { cancer with their physician, to promote } \\
\text { informed decision-making for prostate cancer } \\
\text { screening } \\
\text { Before the appointment with the doctor, in the } \\
\text { waiting room: } \\
\text { EG } 1 \text { high-detail patient education handout } \\
\text { (one single color-printed page) on prostate } \\
\text { cancer screening, including prostate related } \\
\text { information such as its function and location, } \\
\text { prevalence and symptoms of prostate cancer, } \\
\text { available screening tests, as well as advantages } \\
\text { and disadvantaged of screening (information to } \\
\text { be shared with patient as recommended by } \\
\text { experts). The handout concluded with a mes- } \\
\text { sage to ask the doctor for more information. } \\
\text { Use of large characters, simple text written at } \\
\text { a } 6 \text { th grade reading level, illustrations, with a } \\
\text { focus on the most important information, and } \\
\text { following recommendations for low-literacy } \\
\text { educational materials. } \\
\text { EG }{ }_{2} \text { low-detail handout with less information } \\
\text { than EG1: only some information } \\
\text { (prevalence of prostate cancer only - no } \\
\text { information about screening tests) simply } \\
\text { encouraging patients to talk to their doctor } \\
\text { about prostate cancer. No information about } \\
\text { screening tests. Text written at a } 5 \text { th grade } \\
\text { reading level, only one illustration of the } \\
\text { gland's location } \\
\text { CG: control handout, with a picture of a food } \\
\text { pyramid }\end{array}$} & \multirow{23}{*}{$\begin{array}{l}\text { Frequency of dis- } \\
\text { cussion about } \\
\text { prostate cancer } \\
\text { with the doctor } \\
\text { during the medi- } \\
\text { cal visit } \\
\text { PSA test ordered } \\
\text { DRE } \\
\text { Measurements at } \\
\text { baseline \& imme- } \\
\text { diate post-test }\end{array}$} & \multirow{23}{*}{ 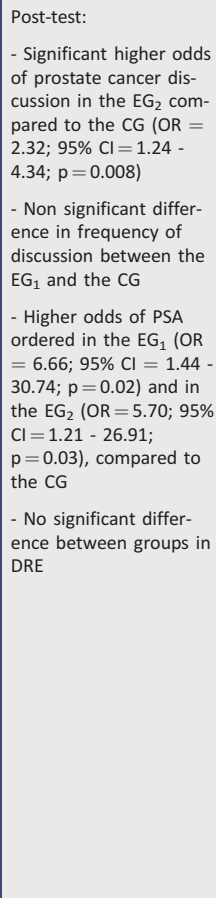 } \\
\hline & & & $\mathrm{N}$ & $86^{\mathrm{a}}$ & 83 & & & \\
\hline & & & & $81^{\mathrm{b}}$ & & & & \\
\hline & & & \begin{tabular}{|l|} 
Mean age in $y$. \\
\end{tabular} & $56^{\mathrm{a}}$ & 55 & & & \\
\hline & & & & $58^{\mathrm{b}}$ & & & & \\
\hline & & & Race $(\mathrm{n})$ & & & & & \\
\hline & & & African American & $72^{\mathrm{a}}$ & 80 & & & \\
\hline & & & & $74^{\mathrm{b}}$ & & & & \\
\hline & & & Caucasian & $12^{\mathrm{a}}$ & 3 & & & \\
\hline & & & & $5^{\mathrm{b}}$ & & & & \\
\hline & & & Other & $2^{\mathrm{a}}$ & 0 & & & \\
\hline & & & & $2^{\mathrm{b}}$ & & & & \\
\hline & & & Education mean in $\mathrm{y}$. & $11^{\mathrm{a}}$ & 11 & & & \\
\hline & & & & $10^{\mathrm{b}}$ & & & & \\
\hline & & & REALM (n) & & & & & \\
\hline & & & $\leq 3$ rd grade & $30^{\mathrm{a}}$ & 33 & & & \\
\hline & & & & $31^{\mathrm{b}}$ & & & & \\
\hline & & & 4 th -6 th grade & $9^{\mathrm{a}}$ & 19 & & & \\
\hline & & & & $18^{\mathrm{b}}$ & & & & \\
\hline & & & 7 th-8th grade & $18^{\mathrm{a}}$ & 19 & & & \\
\hline & & & & $20^{\mathrm{b}}$ & & & & \\
\hline & & & $\geq 9$ th grade & $29^{a}$ & 12 & & & \\
\hline & & & & $12^{\mathrm{b}}$ & & & & \\
\hline
\end{tabular}




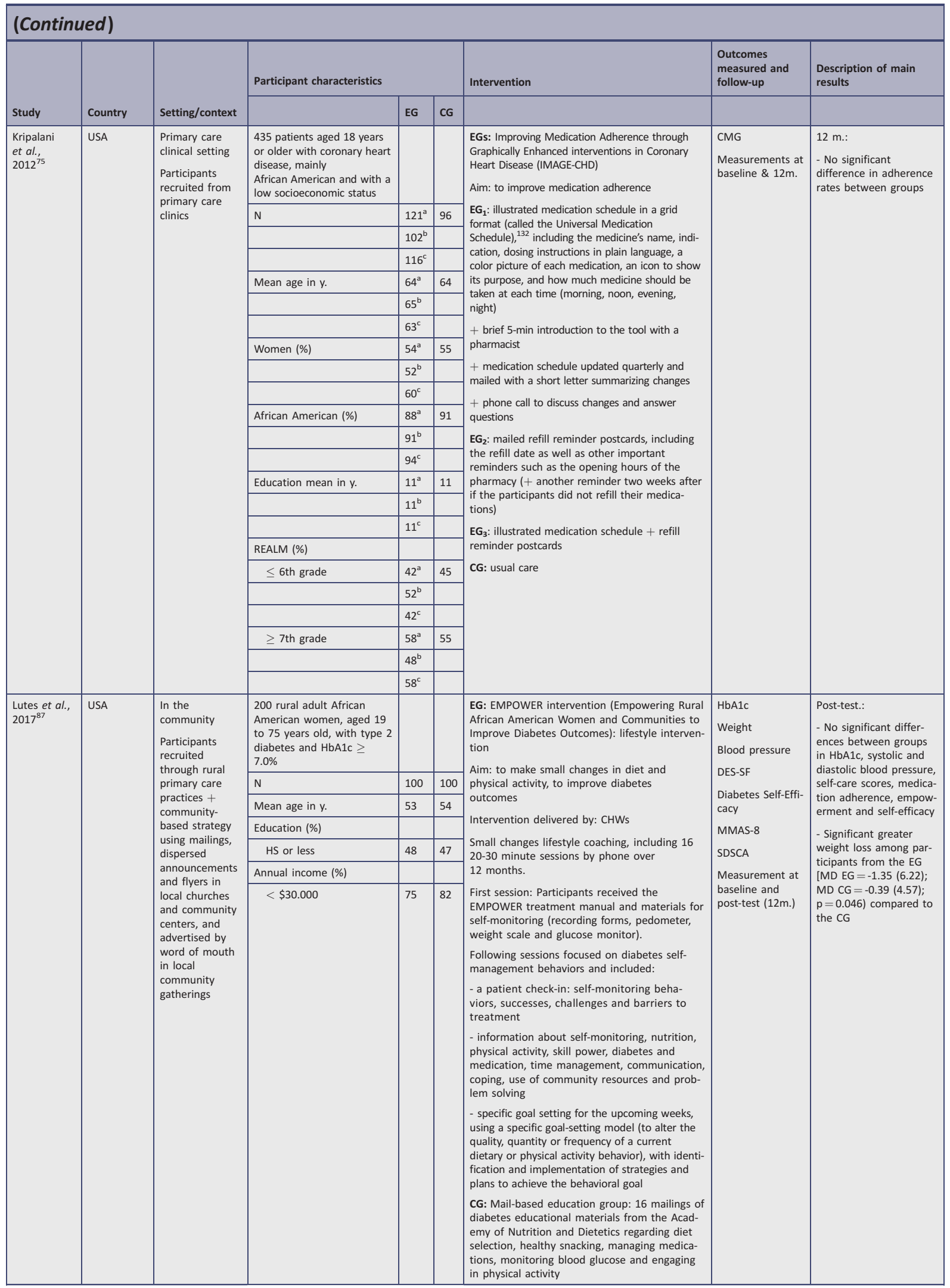




\begin{tabular}{|c|c|c|c|c|c|c|c|c|}
\hline \multicolumn{9}{|c|}{ (Continued) } \\
\hline \multirow[b]{2}{*}{ Study } & \multirow[b]{2}{*}{ Country } & \multirow[b]{2}{*}{ Setting/context } & \multicolumn{3}{|l|}{ Participant characteristics } & \multirow[t]{2}{*}{ Intervention } & \multirow[t]{2}{*}{$\begin{array}{l}\text { Outcomes } \\
\text { measured and } \\
\text { follow-up }\end{array}$} & \multirow[t]{2}{*}{$\begin{array}{l}\text { Description of main } \\
\text { results }\end{array}$} \\
\hline & & & & EG & CG & & & \\
\hline \multirow[t]{22}{*}{$\begin{array}{l}\text { Martin } \\
\text { et al., } \\
2011^{88}\end{array}$} & \multirow[t]{22}{*}{ USA } & \multirow{22}{*}{\begin{tabular}{l|} 
In the commu- \\
nity \\
Participants \\
recruited from \\
community \\
clinics providing \\
free hyperten- \\
sion medications \\
to individuals \\
living in poverty
\end{tabular}} & $\begin{array}{l}434 \text { rural, low-income } \\
\text { hypertensive adults, aged } \\
19 \text { years or older, mainly } \\
\text { African Americans }\end{array}$ & & & \multirow{22}{*}{$\begin{array}{l}\text { EG: The adherence promotion (AP) interven- } \\
\text { tion: multimedia computer-based program } \\
\text { Aim: to improve hypertension medication } \\
\text { adherence, by changing individual behaviors } \\
\text { such as goal setting and self-monitoring } \\
\text { Intervention delivered by: CHAs + } \\
\text { computer-based } \\
4 \text { sessions using a multimedia computer based } \\
\text { program delivered via a "Cyber Nurse" (audio } \\
\text { recording of a female voice giving guidance } \\
\text { and instructions) and a "Video Doc" (videos of } \\
\text { an African American physician), with a CHA } \\
\text { who served as the liaison between the } \\
\text { computer and the participant. } \\
\text { The computer program included: } \\
\text { - Assessments (medical problems, height, } \\
\text { weight, blood pressure, medication } \\
\text { adherence); } \\
\text { - CHA/participant discussion points; } \\
\text { - Video Doc tailored feedback; } \\
\text { - Low-literacy video displays of tailored health } \\
\text { information about hypertension according to } \\
\text { the participant's responses to the assessments: } \\
\text { Video Doc clips, and narratives from hyperten- } \\
\text { sive individuals about challenges and successes } \\
\text { with hypertension medication, consequences } \\
\text { of non-adherence, perceived benefits for taking } \\
\text { medication, and self-monitoring techniques } \\
\text { - Goal setting } \\
+ \text { handouts } \\
+4 \text { phone contact with the CHA } 2 \text { weeks after } \\
\text { each session: to discuss goals set, and to } \\
\text { review and reinforce medication adherence } \\
\text { strategies } \\
\text { CG: } 4 \text { home visits by a CHA, including general } \\
\text { cancer information via laptop computers, } \\
\text { including specific cancers, symptoms, risk fac- } \\
\text { tors, early detection methods and lifestyle } \\
\text { behaviors }\end{array}$} & \multirow{22}{*}{$\begin{array}{l}\text { Medication } \\
\text { adherence } \\
\text { CES-D } \\
\text { Measurements at } \\
\text { baseline \& } 6 \mathrm{~m} .\end{array}$} & \multirow{22}{*}{$\begin{array}{l}6 \mathrm{~m} .: \\
\text { - Greater proportion of } \\
\text { adherent participants in } \\
\text { the } \mathrm{EG} \text { compared to the } \\
\mathrm{CG} \text {, but difference } \\
\text { between groups not } \\
\text { significant }\end{array}$} \\
\hline & & & $\mathrm{N}$ & 221 & 213 & & & \\
\hline & & & Mean age in $y$. & 57 & 55 & & & \\
\hline & & & Men $(\mathrm{n})$ & 76 & 65 & & & \\
\hline & & & Women $(n)$ & 145 & 148 & & & \\
\hline & & & Race $(\mathrm{n})$ & & & & & \\
\hline & & & Black & 209 & 201 & & & \\
\hline & & & White or other & 12 & 11 & & & \\
\hline & & & Education (n) & & & & & \\
\hline & & & $<\mathrm{HS}$ & 109 & 110 & & & \\
\hline & & & $=\mathrm{HS}$ & 85 & 78 & & & \\
\hline & & & $>\mathrm{HS}$ & 27 & 25 & & & \\
\hline & & & Income (n) & & & & & \\
\hline & & & $<\$ 15,000$ & 180 & 175 & & & \\
\hline & & & $\geq \$ 15,000$ & 41 & 38 & & & \\
\hline & & & Marital status (n) & & & & & \\
\hline & & & Married / partnered & 76 & 76 & & & \\
\hline & & & Other & 145 & 137 & & & \\
\hline & & & Employment status ( $\mathrm{n}$ ) & & & & & \\
\hline & & & Employed & 60 & 52 & & & \\
\hline & & & Unemployed & 57 & 62 & & & \\
\hline & & & Other & 104 & 99 & & & \\
\hline \multirow[t]{8}{*}{$\begin{array}{l}\text { Mohan } \\
\text { et al., } \\
2014^{89}\end{array}$} & \multirow[t]{8}{*}{ USA } & \multirow[t]{8}{*}{\begin{tabular}{|l|} 
Clinical setting \\
Participants \\
recruited from a \\
safety net clinic
\end{tabular}} & $\begin{array}{l}200 \text { Latino patients aged } 18 \\
\text { years or older with diabetes } \\
\text { and with a least } 1 \text { chronic } \\
\text { medication }\end{array}$ & & & \multirow{8}{*}{$\begin{array}{l}\text { EG: PictureRx medication lists (plain } \\
\text { language medication lists) } \\
\text { Aim: to improve medication management by } \\
\text { addressing barriers to health literacy } \\
\text { Based on the prescribed medication regimen, } \\
\text { each participant received an education tool: a } \\
\text { printed color illustrated medication schedule in } \\
\text { the form of a grid, including (called the } \\
\text { Universal Medication Schedule): } \\
\text { - how much medicine should be taken at each } \\
\text { time (morning, noon, evening, night) } \\
\text { - a picture of each medication } \\
\text { - a labelled icon to show the purpose of the } \\
\text { medicine } \\
\text { - medication instructions in plain language } \\
+ \text { a 2-min video and a 1-page sheet to explain } \\
\text { how to use the illustrated medication sched- } \\
\text { ule. } \\
\text { CG: usual care: traditional prescription instruc- } \\
\text { tions }\end{array}$} & \multirow[t]{8}{*}{$\begin{array}{l}\text { ARMS } \\
\text { Measurements at } \\
1 \mathrm{w} .\end{array}$} & \multirow{8}{*}{$\begin{array}{l}1 \text { w.: } \\
\text { - No significant } \\
\text { difference between } \\
\text { groups in medication } \\
\text { adherence }\end{array}$} \\
\hline & & & $\mathrm{N}$ & 99 & 101 & & & \\
\hline & & & Mean age in $y$. & 50 & 49 & & & \\
\hline & & & Men (n) & 38 & 23 & & & \\
\hline & & & Women (n) & 61 & 78 & & & \\
\hline & & & Education mean in $y$. & 8 & 8 & & & \\
\hline & & & HL (mean BHLS score) & 10 & 10 & & & \\
\hline & & & Limited HL (\%) & 58 & 60 & & & \\
\hline
\end{tabular}




\begin{tabular}{|c|c|c|c|c|c|c|c|c|}
\hline \multicolumn{9}{|c|}{ (Continued) } \\
\hline \multirow[b]{2}{*}{ Study } & \multirow[b]{2}{*}{ Country } & \multirow[b]{2}{*}{ Setting/context } & \multicolumn{3}{|l|}{ Participant characteristics } & \multirow[t]{2}{*}{ Intervention } & \multirow[t]{2}{*}{$\begin{array}{l}\text { Outcomes } \\
\text { measured and } \\
\text { follow-up }\end{array}$} & \multirow[t]{2}{*}{$\begin{array}{l}\text { Description of main } \\
\text { results }\end{array}$} \\
\hline & & & & EG & CG & & & \\
\hline \multirow[t]{19}{*}{$\begin{array}{l}\text { Muchiri } \\
\text { et al., } \\
2015^{90}\end{array}$} & \multirow[t]{19}{*}{ South Africa } & \multirow{19}{*}{$\begin{array}{l}\text { In the commu- } \\
\text { nity, in a } \\
\text { resource- } \\
\text { limited setting } \\
\text { (limited infra- } \\
\text { structure such } \\
\text { as facilities and } \\
\text { services, lack of } \\
\text { health } \\
\text { professional } \\
\text { specialists) } \\
\text { Participants } \\
\text { recruited from } \\
\text { community } \\
\text { health centers }\end{array}$} & $\begin{array}{l}82 \text { black African adults with } \\
\text { a low socioeconomic status, } \\
\text { and with type } 2 \text { diabetes } \\
\text { aged } \\
40-70 \text { years }\end{array}$ & & & \multirow{19}{*}{$\begin{array}{l}\text { EG: nutrition education tailored to the needs } \\
\text { and preference of participants } \\
\text { Aim: to improve glycaemic control (HbA1c) and } \\
\text { other clinical outcomes (BMI, blood lipids, } \\
\text { blood pressure) through improved dietary } \\
\text { behaviours (dietary intake including portions of } \\
\text { starchy foods) and behaviour-mediating factors } \\
\text { (knowledge, beliefs and attitudes, self-efficacy } \\
\text { and goal setting) } \\
\text { Intervention delivered by: dietitians, nutrition } \\
\text { and food science university student, horticul- } \\
\text { ture officer } \\
3 \text { components: } \\
\text { - eight weekly group sessions (2 to } 2 \cdot 5 \text { h) } \\
\text { about diabetes: pathophysiology, risk factors, } \\
\text { symptoms, complications, treatment, nutrition } \\
\text { (dietary principles, food groups, meal balance, } \\
\text { portion control, planning meals on a limited } \\
\text { budget) } \\
\text { - follow-up sessions: four } 1.5 \mathrm{~h} \text { monthly meet- } \\
\text { ings and two } 1.5 \mathrm{~h} \text { bi-monthly meetings } \\
\text { - vegetable gardening: demonstration of sow- } \\
\text { ing/transplantation of vegetables } \\
+ \text { education materials (pamphlets and } \\
\text { posters) } \\
\text { CG: usual care + education materials (pamph- } \\
\text { lets and posters) }\end{array}$} & \multirow{19}{*}{$\begin{array}{l}\text { HbA1c } \\
\text { BMI } \\
\text { Blood pressure } \\
\text { Blood lipids (total } \\
\text { cholesterol, LDL, } \\
\text { HDL, } \\
\text { triglycerides) } \\
\text { Measurements at } \\
\text { baseline, 6m. \& } \\
12 \mathrm{~m} .\end{array}$} & \multirow{19}{*}{$\begin{array}{l}6 \text { and } 12 \mathrm{~m} .: \\
\text { - No significant differ- } \\
\text { ences between groups } \\
\text { in HbA1c, BMI, total } \\
\text { cholesterol, LDL, HDL, } \\
\text { triglycerides, and blood } \\
\text { pressure }\end{array}$} \\
\hline & & & $\mathrm{N}$ & 41 & 41 & & & \\
\hline & & & \begin{tabular}{|l|} 
Mean age in $\mathrm{y}$. \\
\end{tabular} & 60 & 58 & & & \\
\hline & & & Men (n) & 5 & 6 & & & \\
\hline & & & Women $(n)$ & 36 & 35 & & & \\
\hline & & & Marital status (n) & & & & & \\
\hline & & & Single & 6 & 6 & & & \\
\hline & & & Married & 25 & 28 & & & \\
\hline & & & Widowed & 6 & 6 & & & \\
\hline & & & Separated/divorced & 4 & 1 & & & \\
\hline & & & Education level (n) & & & & & \\
\hline & & & No formal education & 2 & 5 & & & \\
\hline & & & Grade $1-6$ & 11 & 11 & & & \\
\hline & & & Grade 7-9 & 18 & 16 & & & \\
\hline & & & Grade $10-12$ & 7 & 8 & & & \\
\hline & & & Post grade 12 & 3 & 1 & & & \\
\hline & & & Employment status ( $\mathrm{n}$ ) & & & & & \\
\hline & & & Employed & 2 & 6 & & & \\
\hline & & & Not employed & 39 & 35 & & & \\
\hline \multirow[t]{8}{*}{$\begin{array}{l}\text { Peragallo } \\
\text { et al., } \\
2012^{80}\end{array}$} & \multirow[t]{8}{*}{ USA } & \multirow{8}{*}{$\begin{array}{l}\text { In the } \\
\text { community } \\
\text { Participants } \\
\text { recruited } \\
\text { through flyers } \\
\text { from churches, } \\
\text { supermarkets, } \\
\text { and community } \\
\text { organizations. }\end{array}$} & $\begin{array}{l}548 \text { community-dwelling } \\
\text { adult Hispanic women, } \\
\text { aged between } 18 \text { and } 50 \mathrm{y} \text {. } \\
\text { old, reporting sexual activ- } \\
\text { ity in the last } 3 \text { months }\end{array}$ & & & \multirow{8}{*}{$\begin{array}{l}\text { EG: SEPA intervention (Salud/Health, Educa- } \\
\text { cion/Education, Promocion/Promotion, Autocui- } \\
\text { dado/Self-care) = HIV risk reduction } \\
\text { intervention } \\
\text { Aim: to reduce HIV risk factors } \\
\text { Intervention delivered by: bilingual and bicul- } \\
\text { tural Hispanic female facilitators } \\
\text { five, 2-h sessions delivered in small groups. } \\
\text { Sessions covered HIV/AIDS in the Hispanic } \\
\text { community, STIs, HIV/AIDS prevention (e.g., } \\
\text { condom use), negotiation and communication } \\
\text { with the partner, IPV and substance abuse. } \\
\text { Self-efficacy skill building using role play, par- } \\
\text { ticipatory sessions, videos and discussions } \\
+ \text { booster session to discuss topics related to } \\
\text { the HIV intervention at } 6 \text { month follow-up } \\
\text { cG: delayed intervention control group, one- } \\
\text { session, condensed version of SEPA after their } \\
12 \text {-month assessment }\end{array}$} & \multirow{8}{*}{\begin{tabular}{|l} 
Chlamydia infec- \\
tion \\
Condom use \\
The Communica- \\
tion with Partner \\
Scale \\
Perceived bar- \\
riers to condom \\
use \\
CES-D \\
Measurements at \\
baseline, post- \\
test (6m.) \& \\
$12 \mathrm{~m}$.
\end{tabular}} & \multirow{8}{*}{$\begin{array}{l}\text { Post-test: } \\
\text { - No significant differ- } \\
\text { ence between groups in } \\
\text { chlamydia infection } \\
\text { rates, in condom use, in } \\
\text { partner communication, } \\
\text { in perceived barriers to } \\
\text { condom use, and in } \\
\text { depression scores } \\
12 \mathrm{~m} .: \\
- \text { Higher proportion of } \\
\text { participants in the EG } \\
\text { reporting condom use } \\
\text { than in the CG (EG = } \\
49 \%, \mathrm{CG}=35 \% \text {; } \\
\mathrm{p}=0.01 \text { ) } \\
\text { - No significant differ- } \\
\text { ence between groups in } \\
\text { chlamydia infection } \\
\text { rates, in partner com- } \\
\text { munication, in perceived } \\
\text { barriers to condom use, } \\
\text { and in depression scores }\end{array}$} \\
\hline & & & $\mathrm{N}$ & 274 & 274 & & & \\
\hline & & & Mean age in $y$. & 39 & 38 & & & \\
\hline & & & Education in $\mathrm{y}$. & 14 & 13 & & & \\
\hline & & & Employed (n) & 92 & 88 & & & \\
\hline & & & $\begin{array}{l}\text { Monthly income }<\$ 2000 \\
(n)\end{array}$ & 196 & 185 & & & \\
\hline & & & Living with a partner $(\mathrm{n})$ & 181 & 199 & & & \\
\hline & & & Health insurance $(n)$ & 92 & 114 & & & \\
\hline
\end{tabular}




\begin{tabular}{|c|c|c|c|c|c|c|c|c|}
\hline \multicolumn{9}{|c|}{ (Continued) } \\
\hline \multirow[b]{2}{*}{ Study } & \multirow[b]{2}{*}{ Country } & \multirow[b]{2}{*}{ Setting/context } & \multicolumn{3}{|l|}{ Participant characteristics } & \multirow[t]{2}{*}{ Intervention } & \multirow[t]{2}{*}{$\begin{array}{l}\text { Outcomes } \\
\text { measured and } \\
\text { follow-up }\end{array}$} & \multirow[t]{2}{*}{$\begin{array}{l}\text { Description of main } \\
\text { results }\end{array}$} \\
\hline & & & & EG & CG & & & \\
\hline \multirow[t]{20}{*}{$\begin{array}{l}\text { Phelan } \\
\text { et al., } \\
2017^{73}\end{array}$} & \multirow[t]{20}{*}{ USA } & \multirow[t]{20}{*}{$\begin{array}{l}\text { In the commu- } \\
\text { nity } \\
\text { Participants } \\
\text { recruited from } \\
\text { WIC clinics }\end{array}$} & $\begin{array}{l}370 \text { low-income postpartum } \\
\text { women ( } 6 \text { weeks to } 12 \\
\text { months postpartum), aged } \\
18 \text { to } 40 \text { years old, with a } \\
\text { BMI } \geq 25 \text {, or with a BMI } \\
\text { between } 22 \text { and } 24.9 \text { but } \\
\text { exceeding pre-pregnancy } \\
\text { weight by } 4.5 \mathrm{~kg} \text { or more }\end{array}$ & & & \multirow{20}{*}{$\begin{array}{l}\text { EG: Fit Moms/Mamás Activas intervention: } \\
\text { culturally and linguistically adapted, primarily } \\
\text { internet-based behavioral weight loss interven- } \\
\text { tion } \\
\text { Aim: to promote weight loss } \\
\text { Intervention delivered by: internet-based inter- } \\
\text { vention, not mentioned for group sessions } \\
\text { Standard WIC care + a 12-month internet- } \\
\text { based weight loss program. } \\
\text { Content of the internet program: guidance and } \\
\text { resources, automated feedback, weekly lessons, } \\
\text { a web diary, a weight and physical activity } \\
\text { tracker, instructional and inspirational videos, } \\
\text { and a message board } \\
+ \text { monthly face-to-face group sessions at WIC } \\
\text { clinics. } \\
\text { CG: standard WIC care }+6 \text { newsletters every } \\
2 \text { months with information about weight } \\
\text { control, exercise, nutrition and wellness }\end{array}$} & \multirow{20}{*}{$\begin{array}{l}\text { Weight } \\
\text { Proportion of } \\
\text { women returning } \\
\text { to preconception } \\
\text { weight } \\
\text { Physical activity: } \\
\text { accelerometer } \\
\text { ASA24 } \\
\text { Waist circumfer- } \\
\text { ence } \\
\text { Percentage } \\
\text { weight loss } \\
\text { Proportion } \\
\text { achieving } 5 \% \text { or } \\
\text { more weight loss } \\
\text { Proportion } \\
\text { achieving } 10 \% \text { or } \\
\text { more weight loss } \\
\text { Measurement at } \\
\text { baseline \& post- } \\
\text { test (12 m.) }\end{array}$} & \multirow{20}{*}{ 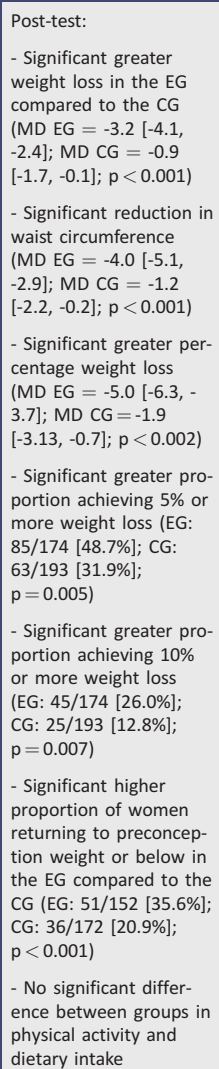 } \\
\hline & & & $\mathrm{N}$ & 174 & 196 & & & \\
\hline & & & Mean age in $y$. & 27 & 29 & & & \\
\hline & & & Hispanic/Latino (\%) & 84 & 80 & & & \\
\hline & & & Marital status (\%) & & & & & \\
\hline & & & $\begin{array}{l}\text { Married or with signifi- } \\
\text { cant other }\end{array}$ & 81 & 75 & & & \\
\hline & & & Divorced & 3 & 7 & & & \\
\hline & & & Widowed/single & 15 & 19 & & & \\
\hline & & & Education (\%) & & & & & \\
\hline & & & $\begin{array}{l}\text { Grade school or junior } \\
\text { high }\end{array}$ & 21 & 22 & & & \\
\hline & & & HS & 37 & 36 & & & \\
\hline & & & $\begin{array}{l}\text { Some college and } \\
\text { college }\end{array}$ & 41 & 41 & & & \\
\hline & & & Employment (\%) & & & & & \\
\hline & & & Unemployed & 71 & 77 & & & \\
\hline & & & Employed & 29 & 23 & & & \\
\hline & & & $\begin{array}{l}\text { Annual household income } \\
\text { (\%) }\end{array}$ & & & & & \\
\hline & & & $<\$ 10,000$ & 17 & 21 & & & \\
\hline & & & $\$ 10,000-\$ 19,999$ & 3 & 31 & & & \\
\hline & & & $\$ 20,000-\$ 29,999$ & 32 & 26 & & & \\
\hline & & & $\geq \$ 30,000$ & 21 & 22 & & & \\
\hline
\end{tabular}




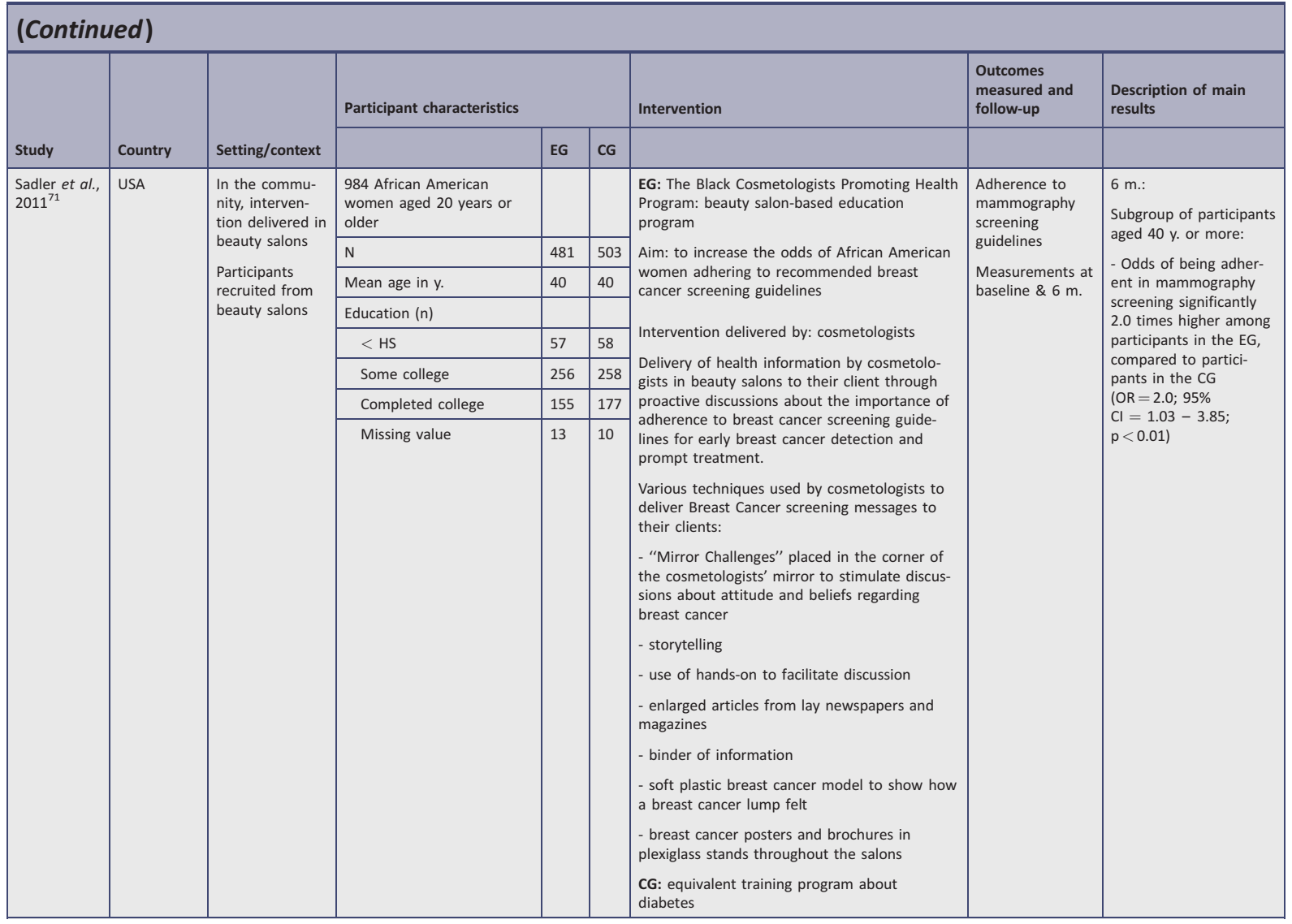




\begin{tabular}{|c|c|c|c|c|c|c|c|c|}
\hline \multicolumn{9}{|c|}{ (Continued) } \\
\hline \multirow[b]{2}{*}{ Study } & \multirow[b]{2}{*}{ Country } & \multirow[b]{2}{*}{ Setting/context } & \multicolumn{3}{|l|}{ Participant characteristics } & \multirow[t]{2}{*}{ Intervention } & \multirow[t]{2}{*}{$\begin{array}{l}\text { Outcomes } \\
\text { measured and } \\
\text { follow-up }\end{array}$} & \multirow[t]{2}{*}{$\begin{array}{l}\text { Description of main } \\
\text { results }\end{array}$} \\
\hline & & & & EG & CG & & & \\
\hline \multirow{12}{*}{$\begin{array}{l}\text { Samuel- } \\
\text { Hodge } \\
\text { et al., } \\
2009^{74}\end{array}$} & \multirow[t]{12}{*}{ USA } & \multirow{12}{*}{$\begin{array}{l}\text { In the commu- } \\
\text { nity } \\
\text { Participants } \\
\text { recruited from } \\
\text { African Ameri- } \\
\text { can churches }\end{array}$} & $\begin{array}{l}201 \text { African Americans aged } \\
20 \text { years or older, with type } \\
2 \text { diabetes }\end{array}$ & & & \multirow{12}{*}{$\begin{array}{l}\text { EG: "A New DAWN" (Diabetes Awareness and } \\
\text { Wellness Network) } \\
\text { Aim: to (1) promote change in dietary, physical } \\
\text { activity, medication adherence and glucose } \\
\text { self-monitoring behaviors to improve metabolic } \\
\text { control } \\
4 \text { components: } \\
\text { - One } 60-\text { min individual counseling visit with a } \\
\text { dietitian: assessment of dietary habits, psycho- } \\
\text { social issues, eating patterns and barriers to } \\
\text { dietary and physical activity behavior changes } \\
+ \text { setting of behavior goals } \\
\text { - Group education sessions: } 12 \text { biweekly inter- } \\
\text { active group education sessions ( } 90 \text { to } 120 \\
\text { minutes) led by a dietitian and the church } \\
\text { diabetes advisor, a health professional from } \\
\text { the local community: } 1 \text { ) information about } \\
\text { diabetes (risk factors, causes, symptoms), food } \\
\text { (carbohydrates, protein, fat, and serving sizes, } \\
\text { and their effect on blood glucose), healthy } \\
\text { eating, blood glucose monitoring, blood pres- } \\
\text { sure control, planning meals, diabetes medica- } \\
\text { tion; } 2 \text { ) } 15 \text { minutes of physical activity + taste } \\
\text { testing of recipes } \\
\text { - One monthly phone contact with the church } \\
\text { diabetes advisor: support for behavior change } \\
\text { to improve diabetes self-management (related } \\
\text { to behavior goals set with the dietician during } \\
\text { the individual counseling session) } \\
\text { - } 3 \text { printed postcard messages of encourage- } \\
\text { ment from healthcare providers (physician), } \\
\text { tailored to behavioral goals and including brief } \\
\text { messages and recommendations relevant to } \\
\text { dietary behavior, physical activity, and HbA1c } \\
\text { and blood pressure control } \\
\text { cG: minimal intervention: } \\
\text { - mailing of two pamphlets on diabetes } \\
\text { self-care ("Healthy Eating" and "Staying } \\
\text { Active") from the American Diabetes } \\
\text { Association } \\
\text { - } 3 \text { bimonthly newsletters with general health } \\
\text { information and study updates }\end{array}$} & \multirow{12}{*}{\begin{tabular}{|l|} 
HbA1c \\
Weight \\
Blood pressure \\
PA: accelerome- \\
ter \\
The Diabetes \\
Knowledge Scale \\
SF-36 \\
Diabetes-related \\
health status \\
Measurements at \\
baseline, 8m. \& \\
12 m.
\end{tabular}} & \multirow{12}{*}{ 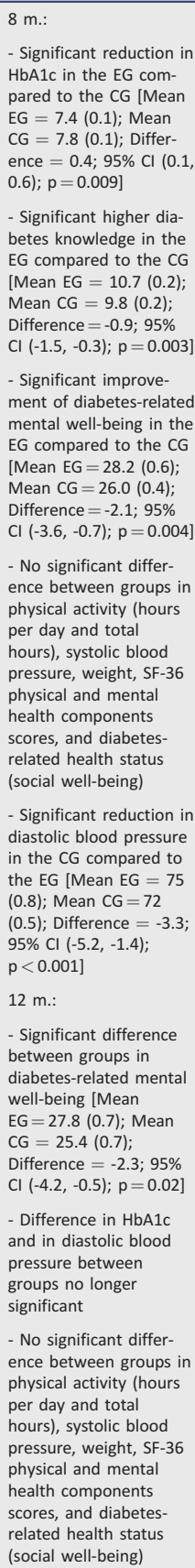 } \\
\hline & & & $\mathrm{N}$ & 117 & 84 & & & \\
\hline & & & Mean age in $y$. & 57 & 61 & & & \\
\hline & & & Men (n) & 42 & 31 & & & \\
\hline & & & Women $(n)$ & 75 & 53 & & & \\
\hline & & & Education mean in $\mathrm{y}$. & 13 & 12 & & & \\
\hline & & & Living with a partner $(\mathrm{n})$ & 58 & 48 & & & \\
\hline & & & Currently employed (n) & 56 & 39 & & & \\
\hline & & & $\begin{array}{l}\text { Household income } \\
<\$ 30,000(n)\end{array}$ & 32 & 21 & & & \\
\hline & & & & & & & & \\
\hline & & & & & & & & \\
\hline & & & & & & & & \\
\hline
\end{tabular}




\begin{tabular}{|c|c|c|c|c|c|c|c|c|}
\hline \multicolumn{9}{|c|}{ (Continued) } \\
\hline \multirow[b]{2}{*}{ Study } & \multirow[b]{2}{*}{ Country } & \multirow[b]{2}{*}{ Setting/context } & \multicolumn{3}{|l|}{ Participant characteristics } & \multirow[t]{2}{*}{ Intervention } & \multirow[t]{2}{*}{$\begin{array}{l}\text { Outcomes } \\
\text { measured and } \\
\text { follow-up }\end{array}$} & \multirow[t]{2}{*}{$\begin{array}{l}\text { Description of main } \\
\text { results }\end{array}$} \\
\hline & & & & EG & CG & & & \\
\hline \multirow[t]{11}{*}{$\begin{array}{l}\text { Stockwell } \\
\text { et al., } \\
2014^{91}\end{array}$} & \multirow[t]{11}{*}{ USA } & \multirow{11}{*}{$\begin{array}{l}\text { In the commu- } \\
\text { nity } \\
\text { Participants } \\
\text { recruited from } \\
\text { community- } \\
\text { based clinics }\end{array}$} & $\begin{array}{l}1153 \text { low-income women, } \\
\text { obstetric patients, initiating } \\
\text { prenatal care }\end{array}$ & & & \multirow{11}{*}{$\begin{array}{l}\text { EG: influenza vaccine-related text messages } \\
\text { Aim: to encourage influenza vaccination } \\
\text { Intervention delivered by: text messages } \\
\text { Usual care }+5 \text { weekly, automated text mes- } \\
\text { sage (written at a fourth grade level) influenza } \\
\text { vaccine reminders providing educational health } \\
\text { information about: } \\
\text { - increased risk for influenza-related disease } \\
\text { during pregnancy and early childhood; } \\
\text { - vaccine safety; } \\
\text { - influenza vaccine recommendations and sug- } \\
\text { gestion to discuss the vaccine with the doctor } \\
\text { during the next prenatal visit. } \\
+ \text { additional text messages if desired by } \\
\text { participants about influenza risk, common mis- } \\
\text { perceptions, side effects } \\
\text { cG: usual care: routine automated telephone } \\
\text { pre and postnatal appointment reminders pro- } \\
\text { vided directly from the clinic network }\end{array}$} & \multirow{11}{*}{$\begin{array}{l}\text { Receipt of influ- } \\
\text { enza vaccination } \\
\text { Measurements at } \\
\text { baseline \& } 4 \mathrm{~m} .\end{array}$} & \multirow{11}{*}{$\begin{array}{l}4 \mathrm{~m} .: \\
- \text { Higher rates of vacci- } \\
\text { nation in the EG com- } \\
\text { pared to the CG }(49.3 \% \\
\text { vs. } 46.6 \% \text { respectively; } \\
p=0.048)\end{array}$} \\
\hline & & & $N$ & 576 & 577 & & & \\
\hline & & & Age & & & & & \\
\hline & & & $<20$ & 41 & 50 & & & \\
\hline & & & $20-29$ & 338 & 308 & & & \\
\hline & & & $30-39$ & 179 & 189 & & & \\
\hline & & & $\geq 40$ & 18 & 30 & & & \\
\hline & & & Insurance status (n) & & & & & \\
\hline & & & Uninsured & 179 & 181 & & & \\
\hline & & & Medicaid / SCHIP & 394 & 387 & & & \\
\hline & & & Private & 3 & 9 & & & \\
\hline \multirow[t]{11}{*}{$\begin{array}{l}\text { Tu et al., } \\
2006^{81}\end{array}$} & \multirow[t]{11}{*}{ USA } & \multirow{11}{*}{$\begin{array}{l}\text { Clinical setting, } \\
\text { primary care } \\
\text { setting } \\
\text { Participants } \\
\text { recruited from a } \\
\text { community } \\
\text { clinic }\end{array}$} & $\begin{array}{l}210 \text { low income Chinese } \\
\text { Americans aged } 50 \text { to } 78 \\
\text { years }\end{array}$ & & & \multirow{11}{*}{$\begin{array}{l}\text { EG: CRC screening education } \\
\text { Aim: to promote CRC screening and FOBT } \\
\text { Intervention delivered by: health educator } \\
\text { One session of CRC screening education with } \\
\text { the health educator, including a motivational } \\
\text { video on CRC screening, print materials (moti- } \\
\text { vational pamphlet, FOBT instruction sheet, CRC } \\
\text { informational pamphlet from the Federation of } \\
\text { Chinese American and Canadian Medical Socie- } \\
\text { ties), and the delivery of a FOBT kit } \\
\text { CG: usual care }\end{array}$} & \multirow[t]{11}{*}{$\begin{array}{l}\text { FOBT screening } \\
\text { Measurements at } \\
\text { baseline } \& 6 \mathrm{~m} \text {. }\end{array}$} & \multirow{11}{*}{$\begin{array}{l}6 \mathrm{~m} .: \\
- \text { Higher proportion of } \\
\text { participants in the EG } \\
\text { received FOBT screening } \\
(69.5 \%), \text { compared to } \\
\text { participants in the CG } \\
(27.6 \%) \text { (no } p \text { value } \\
\text { given), with higher odds } \\
\text { of FOBT screening in the } \\
\text { EG compared to the CG } \\
(\mathrm{OR}=5.98,95 \% \mathrm{Cl}= \\
3.29-10.85)\end{array}$} \\
\hline & & & $N$ & 105 & 105 & & & \\
\hline & & & Age (\%) & & & & & \\
\hline & & & $50-64$ & 59 & 49 & & & \\
\hline & & & $65+$ & 41 & 50 & & & \\
\hline & & & Men (\%) & 36 & 38 & & & \\
\hline & & & Women (\%) & 64 & 62 & & & \\
\hline & & & Insurance (\%) & & & & & \\
\hline & & & Public & 82 & 84 & & & \\
\hline & & & Private & 12 & 11 & & & \\
\hline & & & None & 6 & 5 & & & \\
\hline
\end{tabular}

${ }^{\mathrm{a}}=\mathrm{EG}_{1} ;{ }^{\mathrm{b}}=\mathrm{EG}_{2} ;{ }^{\mathrm{c}}=\mathrm{EG}_{3} ; \mathrm{AHRQ}=$ Agency of Health Research and Quality; AIDS = acquired immune deficiency syndrome; ARMS = Adherence to Refills and Medications Scale; ASA-24 = Automated Self-Administered 24-Hour; BHLS = Brief Health Literacy Screen; BMI = body mass index; CBE = clinical breast examinations; CES-D = Center for Epidemiologic Studies - Depression Scale; CG = control group; CHA = community health advisor; CHW = community health worker; CMG = Cumulative Medication Gap; CRC = colorectal cancer; DES = Diabetes Empowerment Scale; DKQ-24 = Diabetes Knowledge Questionnaire; DRE = digital rectal examination; DKT = Diabetes Knowledge Test; DQOL = Diabetes Quality of Life Measure; EG = experimental group; $F B G=$ fasting blood glucose; FOBT = fecal occult blood testing; $\mathrm{GED}=$ General Educational Development test; $\mathrm{HbA1c}=$ glycated hemoglobin; $\mathrm{HDL}=$ high density lipoprotein; HIV = human Immunodeficiency virus; $\mathrm{HL}=$ health literacy; $\mathrm{HS}=$ high school; IOM = Institute of Medicine; $\mathrm{KDSKA}=$ Kim Depression Scale for Korean Americans; $\mathrm{LDL}=$ low density lipoprotein; $\mathrm{m}$. = month(s); $\mathrm{MD}=$ mean difference; MMAS-8-item = Morisky Medication Adherence Scale; MVPA = moderate to vigorous physical activity; $P A=$ physical activity; PAR-Q $=$ Physical Activity Recall Questionnaire; PSA = prostate specific antigen; REALM = the Rapid Estimate of Adult Literacy in Medicine; SCHIP = State Children's Health Insurance Program; SDSCA = Summary of Diabetes Self-Care Activities scale; SF-36=Short Form-36; STI = sexually transmitted infection; STOFHLA=Short Test of Functional Health Literacy in Adults; TOFHLA = Test of Functional Health Literacy in Adults; w. = week(s); WIC = woman, infant and children; $y$.=year(s). 


\section{Quasi-experimental studies}

\begin{tabular}{|c|c|c|c|c|c|c|c|c|}
\hline \multirow[b]{2}{*}{ Study } & \multirow[b]{2}{*}{ Country } & \multirow{2}{*}{$\begin{array}{l}\text { Setting/ } \\
\text { context }\end{array}$} & \multicolumn{3}{|l|}{ Participant characteristics } & \multirow[t]{2}{*}{ Intervention } & \multirow[t]{2}{*}{$\begin{array}{l}\text { Outcomes measured } \\
\text { and follow-up }\end{array}$} & \multirow[t]{2}{*}{$\begin{array}{l}\text { Description of } \\
\text { main results }\end{array}$} \\
\hline & & & & EG & CG & & & \\
\hline \multirow[t]{34}{*}{$\begin{array}{l}\text { Park, } \\
2011^{72}\end{array}$} & \multirow[t]{34}{*}{ Korea } & \multirow[t]{34}{*}{$\begin{array}{l}\text { In the com- } \\
\text { munity } \\
\text { Participants } \\
\text { recruited fron } \\
\text { senior centers }\end{array}$} & $\begin{array}{l}136 \text { community-dwell- } \\
\text { ing older adults aged } \\
65 \text { years or older, with } \\
\text { a low educational } \\
\text { level } \\
\end{array}$ & & & \multirow{34}{*}{$\begin{array}{l}\text { EG }_{1} \text { : interactive picto- } \\
\text { rial education for safe } \\
\text { medication ( } 340 \text {-min } \\
\text { group sessions, once a } \\
\text { week during } 3 \text { weeks) } \\
\text { Aim: to reduce medi- } \\
\text { cation misuse and } \\
\text { non-adherence, and } \\
\text { improve self-efficacy } \\
\text { and knowledge } \\
\text { towards safe } \\
\text { medication } \\
\text { Intervention delivered } \\
\text { by: nurses } \\
\text { Use of a pictorial } \\
\text { guide map with sym- } \\
\text { bolic images. Each } \\
\text { part of the pictorial } \\
\text { guide map explored a } \\
\text { variety of medication- } \\
\text { related topics and } \\
\text { situations such as } \\
\text { usage, reading medi- } \\
\text { cation labels, calculat- } \\
\text { ing the dosage, side } \\
\text { effects, drug interac- } \\
\text { tions and storage } \\
\text { using pictorial cards } \\
\text { adapted to the learn- } \\
\text { ing patterns and psy- } \\
\text { cho-motor skills of } \\
\text { older adults. } \\
\text { Participants progressed } \\
\text { on the map. At each } \\
\text { stop point, pictorial } \\
\text { cards were used to } \\
\text { ask a set of } \\
\text { medication-related } \\
\text { questions to partici- } \\
\text { pants, leading to inter- } \\
\text { active discussion with } \\
\text { other participants and } \\
\text { the nurse }+ \text { informa- } \\
\text { tion booklet } \\
\text { EG } 2: 3 \text { } 40-\text { min sessions } \\
\text { of conventional educa- } \\
\text { tion only (same con- } \\
\text { tent as the EG }{ }_{1} \text { ) + } \\
\text { information booklet } \\
\text { (written text informa- } \\
\text { tion) } \\
\text { cG: no intervention }\end{array}$} & \multirow[t]{34}{*}{$\begin{array}{l}\text { SEAMS } \\
\text { Measurements at } \\
\text { baseline \& post-test } \\
\text { (3w.) }\end{array}$} & \multirow{34}{*}{$\begin{array}{l}\text { Post-test: } \\
\text { - Significant } \\
\text { improvement in } \\
\text { self-efficacy in the } \\
\mathrm{EG}_{1} \text { and the } \mathrm{EG}_{2} \\
\text { compared to the } \\
\mathrm{CG}_{\mathrm{MD}} \mathrm{EG}_{1}= \\
4.31 ; \mathrm{MD} \mathrm{EG}_{2}= \\
1.98 ; \mathrm{MD} \mathrm{CG}= \\
0.03 ; \mathrm{p}<0.001] \\
\text { with higher } \\
\text { improvements in } \\
\text { the } \mathrm{EG}_{1} \text { compared } \\
\text { to the } \mathrm{GG}_{2} \\
(\mathrm{p}<0.05)\end{array}$} \\
\hline & & & $N$ & $45^{a}$ & 46 & & & \\
\hline & & & & $45^{b}$ & & & & \\
\hline & & & Age & & & & & \\
\hline & & & $65-69$ & $7^{\mathrm{a}}$ & 7 & & & \\
\hline & & & & $9^{b}$ & & & & \\
\hline & & & $70-74$ & $12^{\mathrm{a}}$ & 1 & & & \\
\hline & & & & $14^{\mathrm{b}}$ & & & & \\
\hline & & & $75-79$ & $10^{a}$ & 13 & & & \\
\hline & & & & $10^{\mathrm{b}}$ & & & & \\
\hline & & & $\geq 80$ & $16^{\mathrm{a}}$ & 14 & & & \\
\hline & & & & $12^{\mathrm{b}}$ & & & & \\
\hline & & & Women (n) & $21^{a}$ & 22 & & & \\
\hline & & & & $22^{\mathrm{b}}$ & & & & \\
\hline & & & Men (n) & $24^{\mathrm{a}}$ & 24 & & & \\
\hline & & & & $23^{b}$ & & & & \\
\hline & & & \begin{tabular}{|l|} 
Education \\
\end{tabular} & & & & & \\
\hline & & & None (illiterate) & $4^{a}$ & 5 & & & \\
\hline & & & & $5^{b}$ & & & & \\
\hline & & & None (literate) & $6^{\mathrm{a}}$ & 7 & & & \\
\hline & & & & $6^{\mathrm{b}}$ & & & & \\
\hline & & & Elementary & $23^{\mathrm{a}}$ & 22 & & & \\
\hline & & & & $22^{\mathrm{b}}$ & & & & \\
\hline & & & Middle school & $10^{a}$ & 10 & & & \\
\hline & & & & $11^{\mathrm{b}}$ & & & & \\
\hline & & & $\geq \mathrm{HS}$ & $2^{\mathrm{a}}$ & 2 & & & \\
\hline & & & & $1^{\mathrm{b}}$ & & & & \\
\hline & & & Marital status (n) & & & & & \\
\hline & & & Married & $20^{\mathrm{a}}$ & 19 & & & \\
\hline & & & & $20^{\mathrm{b}}$ & & & & \\
\hline & & & Widowed & $22^{\mathrm{a}}$ & 25 & & & \\
\hline & & & & $23^{\mathrm{b}}$ & & & & \\
\hline & & & Divorced & $3^{a}$ & 2 & & & \\
\hline & & & & $2^{b}$ & & & & \\
\hline
\end{tabular}




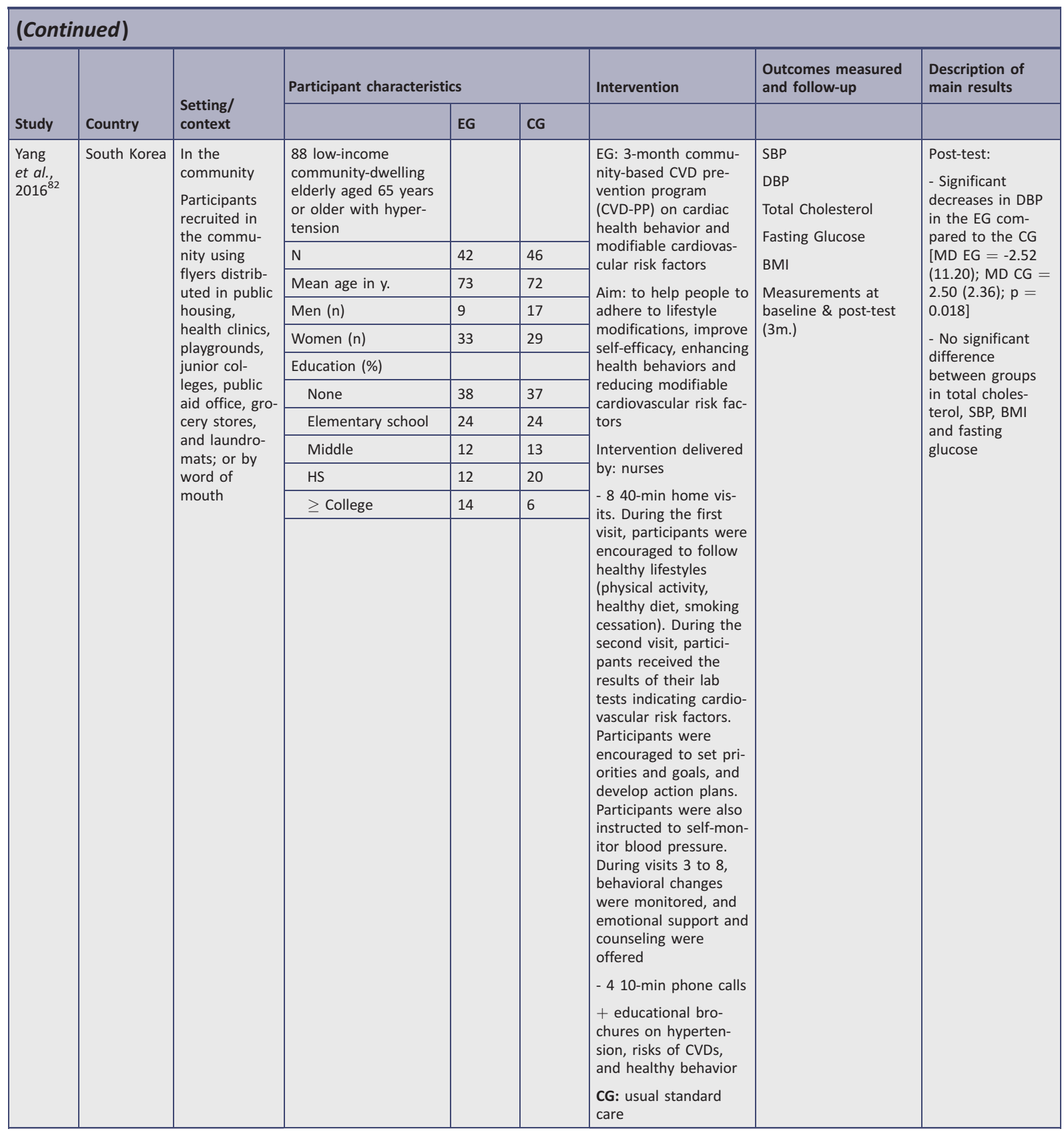

${ }^{\mathrm{a}}=\mathrm{EG}_{1} ;{ }^{\mathrm{b}}=\mathrm{EG}_{2} ; \mathrm{BMI}=$ body mass index; $\mathrm{CG}=$ control group; $\mathrm{CVD}=$ cardiovascular disease; $\mathrm{DBP}=$ diastolic blood pressure; $\mathrm{EG}=$ experimental group; $\mathrm{HS}=$ high school; $\mathrm{m}$. = months; $\mathrm{MD}=$ mean difference; $\mathrm{SBP}=$ systolic blood pressure; SEAMS = Self-Efficacy for Appropriate Medication Use Scale; $\mathrm{W}$. = weeks. 